\title{
b 15686966
}

\section{A NEW MODEL FOR PREDICTING LOW CYCLE FATIGUE BEHAVIOR OF DISCONTINUOUSLY REINFORCED METAL MATRIX COMPOSITES}

\author{
By \\ Qian Zhang \\ B. Sc. Degree in Mechanical Engineering \\ Wuhan University of Technology \\ Wuhan, China, 1988 \\ A thesis presented to Ryerson University \\ in partial fulfillment of the \\ requirements for the degree of \\ Master of Applied Science \\ in the Program of \\ Mechanical Engineering
}

Toronto, Ontario, Canada, 2004

C Qian Zhang 2004 
UMI Number: EC52995

All rights reserved

INFORMATION TO USERS

The quality of this reproduction is dependent upon the quality of the copy submitted. Broken or indistinct print, colored or poor quality illustrations and photographs, print bleed-through, substandard margins, and improper alignment can adversely affect reproduction.

In the unlikely event that the author did not send a complete manuscript and there are missing pages, these will be noted. Also, if unauthorized copyright material had to be removed, a note will indicate the deletion.

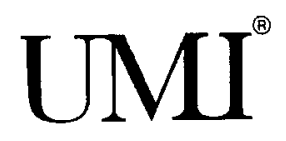

UMI Microform EC52995

Copyright 2008 by ProQuest LLC

All rights reserved. This microform edition is protected against unauthorized copying under Title 17, United States Code.

ProQuest LLC

789 East Eisenhower Parkway

P.O. Box 1346

Ann Arbor, Ml 48106-1346 



\section{Borrower's Page}

Ryerson University requires the signatures of all persons using or photocopying this thesis.

Please sign below, and give address and date.

\begin{tabular}{|c|c|c|c|}
\hline Name & Signature & Address & Date \\
\hline & & & \\
\hline & & & \\
\hline & & & \\
\hline & & & \\
\hline & & & \\
\hline & & & \\
\hline & & & \\
\hline & & & \\
\hline & & & \\
\hline & & & \\
\hline & & & \\
\hline & & & \\
\hline & & & \\
\hline & & & \\
\hline & & & \\
\hline & & & \\
\hline & & & \\
\hline & & & \\
\hline & & & \\
\hline & & & \\
\hline & & & \\
\hline & & & \\
\hline
\end{tabular}




\begin{abstract}
Qian Zhang

A NEW MODEL FOR PREDICTING LOW CYCLE FATIGUE BEHAVIOR OF DISCONTINUOUSLY REINFORCED METAL MATRIX COMPOSITES
\end{abstract}

\author{
MASc, Mechanical Engineering. \\ Ryerson, Toronto, 2004.
}

An analytical model for predicting the crack initiation life of low cycle fatigue (LCF) of discontinuously reinforced metal matrix composites (DR-MMCs) has been proposed. The effects of the volume fraction $V_{f}$, cyclic strain hardening exponent $n^{\prime}$ and cyclic strength coefficient $K^{\prime}$ on the LCF crack initiation life of DR-MMCs were analyzed. While both the lower level of the plastic strain amplitude and the lower $V_{f}$ were found to increase the LCF crack initiation resistance, the effects of $n^{\prime}$ and $K^{\prime}$ were more complicated. By considering the enhanced dislocation density in the matrix and the load bearing effect of particles, a quantitative relationship between the LCF life of DR-MMCs and particle size was also derived. This model showed that a decreasing particle size results in a longer LCF life. The theoretical predictions based on the proposed models were found to be in good agreement with the experimental data reported in the literature. 


\section{ACKNOWLEDGEMENTS}

I wish to acknowledge and thank my supervisor, Professor Daolun Chen, for his strong support and insightful guidance. During my whole study period, I benefited much from Professor Chen's invaluable instructions in both methodology and problem-solving-skills. One thing, which impressed me much in my research and will influence the rest of my life, is his attitude to science and work: "Always do our best, nothing is impossible". Also, I appreciated his thorough reading of this thesis and valuable help in the arrangement of my oral defense.

I would like to thank the financial support provided by the Natural Sciences and Engineering Research Council of Canada (NSERC), and the scholarship provided by the School of Graduate Studies, Ryerson University.

I would also like to take this opportunity to thank my family members and parents for their strong support in my study. 


\section{TABLE OF CONTENTS}

Author's Declaration -

Borrower's Page -----_-

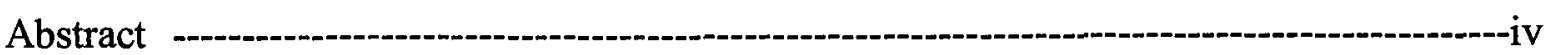

Acknowledgements - -

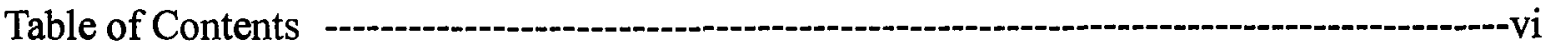

List of Tables - -

List of Figures ---

Nomenclature - -

Chapter 1 Introduction -

Chapter 2 Fundamentals of DR-MMCs and Fatigue - -

2.1 Advantages of DR-MMCs, Their Applications and Fabrication Processes ---------4

2.1.1 Why DR-MMCs? --

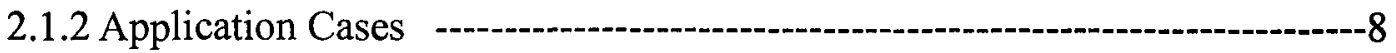

2.1.3 Fabrication Processes --

2.2 Microstructural Changes Induced by Reinforcements - -

2.2.1 Load Bearing Effect - -

2.2.2 Enhanced Dislocation Density --_-_-

2.2.3 Grain Structure and Texture ---..--

2.3 Effects of Microstructural Variables on Fatigue behavior -

2.3.1 Reinforcement Shape -

2.3.2 Reinforcement Size - ---

2.3.3 Volume Fraction of Reinforcement -

2.3.4 Interface strength -

2.3.5 Reinforcement distribution - -

2.4 Basic Fatigue Theories - 
2.4.1 Fatigue Process - -

2.4.2 High Cycle Fatigue and Low Cycle Fatigue

2.4.3 Fatigue Analysis Methods - -

2.4.3.1 Fracture Mechanics Approach for Fatigue Cracks - -.---.---.---.-----24

2.4.3.2 Fatigue Crack Growth Rate - -

2.4.3.3 Fatigue Life Curves - -

2.5 Fatigue of DR-MMCs -

2.5.1 HCF and LCF in DR-MMCs - -

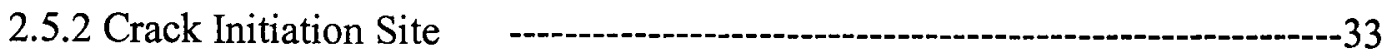

2.5.3 Crack Propagation Characteristics of DR-MMCs

Chapter 3 Crack Initiation Model in DR-MMCs - -

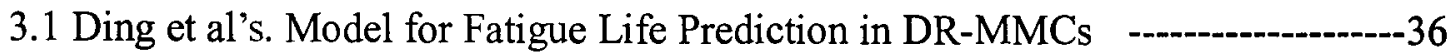

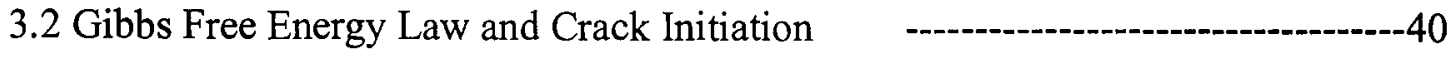

3.3 A New Life Prediction Model for DR-MMCs

3.4 Effect of the Plastic Strain Level and Volume Fraction

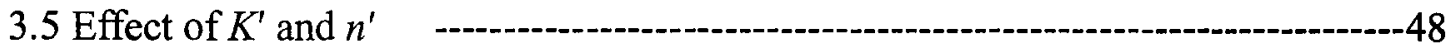

3.6 Verification of the New Model - -

Chapter 4 Effect of the Particle Size on the Fatigue Behavior of DR-MMCs -----58

4.1 Background - -

4.2 Size Effect in Life Prediction Model - -

4.3 Verification of the Size Effect Model - -

4.4 An Alternative Method of Modeling the Particle Size Effect --------------------65

Chapter 5 Discussion -

5.1 Unified Effects of $E_{c}, V_{f}, n^{\prime}$ and $K^{\prime}$ on the Fatigue Crack Initiation -----------68

5.2 $f t$ - An Indicator of the Energy Stored from Cycle to Cycle -------------------70

5.3 On the Crack Initiation Process - -

5.4 Effect of the Particle Size on the Fatigue Life - -

5.5 Effect of Volume Fraction on the Fatigue Life --- 
Chapter 6 Conclusions and Future Work -

6.1 Conclusions - -

6.2 Recommendations for Future Work - -

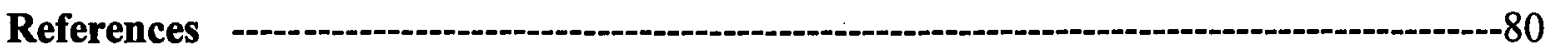

CV - 


\section{LIST OF TABLES}

Table 2.1 Modulus, YS and UTS of unreinforced $6061 \mathrm{Al}$ alloy and the two composites $\mathrm{A}$ and $\mathrm{B}$ for different ageing times at $175^{\circ} \mathrm{C}-$

Table 3.1 Material parameters used in the calculation of unified effects of $E_{c}$, $V_{f}, n^{\prime}, K^{\prime}$ and $f t$ on the fatigue crack initiation illustrated in

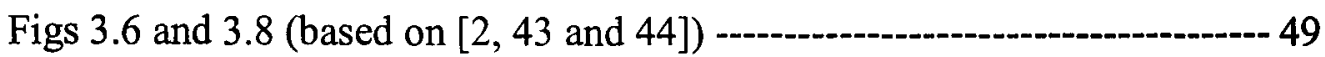

Table 3.2 Parameters used in the calculations in Figs 3.9 - 3.18

Table 5.1 Effect of volume fraction on the LCF life based on the present model with consideration of relevant changes of $E, K^{\prime}, n^{\prime}$ $-77$ 


\section{LIST OF FIGURES}

Figure 1.1 Types of MMCs--- 1

Figure 2.1 Predicted dependence of the coefficient of thermal expansion on reinforcement content for $\mathrm{Al}-\mathrm{SiC}_{\mathrm{p}}$ composites, showing how the value can be matched to those of a wide range of materials $-7$

Figure 2.2 Photograph of a diesel engine piston showing the region of short fibre reinforcement (dark) area in the land (support region) of the groove for the piston ring---

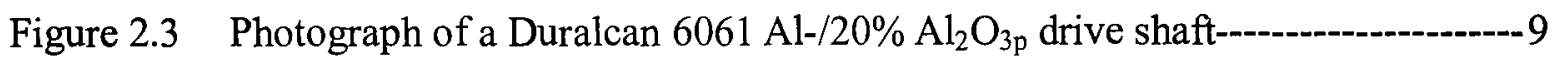

Figure 2.4 Photograph of an instrument rack ( $2 \mathrm{~m}$ in length) fabricated from $6061 \mathrm{Al}-/ 25 \% \mathrm{SiC}_{\mathrm{p}}$ for use in Lockheed production Aircraft9

Figure 2.5 Photograph of a rotor brake disc, made from Duralcan cast $\mathrm{Al}-10 \mathrm{wt} \% / \mathrm{Si} / 20 \mathrm{vol}^{2} \mathrm{SiC}$ $-10$

Figure 2.6 Photograph of the 'Stumpjumper M2' bicycle in action. The Frame is made of Duralcan $6061 \mathrm{Al}-10 \mathrm{vol} \% \mathrm{Al}_{2} \mathrm{O}_{3 \mathrm{p}}$

Figure 2.7 Photograph of a hot-forged connecting rod made up of a $2080 \mathrm{Al}$ alloy $/ 15 \% \mathrm{SiC}$ particulate-

Figure 2.8 Stages of fatigue process--- 21

Figure 2.9 Schematic drawing of fatigue life curve $S$ versus $N_{f}------$

Figure 2.10 Griffith's problem of plane crack under uniform tension-----a-- 25

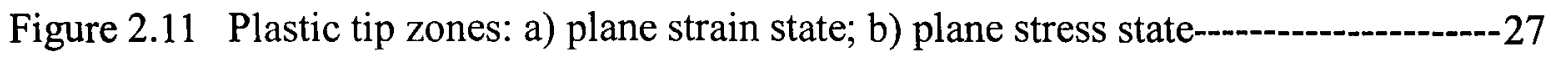

Figure 2.12 Model of thin plastic zone--

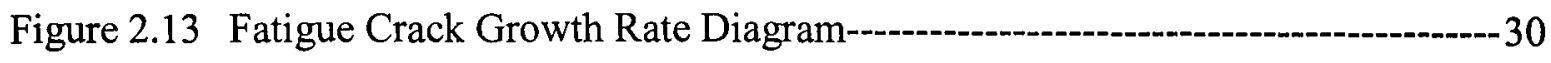

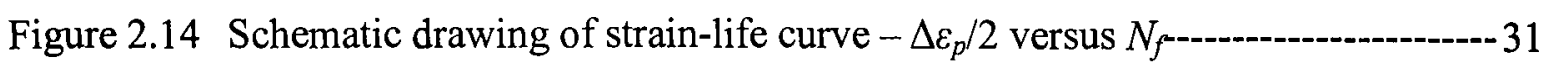

Figure 2.15 Fatigue crack growth behavior in metallic alloys and DR-MMCs ---------34

Figure 3.1 Schematic diagram showing the cyclic plastic zone and 


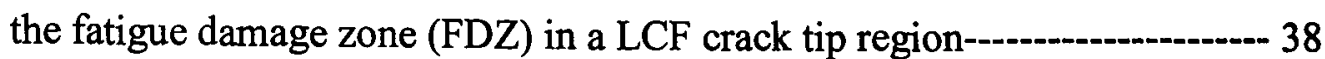

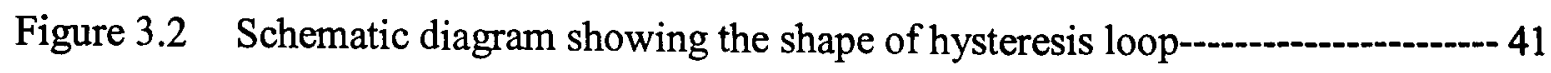

Figure 3.3 Effect of the volume fraction $\left(V_{f}\right)$ on the number of cycles for the fatigue crack initiation (Ni) in the $\mathrm{Al}_{2} \mathrm{O}_{3}$ particulatereinforced, AA6061 aluminum alloy based MMCs tested at $25^{\circ} \mathrm{C}$ (where $E_{\mathcal{c}}, n^{\prime}, K^{\prime}$ and $f t$ are kept constant)

Figure 3.4 Effect of the volume fraction $\left(V_{f}\right)$ on the number of cycles for the fatigue crack initiation $\left(N_{i}\right)$ in the $\mathrm{Al}_{2} \mathrm{O}_{3}$ particulatereinforced, AA6061 aluminum alloy based MMCs tested at $25^{\circ} \mathrm{C}$, with consideration of the variation of $E_{c}, n^{\prime}, K^{\prime}$ and $f t$ with the volume fraction

Figure 3.5 Effect of the cyclic strain hardening exponent $(n)$ on the fatigue crack initiation life $(\mathrm{Ni})$ in the $\mathrm{Al}_{2} \mathrm{O}_{3}$ particulatereinforced, AA6061 aluminum alloy based MMCs tested at $25^{\circ} \mathrm{C}$, without consideration of the variation of $E_{c}, V_{f}, K^{\prime}$ and $f t$

Figure 3.6 Effect of the cyclic strain hardening exponent $\left(n^{\prime}\right)$ on the fatigue crack initiation life $\left(N_{i}\right)$ in the $\mathrm{Al}_{2} \mathrm{O}_{3}$ particulatereinforced, AA6061 aluminum alloy based MMCs tested at $25^{\circ} \mathrm{C}$, with consideration of the variation of $E_{c}, V_{f}, K^{\prime}$ and $f t$ -

Figure 3.7 Effect of the cyclic strength coefficient $\left(K^{\prime}\right)$ on the fatigue crack initiation life $\left(N_{i}\right)$ in the $\mathrm{Al}_{2} \mathrm{O}_{3}$ particulate-reinforced, AA6061 aluminum alloy based MMCs tested at $25^{\circ} \mathrm{C}$, without consideration of the variation of $E_{c}, V_{f}, n^{\prime}$ and $f t$ 50

Figure 3.8 Effect of the cyclic strength coefficient $\left(K^{\prime}\right)$ on the fatigue crack initiation life $\left(N_{i}\right)$ in the $\mathrm{Al}_{2} \mathrm{O}_{3}$ particulate-reinforced, AA6061 aluminum alloy based MMCs tested at $25^{\circ} \mathrm{C}$, with consideration of the variation of $n$ ' 51

Figure 3.9 A comparison of the total fatigue life model with the crack propagation model [2] and with the experimental data [2] for the $\mathrm{Al}_{2} \mathrm{O}_{3}$ particulate-reinforced AA6061 composite material $\left(V_{f}=15 \%\right)$ tested at $25^{\circ} \mathrm{C}$ 
Figure 3.10 A comparison of the total fatigue life model with the crack propagation model [2] and with the experimental data [1] for the $\mathrm{Al}_{2} \mathrm{O}_{3}$ particulate-reinforced $\mathrm{AA} 6061$ composite material $\left(V_{f}=15 \%\right)$ tested at $150^{\circ} \mathrm{C}$

Figure 3.11 A comparison of the total fatigue life model with the crack propagation model [2] and with the experimental data [2] for the $\mathrm{Al}_{2} \mathrm{O}_{3}$ particulate-reinforced $\mathrm{AA} 6061$ composite material $\left(V_{f}=15 \%\right)$ tested at $-30^{\circ} \mathrm{C}$

Figure 3.12 A comparison of the total fatigue life model with the crack propagation model [2] and with the experimental data [50] for the $\mathrm{Al}_{2} \mathrm{O}_{3}$ particulate-reinforced 6061 composite material (D20) $\left(V_{f}=20 \%\right)$ tested at RT

Figure 3.13 A comparison of the total fatigue life model with the crack propagation model [2] and with the experimental data [50] for the $\mathrm{Al}_{2} \mathrm{O}_{3}$ particulate-reinforced 6061 composite material (C85) $\left(V_{f}=20 \%\right)$ tested at RT

Figure 3.14 A comparison of the total fatigue life model with the crack propagation model [2] and with the experimental data [40] for the $\mathrm{Al}_{2} \mathrm{O}_{3}$ particulate-reinforced 2014 composite material $\left(V_{f}=10 \%\right)$ tested at $100^{\circ} \mathrm{C}$

Figure $3.15 \mathrm{~A}$ comparison of the total fatigue life model with the crack propagation model [2] and with the experimental data [40] for the $\mathrm{Al}_{2} \mathrm{O}_{3}$ particulate-reinforced 2014 composite material $\left(V_{f}=15 \%\right)$ tested at $100^{\circ} \mathrm{C}$ 56

Figure 3.16 A comparison of the total fatigue life model with the crack propagation model [2] and with the experimental data [41] for the $\mathrm{SiC}$ particulate-reinforced X2080 composite material $\left(V_{f}=20 \%\right)$ tested at $\mathrm{RT}$ 
Figure 3.17 A comparison of the total fatigue life model with the crack propagation model [2] and with the experimental data [41] for the $\mathrm{SiC}$ particulate-reinforced X2080 composite material $\left(V_{f}=15 \%\right)$ tested at RT

Figure 4.1 Effect of reinforcement particle size on the low cycle fatigue life in an $\mathrm{Al}_{2} \mathrm{O}_{3}$ particulate-reinforced aluminum alloy based MMCs tested at $25^{\circ} \mathrm{C}$

Figure 4.2 Effect of volume fraction on the fatigue life in an $\mathrm{Al}_{2} \mathrm{O}_{3}$ particulate-reinforced AA6061 aluminum alloy MMCs tested at $25^{\circ} \mathrm{C}$

Figure 4.3 A comparison of the present model with Ding et al.'s model [2] and with the experimental data [6] in an $\mathrm{Al}_{2} \mathrm{O}_{3}$ particulatereinforced AA6061 composite material $\left(V_{f}=15 \%, d=15 \mu \mathrm{m}\right)$ Tested at $25^{\circ} \mathrm{C}$ 63

Figure 4.4 A comparison of the present model with Ding et al.'s model [6] and with the experimental data [2] in an $\mathrm{Al}_{2} \mathrm{O}_{3}$ particulate-reinforced AA6061 composite Material $\left(V_{f}=15 \%, d=15 \mu \mathrm{m}\right)$ Tested at $-30^{\circ} \mathrm{C}$ $-64$

Figure 4.5 A comparison of the present model with Ding et al.'s model [2] and with the experimental data [2] in an $\mathrm{Al}_{2} \mathrm{O}_{3}$ particulate-reinforced AA6061 composite material $\left(V_{f}=20 \%, d=12.8 \mu \mathrm{m}\right)$ tested at $25^{\circ} \mathrm{C}$ $-64$

Figure 4.6 A comparison of the present model with Ding et al.'s model [2] and with the experimental data [2] in an $\mathrm{Al}_{2} \mathrm{O}_{3}$ particulate-reinforced AA6061 composite material $\left(V_{f}=20 \%, d=12.8 \mu \mathrm{m}\right)$ tested at $-100^{\circ} \mathrm{C}$ 65

Figure 4.7 Fatigue life as a function of particle size in an $\mathrm{Al}_{2} \mathrm{O}_{3}$ particulate reinforced AA6061 aluminum alloy based MMCs tested at $25^{\circ} \mathrm{C}$ 
Figure 5.1 Effect of the volume fraction on the indicator of the energy (the value of $\mathrm{ft}$ ) in the $\mathrm{Al}_{2} \mathrm{O}_{3}$ particulatereinforced, AA6061 based MMCs (where $E_{c}, n^{\prime}$ and $K^{\prime}$ are kept constant)

Figure 5.2 Effect of the volume fraction on the indicator of the energy (the value of $\mathrm{ft}$ ) in the $\mathrm{Al}_{2} \mathrm{O}_{3}$ particulatereinforced, AA6061 based MMCs at different temperatures, with consideration of the variation of $E_{c}, n^{\prime}$ and $K^{\prime}$ values with the volume fraction 


\section{NOMENCLATURE}

\section{Acronym Definition}

CR-MMCs continuously reinforced metal matrix composites

CTOD crack tip opening displacement

DR-MMCs discontinuously reinforced metal matrix composites

EDD enhanced dislocation density

FDZ fatigue damaged zone

$\mathrm{HCF} \quad$ high cycle fatigue

LCF low cycle fatigue

MMC metal matrix composites

MSL modified shear lag

OA over-aging

PA peak-aging

PSA plastic strain amplitude

PSB persistent slip band

SEM scanning electron microscope

ST cold water quenched to $0^{\circ} \mathrm{C}$

UA under-aging

UTS ultimate tensile strength

YS yield strength

$\triangle \mathrm{CTE}$ difference in the coefficient of the thermal expansion

\section{Symbol Definition}

$A \quad$ area of the just nucleated crack

C a constant

$C_{\varepsilon} \quad$ a constraint parameter

$D_{c} \quad$ characteristic size of the plastic zone

$D_{F D Z} \quad$ size of fatigue damaged zone

E Young's modulus

$E_{c} \quad$ Young's modulus of the DR-MMCs 
$E_{m} \quad$ Young's modulus of the matrix

$E_{p} \quad$ Young's modulus of the reinforcement short fibers (particles)

$G \quad$ Gibbs free energy

$G_{I} \quad$ energy release rate

$G_{I C} \quad$ critical energy release rate

$G_{\mathrm{m}} \quad$ shear modulus of the matrix

$H \quad$ enthalpy

$K^{\prime} \quad$ cyclic strength coefficient

$K_{I} \quad$ Mode I stress intensity factor

$K_{I C} \quad$ plane strain fracture toughness

$N_{i} \quad$ crack initiation life, or number of cycles required to create a fatigue crack

$N_{p} \quad$ crack propagation life

$N_{t}, N_{f} \quad$ total LCF life

$S \quad$ entropy

$T \quad$ temperature

$V_{f} \quad$ volume fraction of the reinforcement particles

$V_{m} \quad$ volume fraction of the matrix

$W_{a d} \quad$ adhesion work

$W_{e} \quad$ elastic energy

a crack length

$a^{*} \quad$ radius of newly created penny-like crack

$a_{f} \quad$ critical crack size

$a_{i} \quad$ initial crack size

$b \quad$ Burgers vector of dislocation

d particle size

$d a \quad$ crack length increment

$f \quad$ defect-energy-absorbing efficiency factor

$f_{d} \quad$ improvement factor associated with the dislocation strengthening of the matrix

$f_{l} \quad$ improvement factor associated with the load bearing effect of the reinforcement

$f t \quad$ indicator of the energy that is stored from cycle to cycle 


\begin{tabular}{|c|c|}
\hline$m$ & a constant \\
\hline$n^{\prime}$ & cyclic strain hardening exponent \\
\hline$s$ & length-to-diameter aspect ratio of the reinforcing particles \\
\hline$t$ & total thickness of crack regions \\
\hline$\Delta J$ & $J$ integral range \\
\hline$\Delta K$ & stress intensity factor range \\
\hline$\Delta K_{t h}$ & fatigue threshold \\
\hline$\Delta K_{t h, e f f}$ & effective fatigue threshold \\
\hline$\Delta T$ & difference in temperature \\
\hline$\Delta \alpha$ & difference in the coefficient of the thermal expansion \\
\hline$\Delta \sigma$ & stress range in the cycle \\
\hline$\Delta \sigma_{e f f} / 2$ & effective stress of DR-MMCs \\
\hline$\Delta \varepsilon_{p}$ & plastic strain range in the cycle \\
\hline$\Delta \varepsilon_{p} / 2$ & plastic strain amplitude \\
\hline$\Pi$ & potential energy of the system \\
\hline$\Phi$ & a constant \\
\hline$\gamma$ & surface energy density \\
\hline$\gamma_{s m}$ & surface energy density of the matrix \\
\hline$\gamma_{s p}$ & surface energy density of the reinforcement particles \\
\hline$\delta$ & crack tip opening displacement (also CTOD) \\
\hline$\delta_{c}$ & critical crack tip opening displacement \\
\hline$\varepsilon_{f}^{\prime}$ & fatigue ductility coefficient \\
\hline$\varepsilon_{r p}$ & average real plastic strain in matrix \\
\hline$\eta$ & specific fracture work related to the unit area of the newly created crack \\
\hline$\lambda$ & cyclic plastic zone correction \\
\hline$v$ & Poisson's ratio \\
\hline$v_{c}$ & Poisson's ratio of DR-MMCs \\
\hline$v_{m}$ & Poisson's ratio of the matrix \\
\hline$v_{p}$ & Poisson's ratio of the reinforcement particles \\
\hline
\end{tabular}


$\rho \quad$ enhanced dislocation density

$\sigma, \Delta \sigma / 2 \quad$ peak stress or stress amplitude within a cycle

$\sigma_{0} \quad$ yield strength of material

$\sigma_{\mathrm{c}} \quad$ critical stress value for crack propagation

$\sigma_{y}, \quad$ yield strength of the material

$\sigma_{y, c} \quad$ yield strength of the DR-MMCs

$\sigma_{y, m} \quad$ yield strength of the matrix

$\sigma_{\infty} \quad$ uniformly remotely applied stress

$\varsigma$

energy of the accumulated dislocations that are lost per unit area of the nucleated crack surface 


\section{CHAPTER ONE}

\section{Introduction}

Metal Matrix Composites (MMCs), which are composed of contiguous metallic matrixes and ceramic reinforcements, may be divided into two groups according to the composite microstructure: continuously reinforced MMCs (CR-MMCs) and discontinuously reinforced MMCs (DR-MMCs). The former are also known as monofilaments reinforced MMCs, and the latter include monofilaments reinforced and particulate reinforced MMCs, as illustrated in Fig.1.1 [1]. Their high strength-to-weight ratio, high specific modulus, high specific strength, excellent wear resistance, and proper thermal expansion coefficient are some of the important attributes that have made them attractive and viable candidates for use in weight-sensitive and stiffness-critical components in the aerospace and automobile industries. Although examples of MMCs stretch back to ancient civilizations, the first composite materials to draw scientific as well as practical attention were those developed from work in 1924 by Schmidt on consolidated mixtures of aluminium/alumina powders, and this work led to extensive research in the 1950s and 1960s [1].

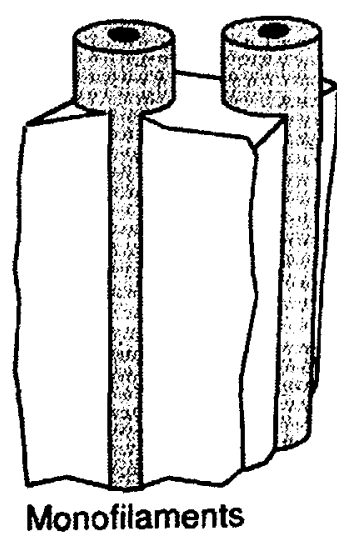

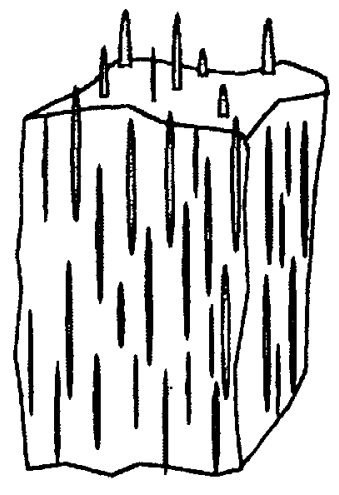

Whiskers/Staple Fibres

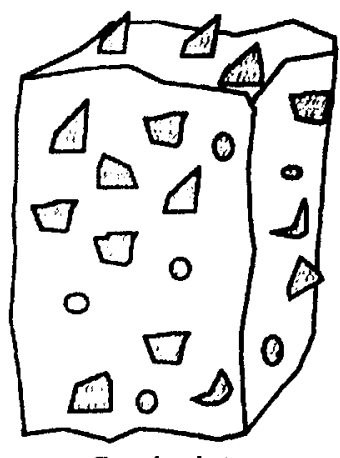

Particulate

Fig.1.1 Types of MMCs [1]. 
The thriving of CR-MMCs was seen in the 1960s. For this kind of material, matrix microstructure and strength are of secondary importance, because the primary role of the matrix is to transmit and distribute the applied load to the continuous fibres. But the high cost and anisotropic character limited their production and led to the waning of research work on them during the 1970s. DR-MMCs, on the other hand, was developed very fast during the 1980 s due to their good transverse properties, low cost, high workability and significant increases in performance over unreinforced alloys. Unlike the CR-MMCs, apart from the load-bearing effect of the reinforcement, the matrix strength in the DR-MMCs, as affected by precipitation and dislocation strengthening, also plays an important role in the mechanical properties of DR-MMCs.

Fatigue failure is a common mode of failure observed in various mechanical components and structures. Therefore, the research work on the fatigue behavior of MMCs is of great theoretical and practical significance. The fatigue process of MMCs is a complicated metallurgical process, and accurate prediction of their fatigue life is critical to their application, otherwise catastrophic failure would occur. Much research work has been carried out on the low cycle fatigue (LCF) life prediction of DR-MMCs [2 - 6]. However, an analytical model on this subject, which takes into account both the crack initiation and the crack propagation, has not been reported in the open literature so far. Although the crack initiation would occur quite quickly in the strain-controlled LCF, to make a more accurate prediction, it should not be ignored, especially for the relatively low stress/strain level.

Recent studies revealed that, while DR-MMCs have a superior fatigue resistance to the corresponding un-reinforced counterparts in the high cycle fatigue, their resistance to LCF is less satisfactory. The microstructural parameters in the composites, such as the volume fraction and size of reinforcing particles, bonding force between the matrix and particles, cyclic strain hardening exponent, cyclic strength coefficient, etc., are expected to exert a 
significant influence on the fatigue damage of the composites. For the effect of particle size, Chawla et al. [7] and Bosi et al. [8] reported that fine particles benefited fatigue resistance within $10^{4}$ cycles. On the other hand, Han et al. $[9,10]$ reported that coarse particle reinforced composites exhibited slightly superior LCF resistance. Furthermore, a recent study by Uygur et al. [11] showed that the reinforcement size has no significant effect on the LCF life of DR-MMCs. The different results reported in the literature indicated that the effect of reinforcement particle size on the LCF life has not been fully understood.

Therefore, the principal purposes of this study are:

1. to develop an analytical LCF crack initiation model to predict the whole LCF life of DR-MMCs;

2. to propose an analytical model that links the LCF life to the particle size;

3. to verify the above models by using data reported in the literature.

After this introduction of the thesis, a literature survey on the fundamentals of DR-MMCs and fatigue is presented in Chapter two which includes the characteristics of DR-MMCs, microstructural change induced by reinforcements, effects of microstructural variables on fatigue behavior, basic fatigue theories and fatigue of DR-MMCs. A new LCF life prediction model is developed in Chapter three, followed by the modeling of particle size effect on the fatigue behavior in Chapter four, both of which represent the main contributions of this thesis. Discussion on the proposed models and results is presented in Chapter five. Finally, conclusions and future work are given in Chapter six. 


\section{CHAPTER TWO \\ Fundamentals of DR-MMCs and Fatigue}

\subsection{Advantages of DR-MMCs, Their Applications and Fabrication Processes}

DR-MMCs consist of metallic alloys and particle or whisker reinforcements. During the last 20 years, they have been rapidly developed with attention focused on Aluminum-based composites reinforced with $\mathrm{SiC}$ particles and $\mathrm{Al}_{2} \mathrm{O}_{3}$ particles and short fibres. Due to the great research effort aimed at characterizing their mechanical behavior, they are currently used in structural components subjected to different types of loading. Their advantages based on their specific microstructure and their standard fabrication processes have made them promising candidates for advanced engineering materials.

\subsubsection{Why DR-MMCs?}

In DR-MMCs, both matrix and reinforcement particles bear a substantial proportion of the load. In addition, the matrix strength, as affected by precipitation and dislocation strengthening, also plays an important role. As a result, the strengthening effects of DR-MMCs fall somewhere in-between the dispersion strengthened and fibre strengthened extremes and lead to the following virtues.

High specific stiffness - To avoid excessive elastic deflection in service is commonly the overriding consideration in engineering component design. However, there is no easy way for increasing the stiffness of a metal by minor additives or microstructural control. As a result, the high specific stiffness of DR-MMCs has made them one of the attractive engineering materials. Research work done by Das et al. [12] on two kinds of particulate-reinforced 6061 aluminum metal matrix composites under different aging 
conditions showed that the addition of both angular and spherical reinforcements significantly increased the elastic modulus. The results are listed in Table 2.1 [12], in which composites $\mathrm{A}$ and $\mathrm{B}$ exhibited a considerable increase in the elastic modulus ranging from a minimum of $9 \%$ to a maximum of $40 \%$, compared to the monolithic alloy subjected to various heat-treatment procedures.

Table 2.1 Modulus, YS and UTS of unreinforced $6061 \mathrm{Al}$ alloy and the two composites $\mathrm{A}$ and $\mathrm{B}$ for different ageing times at $175^{\circ} \mathrm{C}$.

\begin{tabular}{|c|c|c|c|c|}
\hline Material & $\begin{array}{c}\text { Ageing } \\
\text { time } \\
(\mathrm{hr})\end{array}$ & $\begin{array}{c}\text { Elastic } \\
\text { modulus } \\
(\mathrm{GPa})\end{array}$ & $\begin{array}{c}\text { YS } \\
(\mathrm{MPa})\end{array}$ & $\begin{array}{c}\text { UTS } \\
(\mathrm{MPa})\end{array}$ \\
\hline \multirow{6}{*}{6061} & $0(\mathrm{ST})$ & 54 & 256 & 287 \\
\cline { 2 - 5 } & $2.0(\mathrm{UT})$ & 60 & 261 & 290 \\
\cline { 2 - 5 } & $8.0(\mathrm{PA})$ & 65 & 272 & 303 \\
\cline { 2 - 5 } & $72.0(\mathrm{OA})$ & 64 & 271 & 303 \\
\cline { 2 - 5 } & 0.0 & 65 & 257 & 297 \\
\hline \multirow{3}{*}{\begin{tabular}{c} 
Compular reinforcement) \\
\cline { 2 - 5 }
\end{tabular}} & 2.0 & 73 & 301 & 302 \\
\cline { 2 - 5 } & 8.0 & 78 & 311 & 342 \\
\cline { 2 - 5 } & 72.0 & 70 & 305 & 335 \\
\hline \multirow{2}{*}{$\begin{array}{c}\text { Composite B } \\
\text { (spherical } \\
\text { reinforcements) }\end{array}$} & 0.0 & 74 & 262 & 290 \\
\cline { 2 - 5 } & 2.0 & 72 & 281 & 323 \\
\hline
\end{tabular}

$\mathrm{ST}=$ cold water quenched to $0^{\circ} \mathrm{C}$; $\mathrm{UA}=$ under-aging;

$\mathrm{PA}=$ peak-aging; $\mathrm{OA}=$ over-aging

High specific strength - Although the addition of reinforcement reduces the ductility of DR-MMCs, the enhancement of strength expressed in terms of yield stress (YS) or ultimate tensile stress (UTS) can be quite substantial. Table 2.1 gives these results according to Das et al.'s research work [12]. It can be seen that the reinforcement in both composites A and B increased the YS and UTS by $15 \%$ to $20 \%$ compared to those of the unreinforced alloy. In addition, fatigue resistance at low $\Delta \mathrm{K}$ levels can be enhanced. Applications of enhancement 
of strength can be found in those areas where light materials with enhanced strength and resistance to low cycle mechanical fatigue are required, such as aircraft landing gear. Furthermore, because of the improvement of the strength and stiffness, thinner sections and higher stresses can be reached.

High wear resistance - Increased wear resistance is an important virtue of DR-MMCs. By the proper introduction of the reinforcement, it is common for wear rates to be reduced by factors of up to ten. In addition, it is often advantageous to control the distribution of reinforcement to achieve high wear resistance in selected surface areas while other regions are suitably tough, strong, thermally conducting, etc. It is common that the high wear resistance is combined with other properties, such as high stiffness and high thermal conductivity.

Relatively low density - Reduction of density of MMCs depends on the kinds of matrix and reinforcement. For instance, nickel-based MMCs are used in gas turbines to reduce the density of the material. However, in many cases of interest, the addition of the reinforcement raises the density slightly, such as $\mathrm{Al}$ based $\mathrm{SiC}$ or $\mathrm{Al}_{2} \mathrm{O}_{3}$ reinforced MMCs. But the increase is usually more than offset by the enhancement of stiffness, strength, etc.

Isotropic - In CR-MMCs, the well orientated long fibres result in better axial properties than transverse properties. Compared with the long fibres, the discontinuous reinforcements in DR-MMCs are not well orientated, and consequently lead to better transverse properties than those in CR-MMCs. To some extent, they can be treated as isotropic. As a result, in material preparation, the separating direction is not as strict as that in CR-MMCs[13].

Low cost - DR-MMCs can be produced by standard techniques which considerably reduce the manufacturing cost and provide a good balance between price and mechanical properties. 
In general, in progressing from continuous to whisker to particulate reinforcement there is a significant decrease in the reinforcement cost: the typical costs are $\$ 1,000 / \mathrm{kg}$ for continuous fibres, $\$ 20-40 / \mathrm{kg}$ for whiskers and $\$ 10 / \mathrm{kg}$ for particulates [13].

Thermal expansion control - The low thermal expansivity of ceramics can be used to tailor the composite expansivity to match that of different materials [1], as shown in Fig. 2.1. This may be extremely useful for components where distortions must be kept to a minimum when exposed to relatively large changes in temperature.

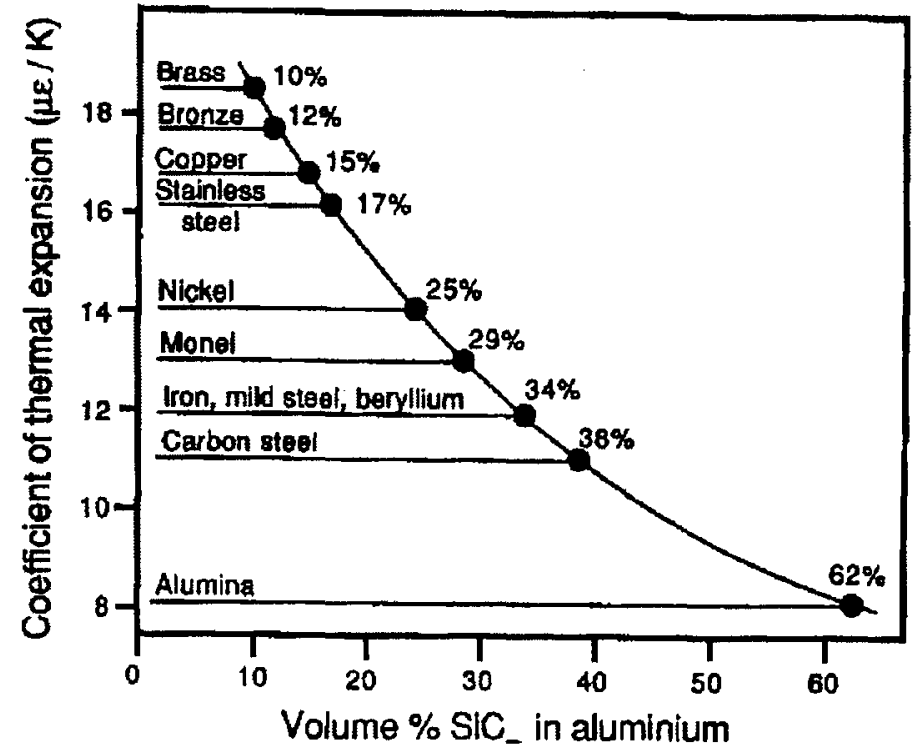

Figure 2.1 Predicted dependence of the coefficient of thermal expansion on reinforcement content for $\mathrm{Al}-\mathrm{SiC}_{\mathrm{p}}$ composites, showing how the value can be matched to those of a wide range of materials [1].

With all the above advantages, it is no wonder that DR-MMCs have the following applications. 


\subsubsection{Application Cases}

- Diesel engine piston [1] $-\mathrm{Al}$ alloy $/ 5 \% \mathrm{Al}_{2} \mathrm{O}_{3}$ short fibre

In 1983 in Toyota Motor Co./Art. Metal Manufact. Co., a 5\% $\mathrm{Al}_{2} \mathrm{O}_{3}$ short fibre insert was used in the piston ring area in order to prevent seizure of the piston ring with the top ring groove and bore (Fig.2.2). The weight was reduced by $5-10 \%$. In standard tests, wear was reduced by over four times and seizure stress doubled relative to the unreinforced $\mathrm{Al}$ alloy. This was combined with high thermal stability and conductivity. Production of these pistons in Japan has been increasing steadily over the past several years and now runs to millions of units annually.

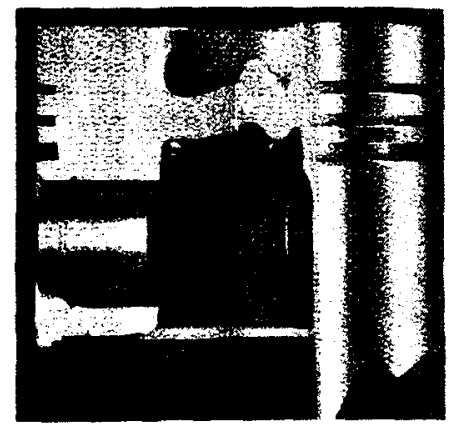

Fig. 2.2 Photograph of a diesel engine piston showing the region of short fibre reinforcement (dark) area in the land (support region) of the groove for the piston ring [1].

- Automotive drive shaft [1]- $\mathrm{Al}$ alloy/20\% $\mathrm{Al}_{2} \mathrm{O}_{3}$ particulate

Onerous dynamic stability and high torque resistance are the basic requirements for automobile drive shaft when it transmits the power to the wheels. The critical velocity at which dynamic instability occurs depends on the shaft length, the inner and outer radii of the tube and the stiffness and density of the tube material [1]. By using Duralcan $6061 \mathrm{Al}-120 \%$ $\mathrm{Al}_{2} \mathrm{O}_{3 \mathrm{p}}$ instead of steel or aluminium (Fig.2.3), the specific stiffness increased from 26.6 $\mathrm{km}^{2} \mathrm{~s}^{-2}$ or $25.9 \mathrm{~km}^{2} \mathrm{~s}^{-2}$ to $34.7 \mathrm{~km}^{2} \mathrm{~s}^{-2}$. As a result, this would allow a significant increase 
$(\sim 14 \%)$ in the maximum shaft rotation speed.

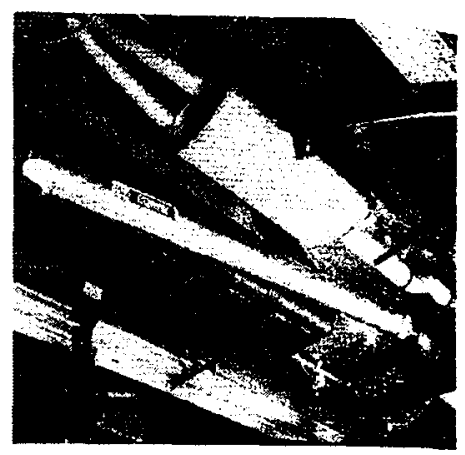

Fig.2.3 Photograph of a Duralcan 6061 $\mathrm{Al}-/ 20 \% \mathrm{Al}_{2} \mathrm{O}_{3 \mathrm{p}}$ drive shaft [1].

- Equipment rack [1]- $\mathrm{Al}$ alloy/25\% $\mathrm{SiC}$ particulate

The $6061 \mathrm{Al}-/ 25 \% \mathrm{SiC}_{\mathrm{p}}$ composite supplied by DWA Composite Specialties Inc. was chosen to produce aircraft racks for its high stiffness, low density and good electrical conductivity (Fig.2.4). The racks are $\sim 65 \%$ stiffer than the $7075 \mathrm{Al}$ alloy racks they replaced, which were flexing too much under the gravitational forces caused by the twisting and turning of the aircraft. Meanwhile, their good electrical conductivity solved the earthing problem caused by Carbon-epoxy.

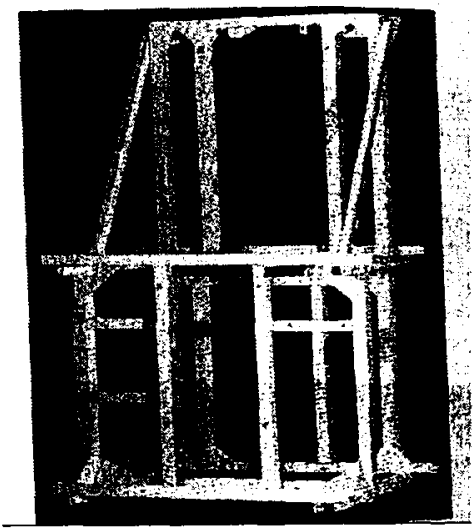

Fig.2.4 Photograph of an instrument rack ( $2 \mathrm{~m}$ in length) fabricated from 6061 $\mathrm{Al}-/ 25 \% \mathrm{SiC}_{\mathrm{p}}$ for use in Lockheed production aircraft [1]. 
- Brake rotor disc [1] - Al-Si alloy $/ 20 \% \mathrm{SiC}$ particulate

Good wear resistance and thermal stability of cast iron have made it a good candidate for brake rotor discs for many years. However, a low density is particularly desirable in rotating components of this type, making replacement with Duralcan cast composite Al-10wt $\% / \mathrm{Si} / 20 \mathrm{vol} \% \mathrm{SiC}_{\mathrm{p}}$ highly attractive. The volume fraction of $20 \%$ was chosen to combine good wear resistance with a thermally and mechanically stable transfer/contact layer (Fig.2.5).

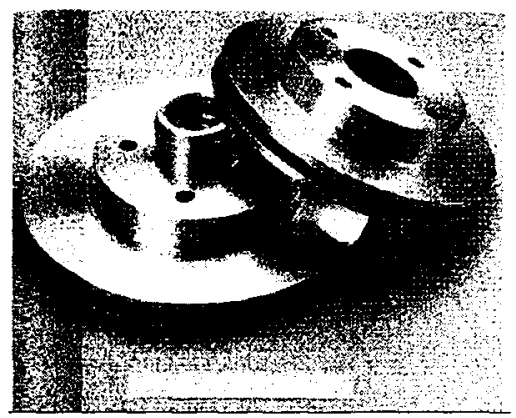

Fig.2.5 Photograph of a rotor brake disc, made from Duralcan cast Al-10wt $\% / \mathrm{Si} / 20 \mathrm{vol} \% \mathrm{SiC}_{\mathrm{p}}[1]$.

- Bicycle frame [1] - $\mathrm{Al}$ alloy $/ 10 \% \mathrm{Al}_{2} \mathrm{O}_{3}$ or $20 \% \mathrm{SiC}$ particulate

The frame of the 'Stumpjumper M2' mountain bike manufactured by Specialized Bicycle Components Inc. was made of Duralcan $6061 \mathrm{Al}-10 \mathrm{vol} \% \mathrm{Al}_{2} \mathrm{O}_{3 \mathrm{p}}$ (Fig.2.6), while the frame of Raleigh's racing bikes was made of $\mathrm{BP} 2124 \mathrm{Al}-20 \% \mathrm{SiC}_{\mathrm{p}}$ composite material. Both models have been successfully tested in extensive sports trials and have been developed for commercial sale. Apart from the improved specific stiffness, both bikes have proven to have exceptionally good fatigue endurance due to their enhanced value of $\Delta \mathrm{K}_{\text {th }}$ compared with unreinforced material. 


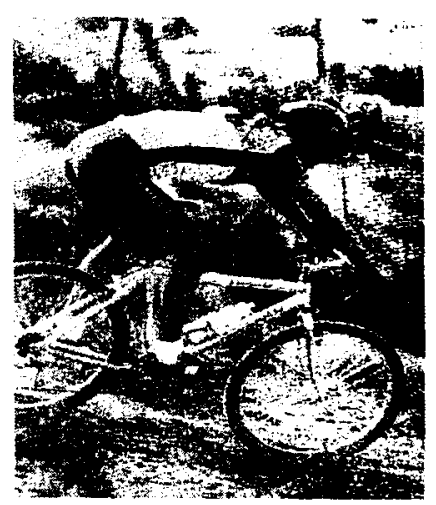

Fig.2.6 Photograph of the 'Stumpjumper M2' bicycle in action. The Frame is made of Duralcan $6061 \mathrm{Al}-10 \mathrm{vol} \% \mathrm{Al}_{2} \mathrm{O}_{3 p}[1]$.

- A hot-forged connecting rod [14] - 2080 $\mathrm{Al}$ alloy/15\% SiC particulate

To achieve the superior fuel economy of four cylinder engines, which was hindered by the development of unbalanced and objectionable secondary shaking forces of the connecting rod/piston assembly in four-cylinder engines, many car manufacturers have considered DR-MMCs to produce lightweight connecting rods and pistons. An example is shown in Fig.2.7. In this case, additional advantages, such as the higher wear resistance, the higher thermal conductivity and the lower coefficient of thermal expansion, are also applied. Furthermore, they have tighter dimensional tolerances and reduced crevice volumes, which reduce engine emissions.

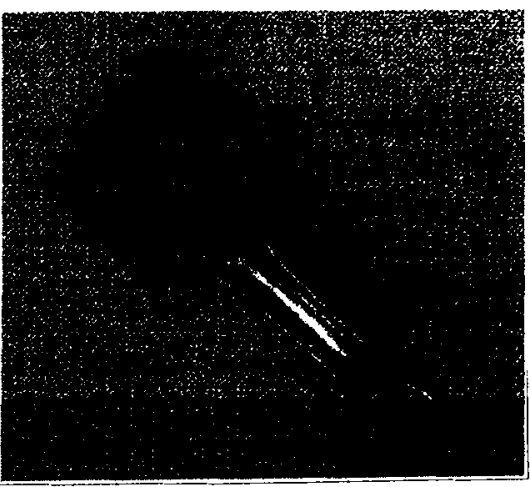

Fig.2.7 Photograph of a hot-forged connecting rod made up of a 2080 $\mathrm{Al}$ alloy/15\% SiC particulate [14]. 


\subsubsection{Fabrication Processes}

Several types of DR-MMC material are available in stock form, such as billet, rod and tube, suitable for various secondary fabrication operations. They can be produced by either solid state (powder metallurgy), liquid state or metal spray methods.

Most powder metallurgy-based processes involve the following steps: 1) mixing and blending of pre-alloyed metallic powder and reinforcements; 2) heating and degassing of the mixture; 3) consolidation of the mixture to a DR-MMC. In general, powder metallurgy requires the availability of powders of the matrix material which can place restrictions on this process. As a result, the powder-based process tends to be more expensive than the liquid-based one, and therefore generally occupies the more specialist high cost markets for DR-MMCs. Against this, several advantages are offered compared to liquid state processing [13]:

- The mechanical properties obtained in the final DR-MMCs are often superior,

- Shrinkage and other defects associated with solidification are avoided,

- A more uniform reinforcement distribution is generally obtained,

- Matrix property improvements can be obtained as a result of the deformation processing involved in solid state routes.

Liquid state routes are seen as cheap, simple and effective ways to the production of DR-MMCs, for they involve incorporation of the reinforcement into the liquid metal prior to casting to near net shape or semi-finished product for subsequent hot working. However, many of them failed for following reasons [13]:

- Lack of wetting of reinforcements by liquid metals,

- Porosity development in final product, especially where high volume fractions of reinforcement are required, 
- Poor bonding between the matrix and reinforcement,

- Excessive reinforcement/matrix reaction and reinforcement degradation.

Squeeze casting and infiltration, melt stirring methods and compocasting [13] are practical ways to overcome these shortcomings.

In spray methods, a mixture of liquid metal droplets and filler particles which are sprayed into a protective gas atmosphere and then impacted onto a substrate. Its advantages include [13]:

- Avoidance of the need for the blending and degassing of powders involved in powder routes,

- Rapid solidification conditions can be established permitting the production of fine grain size and metastable phase formation in the metal matrix,

- Additional strengthening of the matrix,

- Rapid processing and solidification tend to minimize reactions between the matrix and the reinforcement components.

However, in this process, there is a tendency for some porosity to be generated in the product.

The cast or consolidated billet made by the above methods is usually subjected to secondary processes (extrusion, forging, rolling) to break up reinforcement agglomerates, homogenize their distribution, eliminate porosity, improve metal-ceramic bonding, or simply to achieve the desired final shape. 


\subsection{Microstructural Changes Induced by Reinforcements}

In DR-MMCs, the average size of the reinforcing ceramic particles (normally $\mathrm{Al}_{2} \mathrm{O}_{3}$ or $\mathrm{SiC}$ ) is in the range of 3 to $30 \mu \mathrm{m}$ and they are approximately equiaxed (a typical aspect ratio is 2), with irregular shape and sharp corners, although spherical reinforcements are also found. Most of the matrix is very close to the ceramic reinforcements, whose thermal and mechanical properties are different from those of the matrix. As a result, the microstructural development of the matrix during primary and secondary processing is significantly modified by the dispersion of the ceramic reinforcements, and this influences the mechanisms of cyclic deformation and the overall fatigue resistance of DR-MMCs. The most notable changes induced by the reinforcements are briefly described below [14].

\subsubsection{Load Bearing Effect}

In the context of MMCs, one of the objectives might be to combine the excellent ductility and formability of the matrix with the stiffness and load-bearing capacity of the reinforcement. Central to an understanding of the mechanical behavior of a composite is the concept of load bearing effect between the matrix and the reinforcing phase. At equilibrium, if the bonding strength is strong enough, the external load must equal the sum of volume-average loads borne by the matrix and the reinforcement. Thus, for simple two-constituent DR-MMCs under a given applied load, a certain proportion of that load will be carried by the reinforcement and the remainder by the matrix. The reinforcement may be regarded as acting efficiently if it carries a relatively high proportion of the externally applied load. The load bearing effect represents an important characteristic of the composite and depends on the volume fraction, shape and orientation of the reinforcement and the elastic properties of both constituents. 
The most widely used model describing the effect of load bearing effect is the so-called shear lag model, originally proposed by Cox [14] and subsequently developed by others [14]. This model is based on the consideration of the transfer of tensile stress from the matrix to the reinforcement by means of interfacial shear stresses, and the calculation is based on the radial variation of shear stress in the matrix and at the interface. However, the main drawback of this model lies in the neglect of load transfer across the fibre end which is unacceptable in DR-MMCs. Several attempts have been made to introduce corrections, and the modified shear lag model is one of them and will be discussed later.

\subsubsection{Enhanced Dislocation Density}

As the manufacturing of DR-MMCs is always carried out at high temperatures and the thermal expansion coefficient of the ceramic reinforcements is lower than that of the metal, this mismatch will induce thermal residual strains (tensile in the metal and compressive in the ceramic) upon cooling from the processing temperature. It has been shown that the large residual strains generated in the matrix lead to stress relaxation by plastic deformation [14]. As a result, dislocation nucleation was especially intense around the ends of whiskers or at the angular corners of particles, where the computed residual stresses were maximum. Depending on the deformation characteristics and flow stress of the matrix as well as on the presence of precipitates and inclusions, the dislocation structure near the reinforcement may vary very much from one material to another.

The average dislocation densities in the composite matrix were approximately one order of magnitude higher than those in the unreinforced counterpart under the same thermo-mechanical treatment. Various theoretical models were developed to determine the dislocation density as a function of the distance to the interface and there was a broad agreement that the dislocations were able to move over distances of the order of the particle 
or whisker diameter, and this may be increased by a factor of 2-3 around the ends of whiskers [14]. The enhanced dislocation density model is one of these theories and will be presented in Chapter four.

\subsubsection{Grain Structure and Texture}

Cold deformation of the composite induces the generation of dislocations near the interface to accommodate the strain incompatibility between the reinforcement and the matrix. The plastic relaxation, as mentioned above, results in a region (often called the deformation zone) close to the reinforcement. The amount of matrix affected by the deformed zone near the reinforcements was proportional to their volume fraction, and this significantly weakens the grain texture induced by cold deformation in commercial DR-MMCs, as compared to the unreinforced counterparts.

It has been shown that ceramic reinforcements with diameters over $1 \mu \mathrm{m}$ may stimulate the formation of recrystallization nuclei upon annealing in the deformed region formed during cold or hot deformation. As the composite reinforcements are usually much larger than $1 \mu \mathrm{m}$, particle stimulated nucleation is dominant and large particles often nucleate more than one grain. After recrystallization, commercial DR-MMCs exhibit an equiaxed grain structure with an average grain size in the range of a few microns to a few tens of microns, significantly smaller than that of the unreinforced materials processed under the same nominal conditions [14].

\subsection{Effects of Microstructural Variables on Fatigue Behavior}

The mechanical behavior of DR-MMCs can be quite sensitive to the microstructural details, such as reinforcement shape, size, distribution, volume fraction, property mismatch, aging 
condition, bonding strength, whisker orientation, etc. The sensitivity covers the reinforcement, the interface, and the matrix. A brief review is given below.

\subsubsection{Reinforcement Shape}

From the viewpoint of stress concentration, the rates of void initiation and growth are clearly lower for spheres than for angular particles, although sometimes not so dramatically. Aligned whisker material $\left(6061 \mathrm{Al}-20 \% \mathrm{SiC}_{\mathrm{w}}\right)[15,16,17]$ has been shown to offer a greater resistance to crack propagation when the crack grows transverse to the whisker direction. Fatigue threshold $\left(\Delta K_{t h}\right)$ has been found to be the highest in the particulate-reinforced material, but upon correcting for crack closure, its effective fatigue threshold $\left(\Delta K_{t h, e f f}\right)$ was lower than that for an axial crack in the whisker-reinforced material [1].

\subsubsection{Reinforcement Size}

Experimentally, the effect of particle size on particle cracking is well documented for the Al-SiC system $[18,19,20]$. In the situation with a large scatter in size, it is the largest particles which tend to fracture [21]. Consequently, in material containing coarse particles, particle fracture is commonplace, whereas for fine particulate, particle cracking is rare. In fatigue, threshold values have been shown to increase with increasing particle size in $\mathrm{Al}-\mathrm{SiC}_{\mathrm{p}}$ composites [22]. This is attributed to the surface roughness-induced closure effect, which was found to be nearly three times greater for coarse particle reinforced systems compared with fine ones [23].

Particle size also had a significant influence on fatigue strength. In high cycle fatigue (HCF), an increased fatigue strength was observed with decreasing particle size $[24,25,26]$. Tokaji et al. [27] reported that the composite with $5 \mu \mathrm{m} \mathrm{SiC} \mathrm{particles} \mathrm{showed} \mathrm{a} \mathrm{higher} \mathrm{fatigue} \mathrm{strength}$ than the unreinforced alloy. The incorporation of $20 \mu \mathrm{m} \mathrm{SiC}$ particles led to an increase in 
fatigue strength at a high stress level, but the improvement diminished with decreasing stress level, and a slightly decreased fatigue strength was observed at low stress level, as compared with the unreinforced alloy. The composite with $60 \mu \mathrm{m}$ SiC particles exhibited a considerable decrease in fatigue strength. On the other hand, in low cycle fatigue (LCF), different results were reported by different investigators, which will be discussed in chapter 4.

\subsubsection{Volume Fraction of Reinforcement}

In the high cycle fatigue of DR-MMCs, the presence of particulate reinforcements in the metal matrix increases the fatigue limit of the material, and an increasing reinforcement volume fraction makes the fatigue limit even higher. However, in LCF of DR-MMCs, because of the high stress or strain amplitude level, reinforcement cracking occurs very quickly and frequently during the cyclic loading. As a result, the LCF strength of DR-MMCs is inferior to the unreinforced counterparts and a higher volume fraction leads to a lower fatigue strength. This point will be discussed in the later part of this thesis.

\subsubsection{Interface strength}

The interface between the reinforcement and the matrix is an incoherent interface having a high energy level, and thus is a good site for precipitate nucleation and growth which can influence the bonding strength of DR-MMCs. Another factor which influences the bonding

strength is the property mismatch. In most MMCs a stiff reinforcement is incorporated into a weaker, less stiff matrix. The mismatch in properties is thus an essential feature of the composite system. In an attempt to see how closely the interfacial strength was related to fatigue and crack growth in DR-MMCs, an experiment was performed in which $\mathrm{SiC}$ particles with naturally oxidized and heavily oxidized interfaces [28] were incorporated into 
a powder formed $8090 \mathrm{Al}-\mathrm{Li}$ alloy matrix. Fatigue experiments showed that the artificially oxidized composite shows an earlier upturn into phase (4) (see 2.4.1) of the fatigue crack growth curve (i.e., the acceleration towards the final failure at high growth rates). However, the behavior of the two materials in the Paris regime (see 2.4.3.2) is similar.

In terms of fatigue crack growth behavior in DR-MMCs, stronger interfaces and higher void nucleation strains are likely to be beneficial. However, interfacial strength estimates in $\mathrm{Al} / \mathrm{SiC}$ systems $[29,30]$ suggest that the interfacial strength lies in the range of $1650-3000$ $\mathrm{MPa}$. $\mathrm{SiC}$ particle fracture is a function of particle size and is also likely to fall around 3000 MPa. Therefore, for the highest strength interfaces with increasing particle size, interfacial fracture will be replaced by particle fracture as the void nucleation mechanism [1].

\subsubsection{Reinforcement Distribution}

Experimental evidence indicates the preferential nucleation of cracks in regions of locally high volume fraction of particles. During crack growth, clustered regions can behave in one of two distinct ways. If the particles move independently of one another under the stresses at the crack tip, then the constraint gives rise to very large plastic strains and the crack displays a preference for passing through clustered regions [31,32]. This is encouraged by incompletely infiltrated regions, and voids are often present within such clusters. However, if the cluster moves collectively, then it behaves as a single large particle, the region between the particles is less strained and the cluster may deflect the crack. 


\subsection{Basic Fatigue Theories}

Fatigue is a process which causes premature failure or damage of components subjected to repeated or cyclic loading. Fatigue failure is a common mode of failure observed in various mechanical components and structures. Proper prediction of life of these components/structures is very important, and any underestimation can cause catastrophic failure. To accurately describe and model the fatigue process on the microscopic level involves a complicated metallurgical process. Despite this complexity, fatigue analysis methods have been developed, which will be briefly described below.

\subsubsection{Fatigue Process}

It has been generally accepted that the fatigue process can be divided into four phases: (1) Crack initiation; (2) Stage I slip-band crack growth; (3) Stage II crack growth on planes of high tensile stress; (4) Ultimate failure. On the other hand, it is now clear that fatigue failure is caused by cyclic plastic deformation which causes irreversible changes in the material. In cyclic loading, the elastic deformation is fully reversible and may not cause any damage. As a result, there would be no fatigue without repeated plastic deformation. Therefore, on the basis of the types of irreversible changes caused by cyclic plastic deformation, it is possible to divide the whole fatigue process into three consecutive and partly overlapping stages [33] as shown schematically in Fig.2.8:

- Fatigue hardening and/or softening, depending mainly on the original state of the material and the stress or strain amplitude. This stage is characterized by the changes of substructure within the whole volume of the loaded material.

- Microcrack nucleation, taking place in a small part of the total volume.

- Crack propagation ending in final failure. The controlling factor of crack propagation is highly concentrated cyclic plastic deformation within the plastic 


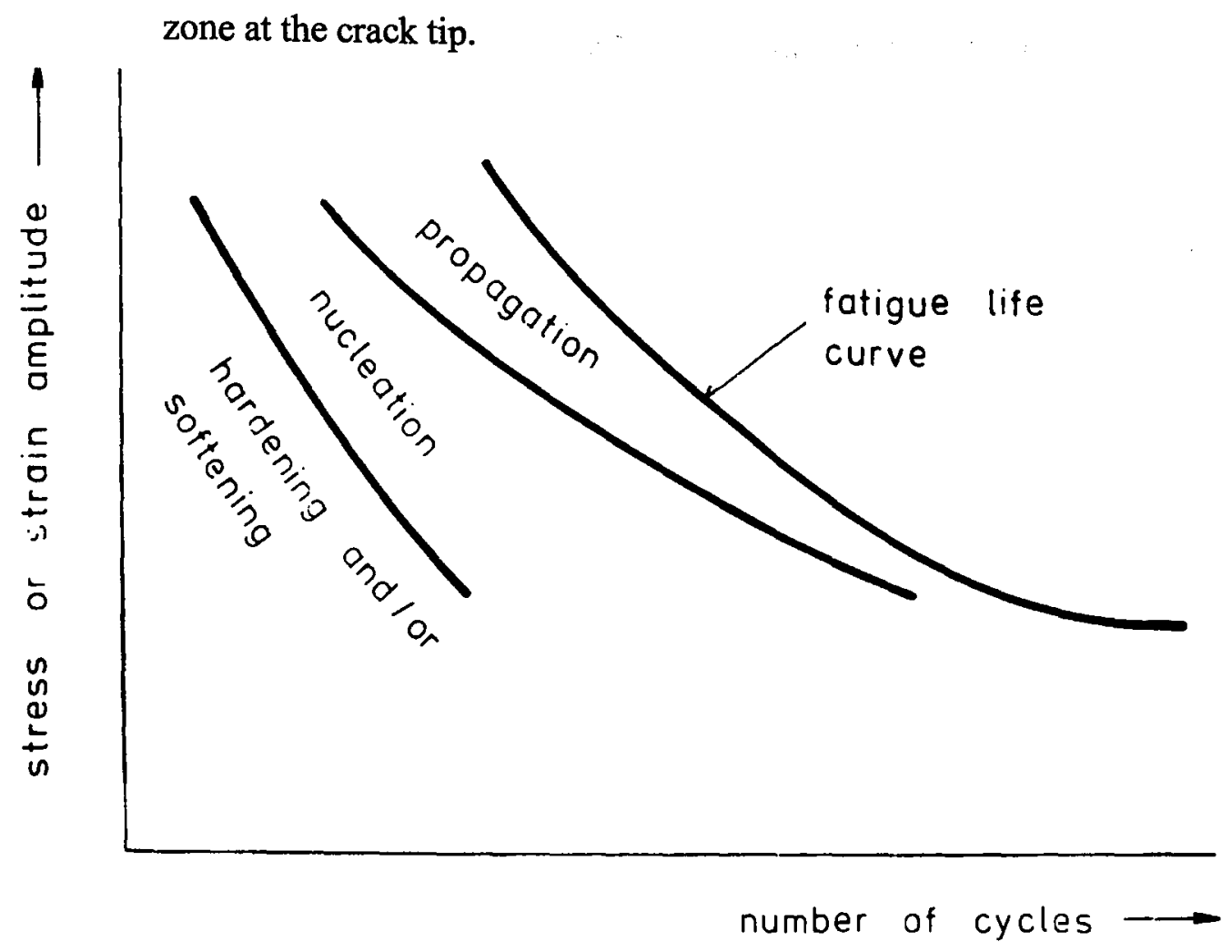

Fig.2.8 Stages of fatigue process [33].

The fatigue-life curve corresponds to the crack propagation and the end of the whole fatigue life. The other two curves represent the end of crack nucleation and material hardening and/or softening, respectively. After cyclic hardening/softening is completed, the cycled material exhibits a steady-state behavior which is known as a saturation state of the material. In this state, stress and strain amplitudes have reached their saturated values, and there are no further changes in the hysteresis loop shape and area. If a series of either stress- or strain-controlled tests is performed at different amplitudes, then a set of stable, saturated hysteresis loop shape and area will be reached.

It is necessary to stress that there is no well defined border between the stages. For example, there is no well defined crack length to separate fatigue nucleation and propagation. It is normally dependent on the techniques to detect the crack size. However, fatigue analysis 
methods which involve both crack initiation and propagation have been developed.

\subsubsection{High Cycle Fatigue and Low Cycle Fatigue}

Two different regimes have been identified in fatigue behavior, namely high cycle fatigue (HCF) and low cycle fatigue (LCF). As the resistance to fatigue depends essentially on a number of factors, such as stress concentration, surface roughness, frequency of loading, loading history, residual stress-strain fields, temperature, environmental condition, etc., the dividing line between HCF and LCF changes with the material being considered, but usually falls between $10^{4}$ and $10^{5}$ cycles.

In HCF, the strains are predominantly elastic and the maximum applied stresses are well below the tensile and compressive yield stress. Therefore, plastic deformation develops slowly in the material to nucleate a crack which propagates until failure, and most of the fatigue life in this regime is spent in the crack initiation. The fatigue limit, $\sigma_{c}$ defined as the maximum stress amplitude which may be sustained infinitely without causing failure (see Fig.2.9), is a critical material property in HCF. However, for some materials which have no clear fatigue limit, such as aluminum, the fatigue limit is defined as the stress amplitude at which the material can experience about $10^{7}$ cycles without failure. It was found to be approximately $30-50 \%$ of the ultimate tensile strength for many metallic materials [14].

On the contrary, plastic strains are dominant in LCF regime. Crack initiation occurs rapidly and most of the fatigue life is spent in propagating the fatigue crack until failure. The Coffin-Manson relation regarding the dependence of the plastic-strain amplitude, $\Delta \varepsilon_{p} / 2$, on the number of cycles to failure, $N_{f}$, can be used to characterize the fatigue life in this region, which can be expressed by, 


$$
\frac{\Delta \varepsilon_{p}}{2}=\varepsilon_{f}^{\prime}\left(2 N_{f}\right)^{c}
$$

where $\varepsilon_{f}^{\prime}$ is the fatigue-ductility coefficient given by the extrapolation of the Coffin-Manson [14] curve to the first half cycle $\left(2 N_{f}=1\right)$ and $c$ is the fatigue ductility exponent, which is in the range of -0.5 to -0.7 for most metals.

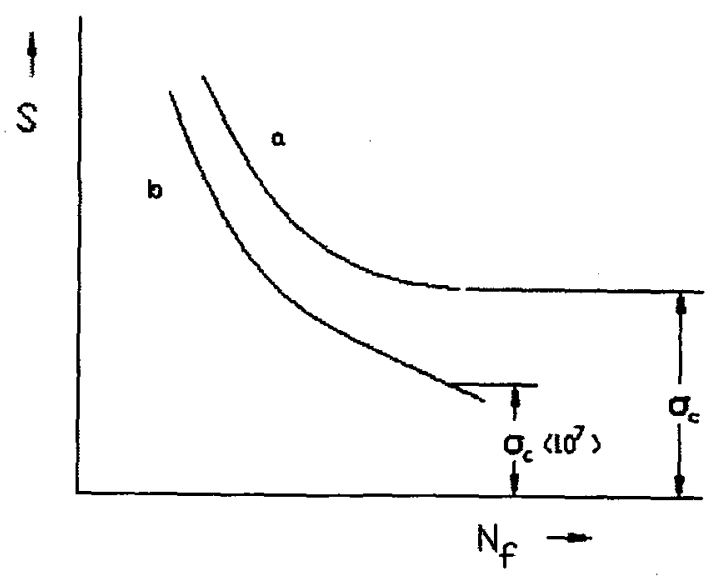

Fig.2.9 Schematic drawing of fatigue life curve $S$ versus $N_{f .}$ [14]

\subsubsection{Fatigue Analysis Methods}

As mentioned above, the fatigue life of a component can be divided into two major processes: crack initiation and propagation. The size of the crack at the transition from initiation to propagation is usually unknown and often depends on the point of view of the analyst and the size of the component being analyzed. At low strain amplitudes, about $90 \%$ of the life is spent at initiation stage, while at high strain amplitudes the majority of the fatigue life may be spent on propagating a crack which can be analyzed as follows. 


\subsubsection{Fracture Mechanics Approach for Fatigue Cracks}

Fracture mechanics approaches are used to estimate the propagation life. It requires an initial crack size to be known for a component with imperfections or defects, such as welding porosities, inclusions and casting defects, etc. Linear elastic fracture mechanics principles are used to relate the stress magnitude and distribution near the crack tip to the remote stress applied to the cracked component with different crack size and shape. An exact calculation of the stress and strain fields at the crack tip is only possible for the elastic case. It is obvious that the response of the material at the crack tip is due to the very high stress concentration of a plastic type. It is the cyclic plastic strain, rather than the total or elastic cyclic strain, that controls the crack behavior. Nevertheless, the elastic solution has produced many important results, which also hold to a good approximation for real fatigue cracks.

\section{(i) Linear Fracture Mechanics}

Griffith [34] formulated the concept that a crack in a component will propagate if the total

- energy of the system is lowered with the newly created crack surfaces. Consider a plane opening mode crack in an unbounded medium (see fig.2.10), the crack with a length of $2 a$ is assumed as a mathematical cut, and the uniformly applied stresses $\sigma_{\infty}$ are normal to the crack plane. The body is in the plane-strain state, and the material is supposed to be linear elastic with Young's modulus E and Poisson's ratio $v$. The work required to advance the crack tip from $a$ to $a+d a$ is proportional to $d a$. In real structural materials the main part of this work is spent in the plastic deformation and other irreversible phenomena. All these factors may be included in the specific fracture work $\eta$ which is related to the unit area of the newly formed crack. When the increment of the potential energy of the system $\Pi$ related to the crack tip advancement is larger than the required fracture work, i.e., $-d \Pi>\eta d a$, due to the energy surplus, dynamic crack growth becomes possible. For half of the body, $x \geq 0$, 

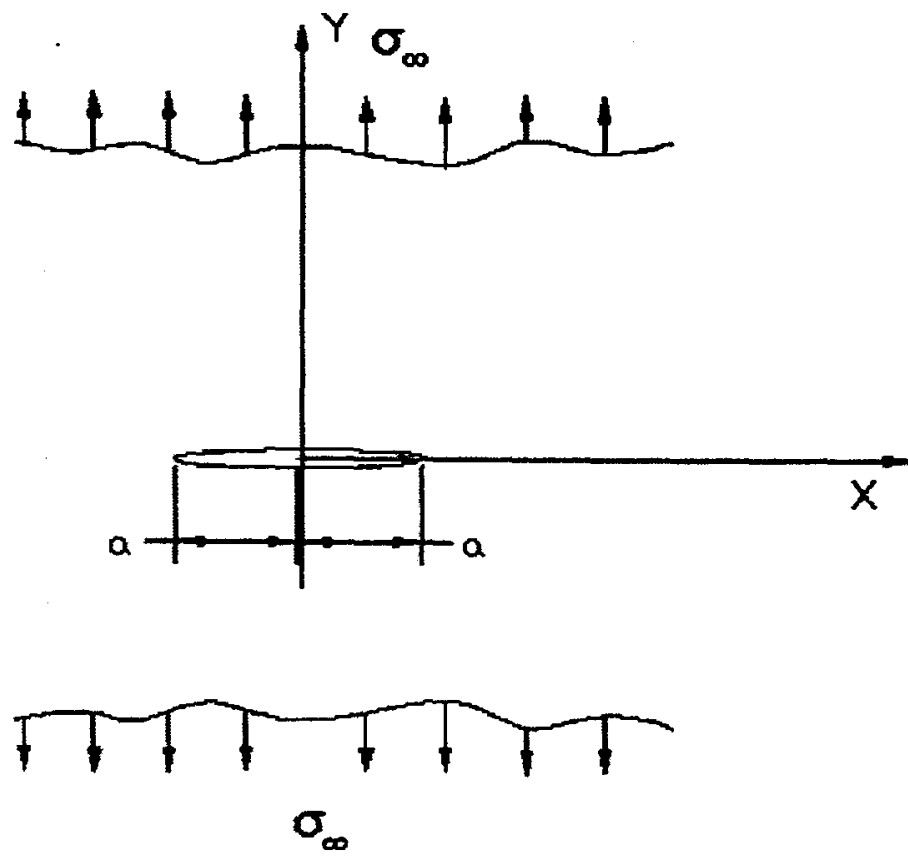

Fig.2.10 Griffith's problem of plane crack under uniform tension. [34]

the potential energy is [35]

$$
\Pi=\text { const }-\frac{\pi \sigma_{\infty}^{2} a^{2}\left(1-v^{2}\right)}{2 E} .
$$

Let $-d \Pi=\eta d a$, then the critical stress for crack propagation $\sigma_{c}$ can be expressed

$$
\sigma_{c}=\left[\frac{\eta E}{\pi a\left(1-v^{2}\right)}\right]^{1 / 2}
$$

In mode I cracking, stress intensity factor, $K_{I}=\sigma_{\infty}(\pi a)^{1 / 2}$, is another parameter used to rate the initiation of crack growth. A crack does not grow if $K_{I}<K_{I C}$, where $K_{I C}$ is the critical 
stress intensity factor, or fracture toughness. The critical condition is $K_{I}=K_{I C}$. By using Eq.2.3, $K_{I C}$ can be expressed as

$$
K_{I C}=\left(\frac{\eta E}{1-v^{2}}\right)^{1 / 2}
$$

The fundamental relationship bridges the approaches based on the stress intensity factors and the energy conservation law. The amount of potential energy released when a crack propagates in a unit of length is defined as $G_{I}=-\frac{\partial \Pi}{\partial a}$, which is called energy release rate or crack tip driving force. Substituting Eq.2.2 into $G_{I}$ yields,

$$
G_{I}=\frac{\pi \sigma_{\infty}^{2} a\left(1-v^{2}\right)}{E}
$$

In terms of the crack tip driving force, the critical crack growth initiation condition can also be expressed as $G_{I}=G_{I C}$, when $\sigma_{\infty}=\sigma_{c}$. Based on Eq.2.3, $G_{I C} \equiv \eta$.

(ii) Nonlinear Fracture Mechanics

Strictly speaking, linear elastic fracture mechanics fails when a plastic zone at the crack tip occurs. Unfortunately, such zones are present in all real situations. To apply linear elastic fracture mechanics to engineering design, the characteristic size $D_{c}$ of the plastic zone, as shown in Fig.2.11, should be small compared with the size of the crack. $D_{c}$ may be expressed as

$$
D_{c}=\frac{K_{l}^{2}}{3 \pi \sigma_{y}^{2}}
$$




$$
D_{c}=\frac{K_{I}^{2}}{\pi \sigma_{y}^{2}}
$$

for plane strain and plane stress respectively [35].

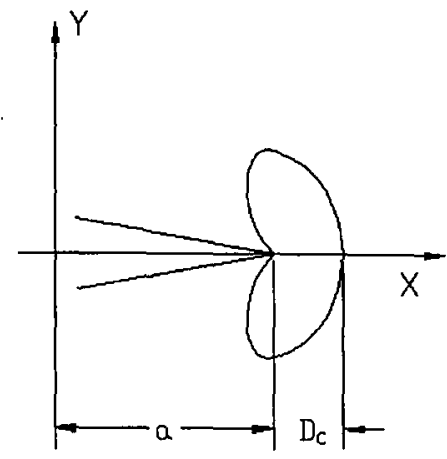

a)

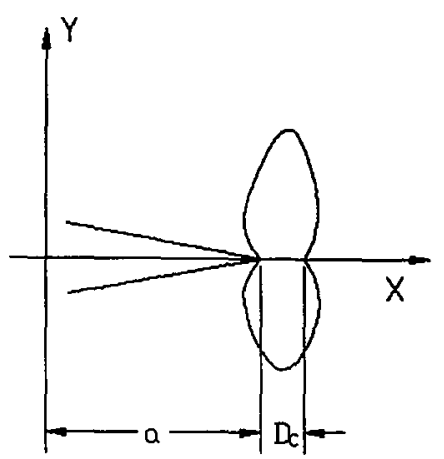

b)

Fig.2.11 Plastic tip zones: a) plane strain state; b) plane stress state. [35]

Irwin suggested an elementary approach to include the plastic deformation in the concept of linear elastic fracture mechanics. A size of plastic zone was added to the actual crack, and the modified stress intensity factor was introduced as,

$$
K_{I}=\sigma_{\infty}\left[\pi\left(a+D_{c}\right)\right]^{1 / 2} .
$$

The crack driving force can be approximately expressed as [35],

$$
G_{l} \approx \frac{\pi \sigma_{\infty}^{2} a}{E}\left[1+\frac{1}{2}\left(\frac{\sigma_{\infty}}{\sigma_{y}}\right)^{2}\right] .
$$

Such an approach is valid only when the correction for the plastic effect is comparatively small. In principle, nonlinear fracture mechanics ought to be based on the theory of plasticity in which fatigue is considered as cyclic plastic deformation taking into account hysteretic phenomena, strain hardening and/or softening. 
A simplified approach is the model of a thin plastic zone suggested by Leonov with Panasyuk and Dugdale [35], see Fig.2.12. In this model, all the plastic effects are concentrated in the plastic zone $D_{c}$, while the basic part of the material remains elastic. A crack begins to grow when the crack tip opening displacement $\delta$ reaches a critical magnitude, $\delta_{c}$, which is treated as a fracture toughness parameter given by formula:

$$
\delta_{c}=\frac{K_{I C}^{2}}{E \sigma_{0}}
$$
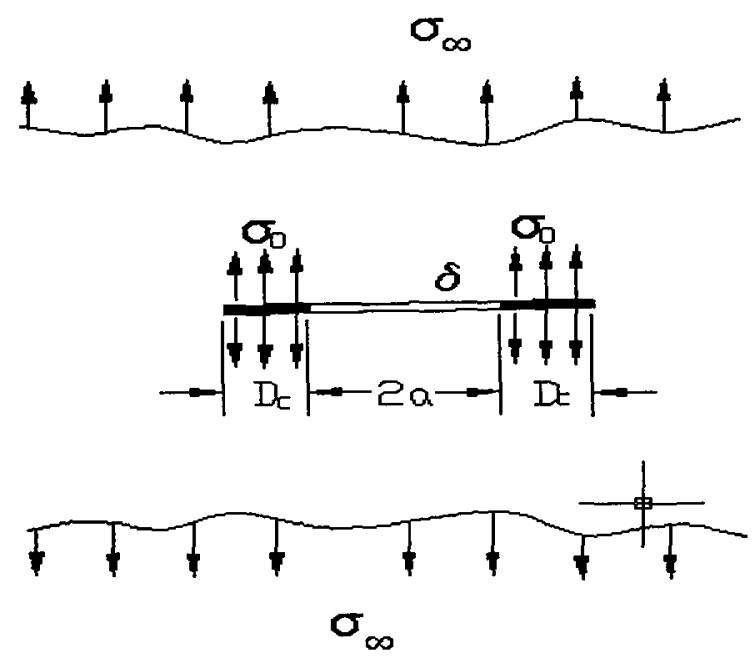

Fig. 2.12 Model of thin plastic zone [35].

where $\sigma_{0}$ is the yield strength of the material.

Linear and nonlinear fracture mechanics may be connected through the use of the so-called path-independent integral technique. J-integral is one of them. It is concluded that the J-integral taken along any unclosed contour between crack surfaces is in fact path independent. Thus, even though considerable plasticity may occur in the vicinity of the crack tip, any path sufficiently far from the crack tip can be selected to be conveniently analyzed. 


\subsubsection{Fatigue Crack Growth Rate}

In mode I cracking as mentioned above, when $K_{l} \geq K_{I C}$, immediate failure will occur. However, when $K_{I}<K_{I C}$, although catastrophic failure will not happen, sub-critical crack growth still exists at undetectable rates (under $10^{-11} \mathrm{~m} / \mathrm{cycle}$ ). The most common cause of sub-critical crack growth is fatigue loading. When fatigue is considered, the difference in the stress intensity between the maximum and minimum loading $\left(\Delta K_{I}\right)$ is an important parameter. The resistance of the material to crack propagation is given in terms of the crack growth rate per loading cycle $(d a / d N)$. At intermediate $\Delta K_{l}$, the crack growth rate can be described by the Paris-Erdogan [35] relation

$$
\frac{d a}{d N}=C\left(\Delta K_{I}\right)^{m}
$$

where $C$ and $m$ are constants which can be determined for a given material and environment. Hence, a plot of crack growth rate against $\Delta K_{I}$, in log scales, should give a straight line in the Paris regime, with a gradient equal to $\mathrm{m}$, see Fig.2.13. At low stress intensities, there exists a threshold, $\Delta K_{t h}$, below which no crack growth occur, while the crack growth rate usually accelerates as the level for fast fracture, $K_{I C}$, is approached. The threshold region was identified when the average crack increment per cycle was equivalent to or smaller than one atomic lattice spacing [14]. The crack growth rate in this regime is very sensitive to the microstructure, environment, and stress ratio. 


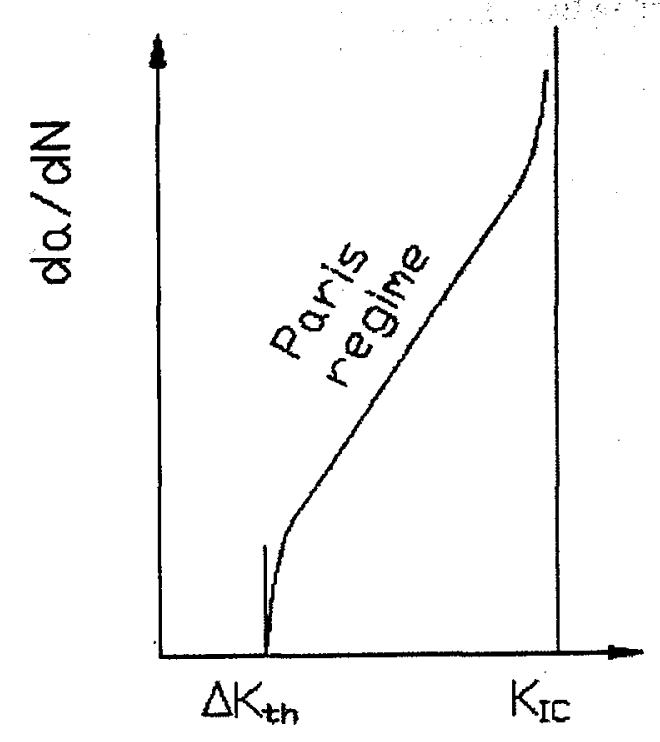

Fig.2.13 Fatigue Crack Growth Rate Diagram. [14]

\subsubsection{Fatigue Life Curves}

(i) The Stress-Life (S/N) Curve: For evaluation of the basic fatigue strength of materials, machine parts, and whole structures, the $\mathrm{S} / \mathrm{N}$ curve has so far been used. It is defined as the dependence of the stress amplitude on the number of cycles to failure, as shown schematically in Fig. 2.9. In this drawing, curve $a$ is typical in the asymptotic approach to a limiting value - the fatigue limit $\sigma_{c}$ below which fatigue fracture will not happen. In the case of curve $b$, the stress amplitude decrease steadily with increasing number of cycles to failure in such a way that the rate of decrease is lower for higher number of cycles, but there is no clear fatigue limit as in the preceding case. Instead, the endurance limit is defined conventionally, usually as the stress amplitude corresponding to a number of cycles to failure of $10^{7}$. This approach is used in HCF where the applied stress is controlled and resultant fatigue lives are relatively long. In cases of structural component designing where 
finite life is required, the $\mathrm{S} / \mathrm{N}$ curve fails. While in HCF the resistance of a material against cyclic stress might be considered of primary importance, in LCF the resistance against the cyclic plastic strain is much more important. Thus, another fatigue life curve which is based on the plastic strain amplitude became a necessity for engineering purposes.

(ii) Strain-Life $\left(\Delta \varepsilon_{p} / 2-N_{f}\right)$ curve: This method is used in the high strain/low cycle regime, taking into account the actual plastic strain and stress-strain response of the material. The plastic strain or deformation is directly measured and quantified. It is based on the Coffin-Manson relation as presented above. Fig.2.14 shows a schematic log-log plot of the strain-life curve [2] .

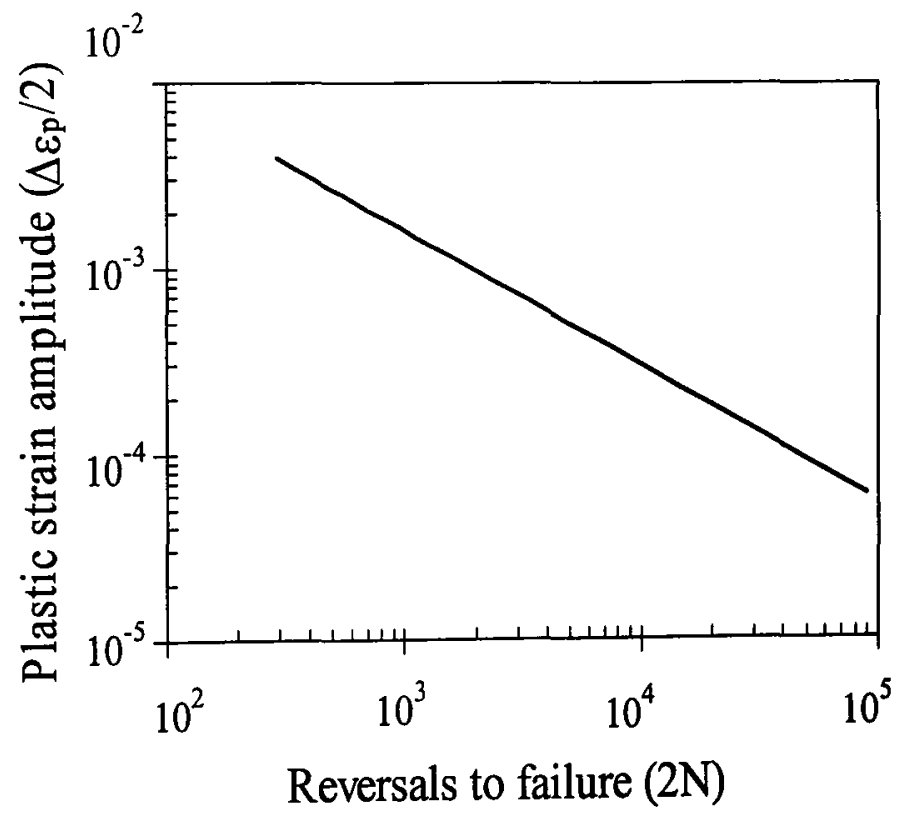

Fig.2.14 Schematic drawing of strain-life curve $-\Delta \varepsilon_{p} / 2$ versus $N_{f .}$ [2]

\subsection{Fatigue of DR-MMCs}

Fatigue failure of metallic materials is induced by the nucleation of one or several 
microcracks which propagate slowly during cyclic loading until one of them reaches the critical size and catastrophic failure occurs. In DR-MMCs, the changes in the composite response upon cyclic loading are primarily induced by the plastic deformation of the matrix. It was found that the damage was initially generated randomly by reinforcement fracture, decohesion at the matrix/reinforcement interface and the formation of matrix cracks. This homogeneous damage condition continued until a dominant microcrack was nucleated and damage was then rapidly localized around the propagating crack.

\subsubsection{HCF and LCF in DR-MMCs}

The division of HCF and LCF in metallic materials is also valid for DR-MMCs. It is well known that the nucleation phase takes up to $90 \%$ of the fatigue life in the HCF regime and, on the contrary, up to $80 \%$ of fatigue life is spent on fatigue crack propagation in the LCF region.

In the LCF of DR-MMCs, the composite fatigue life is normally inferior to that of the matrix if they are compared in terms of the cyclic strain amplitude (either total or plastic). However, this result is based on the fact that the unreinforced matrix carries a significantly lower stress at equivalent strain levels owing to its lower stiffness and strain hardening capacity. In fact, opposite result would occur if they are compared in terms of the cyclic stress amplitude rather than the cyclic strain amplitude [14].

The overall HCF performance as well as the fatigue limit of DR-MMCs improved with increasing reinforcement volume fraction due to an increase in the number of cycles to initiate a crack. The benefits in the crack nucleation time have to be added to those of the lower crack propagation rates in the near-threshold region at low stress ratios, because the increases in stiffness and strength with reinforcement volume fraction reduced the crack 
opening levels and promoted higher levels of fatigue crack closure. In the mean time, the ceramic reinforcements reduced the average inclusion size as well as the average stresses acting on the matrix and on the inclusions which increases the crack nucleation time. Therefore, a higher fatigue limit was reported for the composites [14].

It should be noted that if the composite is correctly processed, the fatigue limit and the fatigue strength can be improved. Porosity, particle clusters and other microstructural defects related to the presence of the ceramic reinforcements may reduce the composite fatigue strength, compared to the matrix values.

\subsubsection{Crack Initiation Site}

The microstructural features which led to the nucleation of a fatigue crack can be determined from the analysis of the fracture surfaces as well as of the longitudinal sections under the scanning electron microscope (SEM). It is shown that, in LCF of DR-MMCs, a large number of microcracks nucleated rapidly at the specimen surface from broken or decohered particles when the applied stress amplitude was equivalent to the composite yield strength, then these microcracks grow quickly and coalesce to form a dominant crack, which leads to the specimen failure.

On the other hand, several typical sites for crack nucleation in HCF were observed [36]. The first type was imperfections associated with cast materials, such as porosity and large reinforcement clusters formed by particle segregation during solidification. The second group of nucleation sites was related to the reinforcing particles. In cast composites, cracks were initiated by decohesion at the interface in materials reinforced with particles, whiskers, and short fibers. On the contrary, fatigue crack initiation at the reinforcements in powder-metallurgy composites was normally due to particle fracture. These broken particles 
were well above the average particle size or were found in particle clusters with a high local volume fraction of reinforcement. Thirdly, a large lumber of fatigue cracks nucleated at large intermetallic inclusions in the matrix in all materials.

\subsubsection{Crack Propagation Characteristics of DR-MMCs}

The relationship between the crack growth rate $d a / d N$ and the variation in the stress intensity factor $\Delta K$ (Fig.2.12), which is the theoretical framework to analyze the kinetics of crack propagation in metals, can be extrapolated to DR-MMCs. However, the interaction between the fatigue crack and the ceramic reinforcements during fatigue crack propagation increases the $\Delta K_{t h}$ and the exponent $m$, while the fracture toughness of the composite was reduced, see Fig.2.15 [14].

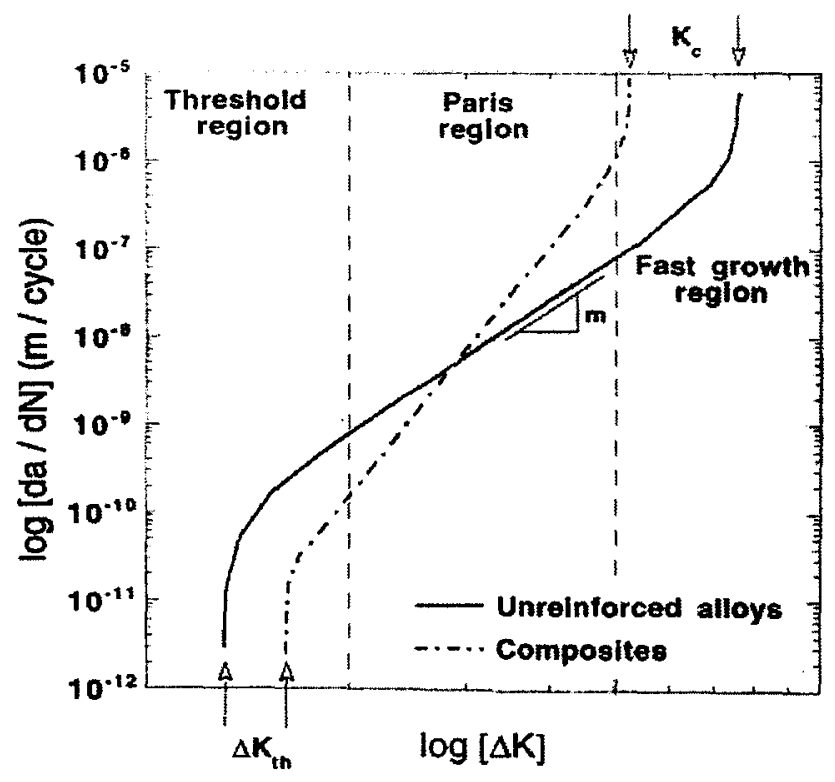

Fig.2.15 Fatigue crack growth behavior in metallic alloys and DR-MMCs [14]. 


\section{CHAPTER THREE \\ Crack Initiation Model in LCF of DR-MMCs}

As mentioned above, while DR-MMCs have a superior fatigue resistance to the corresponding un-reinforced counterpart in the HCF, their resistance to the LCF is less satisfactory. A number of factors are involved in the degradation, including the brittle nature of the reinforcement particles, the plastic flow constraint of the metallic matrix due to the presence of reinforcement particles, the stress concentration, and the increased dislocation density near the interfaces and the hydrostatic stresses within the constrained matrix. The microstructural parameters of the composites, such as the volume fraction, shape and size of reinforcing particles, bonding force between the matrix and particles, cyclic strain hardening exponent, cyclic strength coefficient, etc., are expected to have a significant influence on the fatigue damage of the composites.

A lot of research work has been carried out on the LCF life prediction of DR-MMCs [e.g., 2-6]. However, an analytical model on this subject based on the whole fatigue process is still lacking. As described in section 2.4.1, it has been generally accepted that the fatigue process can be divided into four phases: (1) crack initiation; (2) stage I slip-band crack growth; (3) stage II crack growth on planes of high tensile stress; (4) ultimate failure. In general, phase three involves a large proportion of the total cycles to failure in the high stress LCF, while phase two occupies most part of the life in the low stress high cycle fatigue [37]. As the ultimate ductile failure accounts for only a very small fraction of fatigue life and materials in this phase are considered in failure, it is thus reasonable to exclude this phase from the fatigue life prediction. As a result, fatigue life prediction should consist of crack initiation and propagation (phases (2) and (3)). In the DR-MMCs, the preferred locations for the fatigue crack initiation are broken reinforcement particles or interfaces between the particles and matrix $[5,8,14]$. It would be reasonable to regard the formation of a dominant 
microcrack as the crack initiation, and then fatigue damage propagates along this crack until the catastrophic failure occurs. The relative proportion of the life in the crack initiation and propagation depends on the loading conditions. For the HCF, the crack initiation takes up about $90 \%$ of the total fatigue life, while in the LCF it accounts for less than $20 \%$ because of the high stress level.

Ding et al. [2] proposed a LCF life prediction model based on the fatigue crack propagation process, but a LCF life prediction model for the DR-MMCs, which takes into account both the crack initiation and the crack propagation, has not been reported so far. Although the crack initiation would occur very quickly in the strain-controlled LCF, to make a more accurate prediction, it should not be ignored, especially for the relatively low stress/strain level. This part of the thesis is, therefore, aimed at developing an analytical LCF crack initiation model, which is based on Gibbs free energy change, and consequently, predicting the whole fatigue life of DR-MMCs. Several factors on the crack initiation, such as, strain level, volume fraction, cyclic strain hardening exponent, cyclic strength coefficient, etc., will be discussed. The results obtained from the crack initiation model in conjunction with Ding et al.'s crack propagation model [2], which forms the total fatigue life prediction, will be compared with the experimental data reported in the literature.

\subsection{Ding et al.'s Model for Fatigue Life Prediction in DR-MMCs}

A LCF life prediction model for DR-MMCs was presented by Ding et al. in 2002 [2]. In their model, the LCF behavior of particulate-reinforced MMCs is treated as a localized damage development phenomenon activated by the applied cyclic loading. The localized cyclic stress and strain concentration and fatigue damage evolution of microstructural elements within the fatigue damaged zone ahead of the crack tip are considered to dominate the whole low-cycle fatigue processes. In high-strain low-cycle fatigue conditions, the fatigue-damaged zone is described as the region in which the local cyclic stress level approaches the ultimate tensile 
strength of the composite and within which the actual degradation of the composite material takes place. The fatigue crack growth rate is directly correlated to the range of the crack tip opening displacement. The following is a brief introduction of this model [2], which will form the basis of our model.

It is well established that the reinforcement of hard particles in a soft metallic matrix produces composites with a higher yield strength compared to that of the matrix, and the strengthening effect can be expressed as

$$
\sigma_{y, c}=\sigma_{y, m}\left[\frac{V_{f}(s+2)}{2}+V_{m}\right]
$$

where $\sigma_{y, c}$ and $\sigma_{y, m}$ are the yield strength of the composite and matrix; $V_{f}$ and $V_{m}$ are the volume fraction of the reinforcing particles and the matrix, respectively; and $s$ is the length-to-diameter aspect ratio of the reinforcing particles. The addition of high-strength brittle particles in the metal matrix will not only strengthen the microstructure of the matrix, but also constrain the plastic deformation of the matrix. The constraint effect was denoted as the constraint $C_{\varepsilon}$. Then, the effective stress of the DR-MMCs, $\Delta \sigma_{e f f} / 2$, can be calculated by

$$
\frac{\Delta \sigma_{e f f}}{2}=\frac{1}{2 C_{\varepsilon}}\left(\frac{\Delta \sigma}{2}\right)
$$

It is well known that there is a cyclic plastic zone or fatigue damaged zone (FDZ) in front of the crack tip (see Fig.3.1). The FDZ is a zone that is very close to the crack tip within which the actual degradation process of the composite material occurs, its size $D_{F D Z}$ can be calculated by

$$
D_{F D Z}=\frac{\lambda \pi}{16 C_{\varepsilon}^{2}}\left[V_{f}(s+2) / 2+V_{m}\right]^{[}\left[\frac{\left(K^{\prime}\right)^{3+1 / n^{\prime}}}{\sigma_{y, m}^{1+1 / n^{\prime}}\left(\sigma_{y, c}\right)^{2}}\right]\left(\frac{\Delta \varepsilon_{p}}{2}\right)^{3 n^{\prime}+1} a,
$$


where $\lambda$ is the cyclic plastic zone correction, $n^{\prime}$ and $K^{\prime}$ are the cyclic strain hardening exponent and cyclic strength coefficient, $a$ is the initial crack size, $\Delta \varepsilon_{p} / 2$ is the plastic strain amplitude.

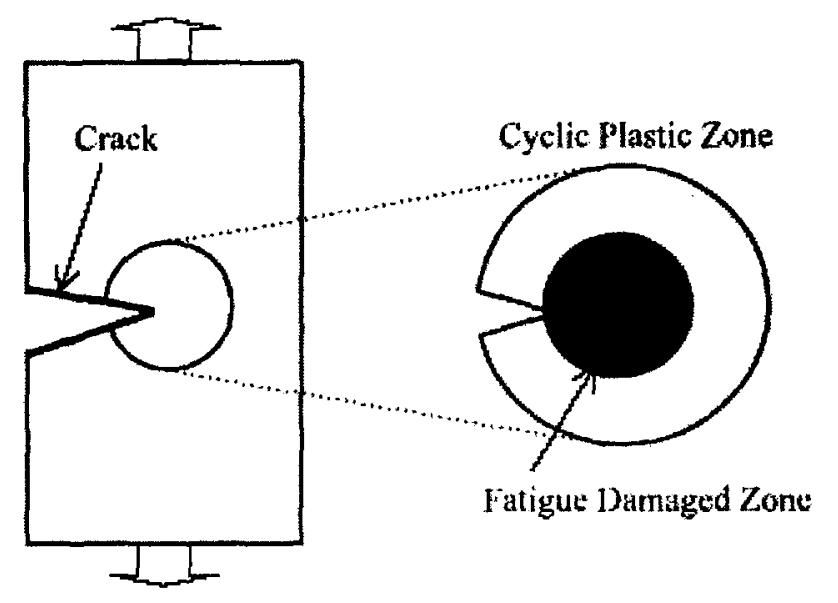

Fig.3.1 Schematic diagram showing the cyclic plastic zone and the fatigue damage zone (FDZ) in a LCF crack tip region [2].

The local driving force in the LCF of DR-MMCs was correlated with the cyclic $J$ integral referred to as $\Delta J$, which can be expressed as

$$
\Delta J=\frac{\lambda \pi^{2}}{32 C_{\varepsilon}^{2}}\left[V_{f}(s+2) / 2+V_{m}\right]^{2}\left(\frac{n^{\prime}+1}{n^{\prime}}\right)\left[\frac{\left(K^{\prime}\right)^{3}}{\left(\sigma_{y, c}\right)^{2}}\right]\left(\frac{\Delta \varepsilon_{p}}{2}\right)^{3 n^{\prime}+1} a .
$$

The cyclic $J$ integral is directly related to the range of crack tip opening displacement (CTOD) $\delta$, which is

$$
\delta=\frac{\lambda \pi^{2}}{48 C_{\varepsilon}^{2}}\left[V_{f}(s+2) / 2+V_{m}\right] 2\left(\frac{n^{\prime}+1}{n^{\prime}}\right)\left(\frac{K^{\prime}}{\sigma_{y, c}}\right)^{3}\left(\frac{\Delta \varepsilon_{p}}{2}\right)^{3 n^{\prime}+1} a
$$

The LCF crack growth rate, $d a / d N$, is directly associated with the local driving force acting upon the FDZ and, therefore, to the range of crack tip opening displacement $\delta . d a / d N$ can then be predicted by 


$$
\frac{d a}{d N}=\frac{1}{2} \delta=\frac{\lambda \pi^{2}}{96 C_{\varepsilon}^{2}}\left[V_{f}(s+2) / 2+V_{m}\right]^{2}\left(\frac{n^{\prime}+1}{n^{\prime}}\right)\left(\frac{K^{\prime}}{\sigma_{y, c}}\right)^{3}\left(\frac{\Delta \varepsilon_{p}}{2}\right)^{3 n^{\prime}+1} a
$$

In view of the micro-mechanism of LCF damage development as described above, the number of cycles to failure during the fatigue crack growth can be calculated by integrating Eq. (3.6) from an assumed initial crack size $a_{\mathrm{i}}$ to a critical crack size $a_{f}$. Finally, the fatigue life, $N_{p}$ is

$$
N_{p}=\left[\frac{96 C_{\varepsilon}^{2}}{\lambda \pi^{2}}\left[V_{f}(s+2) / 2+V_{m}\right]^{-2}\left(\frac{n^{\prime}}{n^{\prime}+1}\right)\left(\frac{\sigma_{y, c}}{K^{\prime}}\right)^{3} \ln \left(\frac{a_{f}}{a_{i}}\right)\right]\left(\frac{\Delta \varepsilon_{p}}{2}\right)^{-\left(3 n^{\prime}+1\right)}
$$

Given a set of $N_{p}$ and $\Delta \varepsilon_{p} / 2$, an average value of $\lambda$ can be calculated which will be used in the life prediction calculation later.

The theoretical predictions via this model were reported to be in agreement with the low-cycle fatigue life data of AA6061-T6 aluminium alloy reinforced with 15 and 20 vol.\% alumina particles, respectively, in a temperature range between -100 and $150^{\circ} \mathrm{C}$ in a total-strain controlled mode.

This model was essentially an LCF crack growth model. It does not take into account the LCF crack initiation which should occupy a fraction of fatigue life in particular in the range of smaller plastic strain amplitudes. In order to give a more accurate prediction of LCF life of DR-MMCs, the addition of crack initiation period is necessary. Therefore, one of the purposes of this research is to develop a crack initiation model based on Gibbs free energy change, which is briefly explained in the following section. 


\subsection{Gibbs Free Energy Change and Crack Initiation}

Bhat and Fine [38] reported a fatigue crack nucleation model for iron and high strength low alloy steel, according to Gibbs free energy change. In thermodynamics, the Gibbs free energy is a state function of any system defined as $G=H-T S$, where $H$ is the enthalpy, $T$ is the temperature, and $S$ is the entropy. Any natural process occurs if and only if the associated change in $G$ for the system is zero. The mechanical deformation of a solid leading to the nucleation of a crack may be considered as an example of phase transformations and, therefore, Gibbs free energy can be applied. For most metals and alloys, cyclic deformation at room temperature is at a low homologous temperature, and, as a result, thermal activation is not expected to play a significant role.

When a crack forms, the change in the free energy consists of three parts: (1) the release of stored elastic energy $\left(W_{e}\right) ;(2)$ the reduction of internal energy because of defects lost at the new created surface, $A \varsigma$, where $\varsigma$ was defined as the energy of the accumulated dislocations that are lost per unit area of the nucleated crack surface, and $A$ is the area of the just nucleated crack; (3) the energy increase due to the creation of the new crack surface, $A \gamma$, where $y$ is the surface energy density. Thus the change in the free energy to form a crack of area, $\mathrm{A}$, is

$$
\Delta G=-W_{e}-A \varsigma+A \gamma
$$

Before the nucleation of the fatigue crack, the accumulated damage is in the form of increased lattice defects, such as dipoles, vacancy clusters, veins, persistent slip bands (PSBs), etc. The area of the hysteresis loop is a measure of the total mechanical energy spent in cycling (see Fig. 3.2). However, most of the irreversible energy is converted to heat and only a small portion of this irreversible energy is stored as defects. After the initial transient stage, the area under the hysteresis loop is assumed to remain constant and, therefore, the 
reduction of internal energy because of defects lost at the new created surface, $A \varsigma$, can be connected to the area of the hysteresis loop.

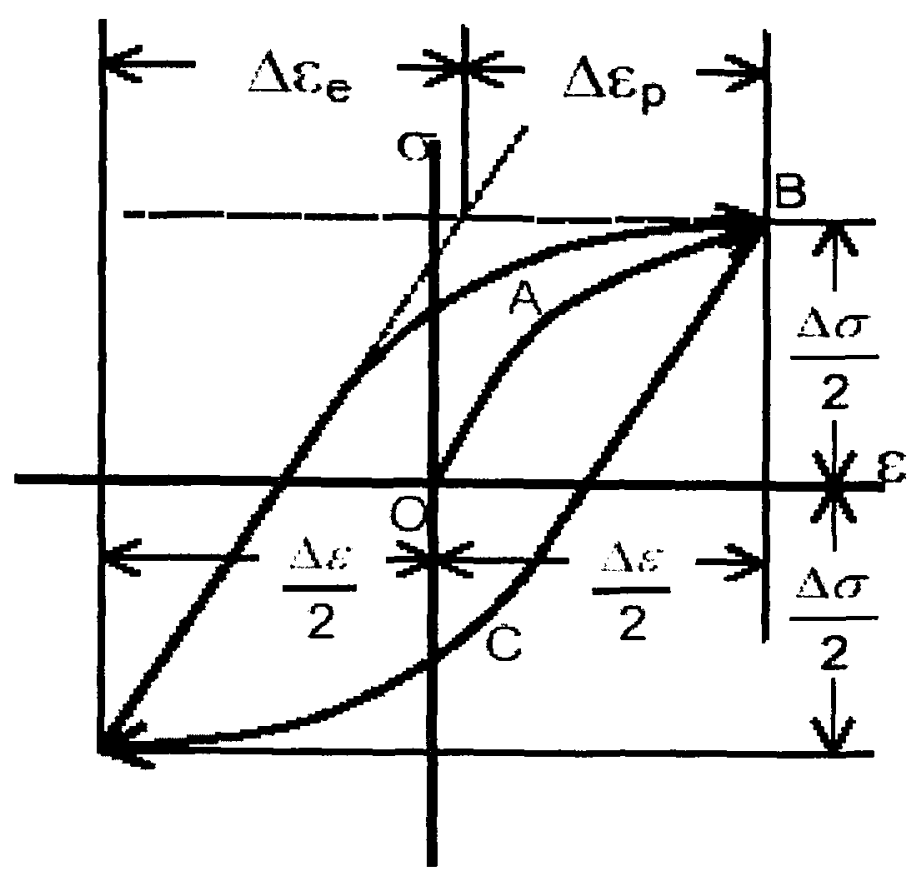

Fig. 3.2 Schematic diagram showing the shape of hysteresis loop [38].

By assuming that in the low strain cycling, cracks often nucleate in the persistent slip bands (PSBs) and the shape of the new created crack is approximately that of a half of a penny with radius, $a^{*}$, an equation proposed to predict the number of cycles $\left(N_{i}\right)$ required to create a fatigue crack was developed [38]:

$$
N_{i}=\frac{\pi E \gamma-4 \sigma^{2} a^{*}\left(1-v^{2}\right)}{\pi E f t \Delta \sigma \Delta \varepsilon_{p}},
$$

where $N_{i}$ is the number of cycles to create a fatigue crack, $E$ is Young's modulus, $\gamma$ is the surface energy density, $\sigma$ is the peak stress or the stress amplitude within a cycle, $v$ is Poisson's ratio, $\Delta \sigma$ and $\Delta \varepsilon_{p}$ are the stress and plastic strain ranges in the cycle, $f$ is the 
defect-energy-absorbing efficiency factor, $t$ is the total thickness of the regions on each side of the crack drained of defects when the crack forms, $f t$ may be regarded as an indicator of the energy that is stored from cycle to cycle, and $a^{*}$ is the critical crack radius [38].

Experimental data from commercial purity iron and a high strength low alloy steel were used to verify the model. A reasonable agreement with the experimental data was reported. However, because the fatigue mechanism of DR-MMCs is different from that of pure iron or steel, this model can not be directly applied to DR-MMCs. A new model has to be developed based on the presented model.

\subsection{A New Life Prediction Model for DR-MMCs}

The above model is basically applicable for the crack initiation occurred at PSBs. In the LCF of DR-MMCs the locations of crack initiation are not normally at the PSBs, as reported by several researchers. Llorca [14] pointed out that the stiff ceramic reinforcements acted as preferential sites for the crack nucleation, and were ultimately responsible for the poor LCF properties of the DR-MMCs. Fractographic studies by Bosi et al. [8] showed that the crack initiation occurred at the specimen surface and was associated with the microstructural defects such as clusters of particles, coarse particles or other inclusions. Levin and Karlsson [5] reported that cracks initiated either near the particle-matrix interfaces in regions of high volume fraction of particles or by the fracturing of individual particles. However, it would be reasonable to consider that the crack initiation process of DR-MMCs is similar to that of purity iron and high strength low alloy steel based upon the energy point of view, irrespective of the crack initiation site or the type of materials. That is, the formation of a crack leads to the reduction of elastic strain energy and the generation of surface energy. In the case of particle/matrix decohesion in the DR-MMCs, two different kinds of surface energy for the matrix surface and particle surface should be taken into consideration. 
Suppose that the first crack occurs at the interface between the matrix and the particles, then the total change in the surface energy per unit area of the crack consists of two parts: (1) the energy increased by the new generated particle surface and matrix surface $\left(\gamma_{s p}+\gamma_{s m}\right) ;(2)$ the energy decreased by the release of adhesion work $\left(-W_{a d}\right)$ between the particle and the matrix. Dhindaw used Firifalco-Good relationship (Adamson 1982) [39] to calculate $W_{a d}$ as:

$$
W_{a d}=2 \Phi \sqrt{\gamma_{s p} \gamma_{s m}}
$$

where $\gamma_{s p}$ and $\gamma_{s m}$ are the surface energy density of the reinforced particle and matrix, respectively, and $W_{a d}$ is the adhesion work between them. The coefficient $\Phi$ has a value of 0.24 [39]. By assuming a perfect contact between the matrix and particle, the total change in the surface energy per unit area of a crack can be expressed as:

$$
\gamma=\gamma_{s p}+\gamma_{s m}-0.48 \sqrt{\gamma_{s p} \gamma_{s m}}
$$

If the crack initiation occurs in the matrix, $\gamma_{s p}$ in Eq.(3.11) could be replaced by $\gamma_{s m}$, resulting in:

$$
\gamma=1.52 \gamma_{s m}
$$

On the other hand, if the crack initiation mechanism is associated with the particle fracture, $\gamma_{s m}$ in Eq.(3.11) could be replaced by $\gamma_{s p}$, giving rise to:

$$
\gamma=1.52 \gamma_{s p}
$$

According to references $[40,41], \gamma_{s p}$ and $\gamma_{s m}$ could be assumed to be approximately $1 \mathrm{Nm}^{-1}$. As a result, there would be no big difference among Eqs. (3.11), (3.11a), and (3.11b). Therefore, Eq. (3.11) will be used in the following derivation.

In the LCF, the peak stress or the stress amplitude, $\sigma$, can be expressed as [2]: 


$$
\sigma=\frac{\Delta \sigma}{2}=K^{\prime}\left(\frac{\Delta \varepsilon_{p}}{2}\right)^{n^{\prime}}
$$

where $\Delta \varepsilon_{p} / 2$ is the externally applied/measured plastic strain amplitude. Han et al. [42] considered in the LCF of DR-MMCs, due to the high constraint effect of the reinforcement on the matrix, the external strain measured in the composites is lower than the "real" or "actual" strain in the matrix near the reinforcement. As the crack initiation is a localized phenomenon, the real plastic strain around the crack is apparently higher than the external measured one. However, the localized real plastic strain is a complicated parameter which is influenced by a number of microstructural parameters, such as the size, shape, volume fraction and clustering of particles. As a first approximation, it may be reasonable to use the "average real plastic strain in matrix" to replace the "localized real plastic strain". The "average real plastic strain in matrix", $\varepsilon_{r p}$, proposed by Han et al. [42], can be expressed as follows,

$$
\varepsilon_{r p}=\varepsilon_{p} /\left(1-V_{f}\right)
$$

where $V_{f}$ is the volume fraction of the reinforcement particles. Substituting Eqs. (3.11) and (3.12) into Eq. (3.9), and replacing $\varepsilon_{p}$ by $\varepsilon_{r p}, E$ by $E_{c}$ (Young's modulus of the DR-MMCs) and $v$ by $v_{c}$ (Poisson's ratio of the DR-MMCs), one can obtain the following equation:

$$
N_{i}=\frac{\pi E_{c}\left(\gamma_{s p}+\gamma_{s m}-0.48 \sqrt{\gamma_{s p} \gamma_{s m}}\right)-4\left\{K^{\prime}\left[\frac{\Delta \varepsilon_{p}}{2\left(1-V_{f}\right)}\right]^{n^{\prime}}\right\}^{2} a^{*}\left(1-v_{c}{ }^{2}\right)}{2 \pi E_{c} f t K^{\prime}\left[\frac{\Delta \varepsilon_{p}}{2\left(1-V_{f}\right)}\right]^{n^{\prime}} \frac{\Delta \varepsilon_{p}}{\left(1-V_{f}\right)}}
$$

As mentioned above, $\gamma_{s p}$ and $\gamma_{s m}$ could be assumed to be $1 \mathrm{Nm}^{-1}$, and a conservative value of $250 \mathrm{~nm}$ is used for $a^{*}$, which was detected by Bhat and Fine [38]. Given a group of data of 
the plastic strain amplitude $\Delta \varepsilon_{p} / 2$ and the related critical number of cycles to initiate a fatigue crack $N_{i}$, together with the material parameters $E_{c}, n^{\prime}, K^{\prime}, V_{f}$ and $v_{c}$, an average value for $f t$ - the indicator of the energy that is stored from cycle to cycle - can be obtained. Then Eq. (3.14) can be used to further predict the fatigue crack initiation life $N_{i}$, in conjunction with the effects of a number of factors.

\subsection{Effect of the Plastic Strain Level and Volume Fraction}

The volume fraction of the reinforcement particles can affect various properties of DR-MMCs, such as Young's modulus $E$, internal energy efficiency factor $f$, cyclic strength coefficient $K^{\prime}$, cyclic strain hardening exponent $n^{\prime}$, etc. To indicate the effect of the volume fraction on the crack initiation, the situation in which all other parameters except the volume fraction are kept constant is first considered. Data based on an $\mathrm{Al}_{2} \mathrm{O}_{3}$ particulate reinforced AA6061-T6 composite with a volume fraction of $15 \%$ tested at $25^{\circ} \mathrm{C}$ are selected: $K^{\prime}=1066$ MPa, $n^{\prime}=0.163, \gamma_{s p}=\gamma_{s m}=1 \mathrm{Nm}^{-1}[40,41], \mathrm{a}^{*}=250 \mathrm{~nm}$ [38]. $\mathrm{ft}$ is $3.74 \times 10^{-9} \mathrm{~m}$, which is an average value calculated on the basis of the experimental data obtained at $25^{\circ} \mathrm{C}$ and $V_{f}=0.15$ [2]. Based on Gorsse et al.'s studies for Young's modulus of the MMCs reinforced by short fibers [43], $E_{c}$ may be calculated by the following equation:

$$
E_{c}=E_{\text {random }}=\frac{3}{8} E_{11}+\frac{5}{8} E_{22} \text {, }
$$

with

$$
\begin{gathered}
E_{11}=\frac{1+2 s \eta_{l} V_{f}}{1-\eta_{l} V_{f}} E_{m}, \\
E_{22}=\frac{1+2 s \eta_{T} V_{f}}{1-\eta_{T} V_{f}} E_{m}, \\
\eta_{l}=\frac{\frac{E_{p}}{E_{m}}-1}{\frac{E_{p}}{E_{m}}+2 s}
\end{gathered}
$$




$$
\eta_{T}=\frac{\frac{E_{p}}{E_{m}}-1}{\frac{E_{p}}{E_{m}}+2},
$$

where $E_{p}$ is the Young's modulus of the reinforcement short fibers (particles), $E_{m}$ is the Young's modulus of the matrix, $s$ is the aspect ratio. Substituting $E_{p}=400 \mathrm{GPa}, E_{m}=70.3 \mathrm{GPa}$ [44], and $s=1.7$ [2] into Eq. (3.15) yields: $E_{c}=93.3 \mathrm{GPa}$.

Poisson's ratio of the DR-MMCs, $v_{c}$, may be estimated on the basis of the rule of mixtures:

$$
v_{c}=v_{p} V_{f}+v_{m} V_{m},
$$

where $v_{p}$ and $v_{m}$ are the Poisson's ratio of the reinforcement particles and the matrix, $V_{m}$ is the volume fraction of the matrix. Substituting $v_{p}=0.22, v_{m}=0.345$ [44], $V_{m}=0.85$, and $V_{f}$ $=0.15$ [2] into Eq. (3.16) yields: $v_{c}=0.326$.

Figs. 3.3 and 3.4 illustrate the effect of the volume fraction on the number of cycles for the LCF crack initiation in an $\mathrm{Al}_{2} \mathrm{O}_{3}$ particulate-reinforced AA6061-T6 aluminum alloy based MMCs tested at $25^{\circ} \mathrm{C}$, where different values of the plastic strain amplitude (PSA): $2.41 \times 10^{-3}, 1.24 \times 10^{-3}, 8.67 \times 10^{-4}, 4.66 \times 10^{-4}$ based on [2] were selected for $V_{f}$ values changing from $0.0 \%$ to $30 \%$. From Fig. 3.3 (where $E_{c}, f t, n^{\prime}=0.163$ and $K^{\prime}=1066 \mathrm{MPa}$ [2] are kept constant), it is seen that while the lower plastic strain level results in a longer fatigue crack initiation life, the higher volume fraction leads to an earlier crack initiation regardless of the plastic strain level. Similar results were found after the variation of $E_{c}, f t, n^{\prime}$ and $K^{\prime}$ with the volume fraction was taken into account, as shown in Fig.3.4. In this case, the effect of the volume fraction on the LCF crack initiation for a given plastic strain amplitude became stronger. 


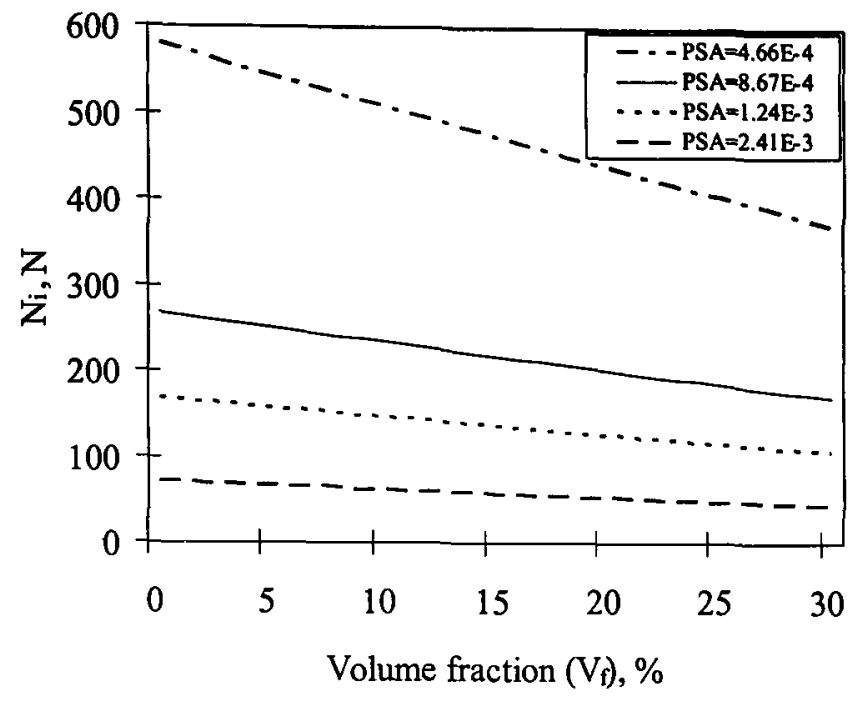

Figure 3.3 Effect of the volume fraction $\left(V_{f}\right)$ on the number of cycles for the fatigue crack initiation $\left(N_{i}\right)$ in the $\mathrm{Al}_{2} \mathrm{O}_{3}$ particulate-reinforced, AA6061 aluminum alloy based MMCs tested at $25^{\circ} \mathrm{C}$ (where $E_{c}, n^{\prime}, K^{\prime}$ and $f t$ are kept constant).

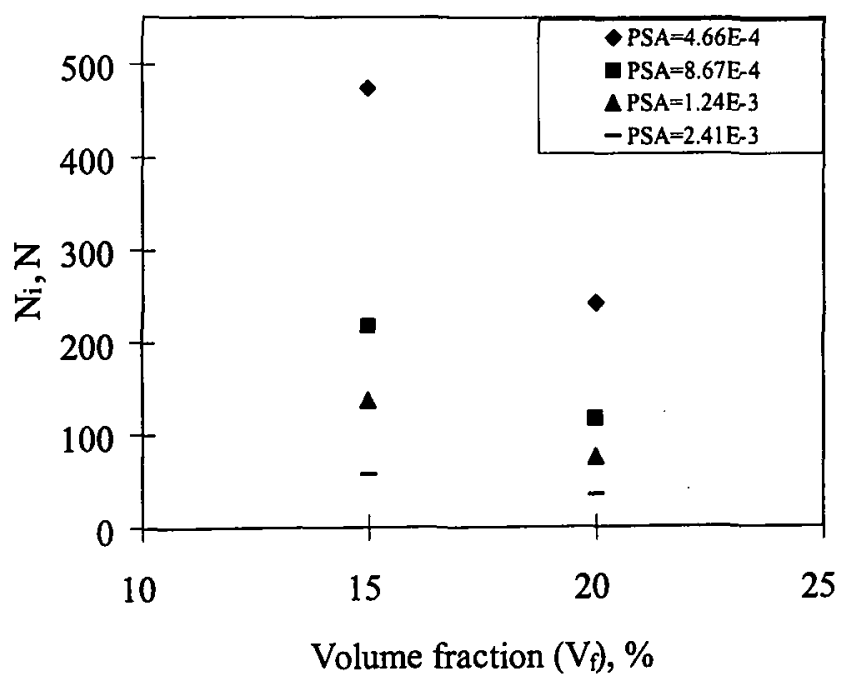

Figure 3.4 Effect of the volume fraction $\left(V_{f}\right)$ on the number of cycles for the fatigue crack initiation $\left(N_{i}\right)$ in the $\mathrm{Al}_{2} \mathrm{O}_{3}$ particulate-reinforced, $\mathrm{AA} 6061$ aluminum alloy based MMCs tested at $25^{\circ} \mathrm{C}$, with consideration of the variation of $E_{c}, n^{\prime}, K^{\prime}$ and $f t$ with the volume fraction. 


\subsection{Effect of $K^{\prime}$ and $n^{\prime}$}

Figs.3.5 and 3.6 present the analytical results of the effect of the cyclic strain hardening exponent $(n)$ on the crack initiation. In Fig.3.5, $n^{\prime}$ is the only variable and other parameters are kept constant. The cyclic number to nucleate a fatigue crack, $N_{i}$, is calculated as a function of $n^{\prime}$ based on Eq. (3.14) under different levels of the plastic strain amplitude, $\Delta \varepsilon_{p} / 2$. Again, the data for the $\mathrm{Al}_{2} \mathrm{O}_{3}$ particulate reinforced AA6061-T6 composite $\left(V_{f}=15 \%\right)$ tested at $25^{\circ} \mathrm{C}$ [1] are used: $E_{c}=93.3 \mathrm{GPa}, K^{\prime}=1066 \mathrm{MPa}, \gamma_{s p}=\gamma_{s m}=1 \mathrm{Nm}^{-1}, a^{*}=250 \mathrm{~nm}, v_{c}=0.326$, $f t=4.83 \times 10^{-9} \mathrm{~m}$ (an average value for this material with different volume fractions and tested at different temperatures), $V_{f}=0.15, \Delta \varepsilon_{p} / 2=2.41 \times 10^{-3}, 1.24 \times 10^{-3}, 8.67 \times 10^{-4}, 4.66 \times 10^{-4}$ respectively, and $n^{\prime}$ is changed from 0.1 to 0.34 . A trend can be seen from Fig.3.5: a larger cyclic strain hardening exponent $\left(n^{\prime}\right)$ results in a higher crack initiation life $\left(N_{i}\right)$, irrespective of the plastic strain amplitude level. However, after the variation of $E_{c}, K^{\prime}$ and $f t$ with $n^{\prime}$ is taken into consideration (Table 3.1), the effect of $n^{\prime}$ on the LCF crack initiation life becomes quite complicated. When $n^{\prime}$ is smaller than 0.261 , there is only a weak or little $n^{\prime}$ effect. When $n^{\prime}$ is greater than $0.261, n^{\prime}$ has a strong influence on the LCF crack initiation life. This is mainly due to the combined effects of both $n^{\prime}$ and $K^{\prime}$, which will be explained later.

The effect of the cyclic strength coefficient, $K^{\prime}$, on the LCF crack initiation life can be analyzed in the way similar to that of $n^{\prime}$. The results are presented in Figs. 3.7 and 3.8. If $K^{\prime}$ is the only variable (other parameters are the same as those used in Fig.3.5 except $n^{\prime}$ $=0.163$ ), an increasing $K^{\prime}$ leads to a decreasing LCF crack initiation life, as shown in Fig.3.7. Also, the effect of the plastic strain amplitude level, $\Delta \varepsilon_{p} / 2$, on the LCF crack initiation life can be seen from this figure. If a combined effect of both $K^{\prime}$ and $n^{\prime}$ (see the values given in Table 3.1) is considered, as demonstrated in Fig.3.8, the monotonic decreasing trend with increasing $K^{\prime}$ value disappears. It is replaced by the occurrence of a maximum $N_{i}$ value at $K^{\prime}$ $=1839 \mathrm{MPa}$. That is, the LCF crack initiation life first increases and then decreases with 
increasing cyclic strength coefficient, $K^{\prime}$, for a given plastic strain amplitude, which will be discussed later.

Table 3.1 Material parameters used in the calculation of unified effects of $E_{c,}, V_{f}, n^{\prime}, K^{\prime}$ and $f t$ on the fatigue crack initiation illustrated in Figs.3.6 and 3.8 (based on [2, 43 and 44] ).

\begin{tabular}{|c|c|c|c|c|c|}
\hline \multicolumn{3}{|c|}{ Material condition } & \multicolumn{3}{c|}{ Material parameters } \\
\hline Test temp., ${ }^{\circ} \mathrm{C}$ & $V_{f}, \%$ & $n^{\prime}$ & $E_{c}, \mathrm{GPa}$ & $K^{\prime}, \mathrm{MPa}$ & $f t, 10^{-9} \mathrm{~m}$ \\
\hline 25 & 20 & 0.110 & 97.2 & 792 & 5.91 \\
\hline-30 & 15 & 0.122 & 93.3 & 866 & 6.66 \\
\hline 25 & 15 & 0.163 & 93.3 & 1066 & 3.74 \\
\hline 150 & 20 & 0.261 & 97.2 & 1496 & 7.86 \\
\hline-100 & 20 & 0.283 & 97.2 & 2500 & 2.74 \\
\hline 150 & 15 & 0.312 & 93.3 & 1839 & 2.09 \\
\hline
\end{tabular}

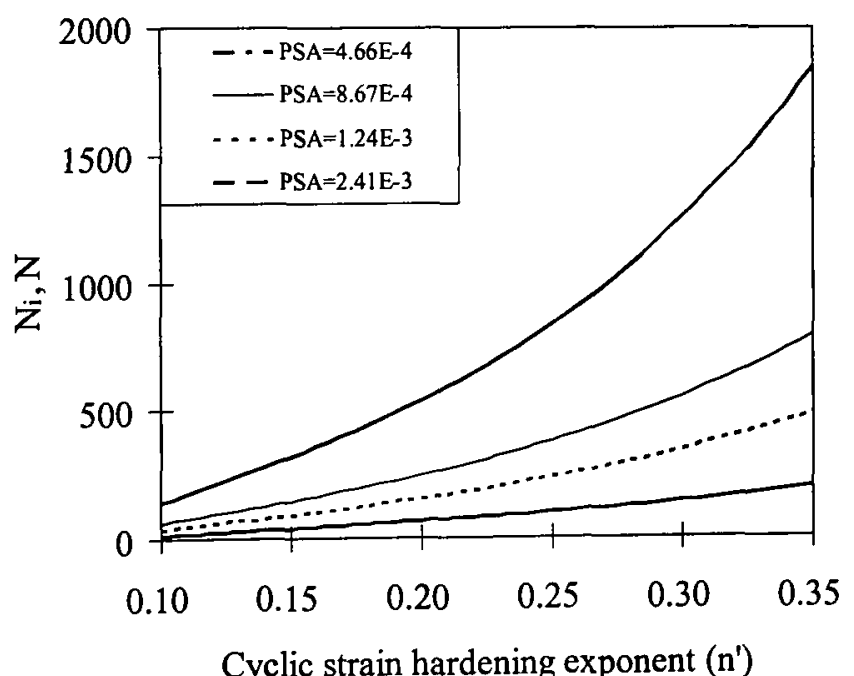

Figure 3.5 Effect of the cyclic strain hardening exponent $(n)$ on the fatigue crack initiation life $\left(N_{i}\right)$ in the $\mathrm{Al}_{2} \mathrm{O}_{3}$ particulate-reinforced, AA6061 aluminum alloy based MMCs tested at $25^{\circ} \mathrm{C}$, without consideration of the variation of $E_{c}, V_{f}, K^{\prime}$ and $f t$. 


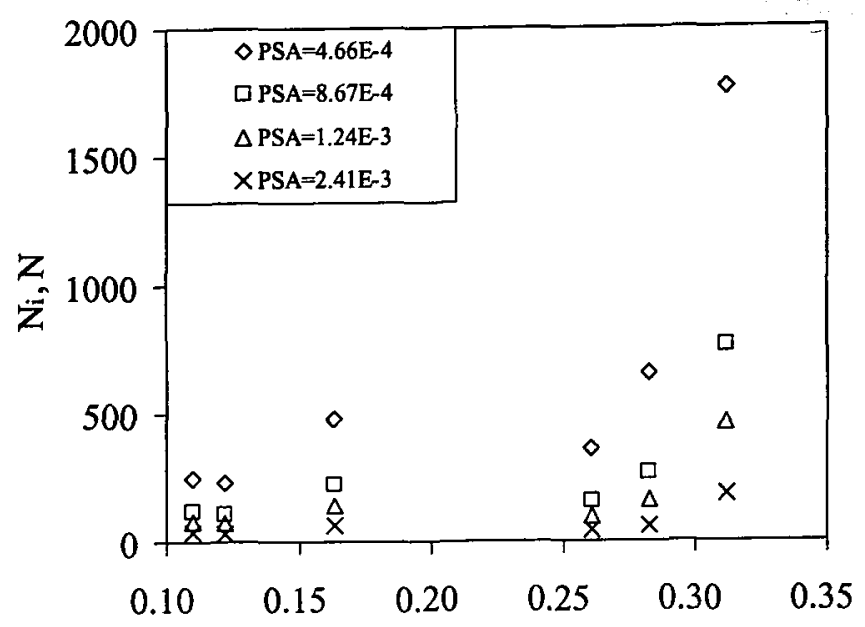

Cyclic strain hardening exponent $\left(n^{\prime}\right)$

Figure 3.6 Effect of the cyclic strain hardening exponent $(n)$ on the fatigue crack initiation life $\left(N_{i}\right)$ in the $\mathrm{Al}_{2} \mathrm{O}_{3}$ particulate-reinforced, AA6061 aluminum alloy based MMCs tested at $25^{\circ} \mathrm{C}$, with consideration of the variation of $E_{c}, V_{f}, K^{\prime}$ and $f t$.

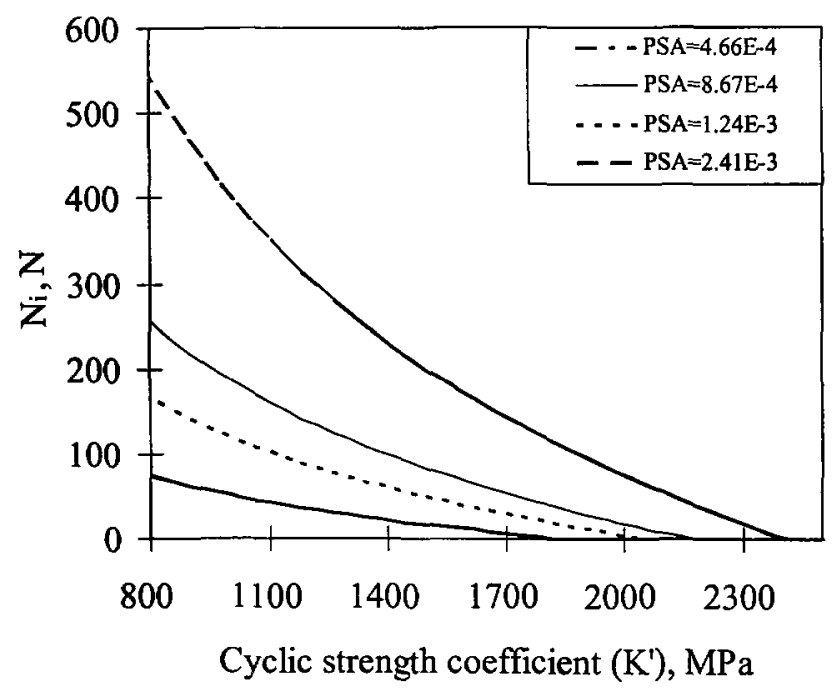

Figure 3.7 Effect of the cyclic strength coefficient $\left(K^{\prime}\right)$ on the fatigue crack initiation life $\left(N_{i}\right)$ in the $\mathrm{Al}_{2} \mathrm{O}_{3}$ particulate-reinforced, $\mathrm{AA} 6061$ aluminum alloy based MMCs tested at $25^{\circ} \mathrm{C}$, without consideration of the variation of $E_{c}, V_{f}, n^{\prime}$ and $f t$. 


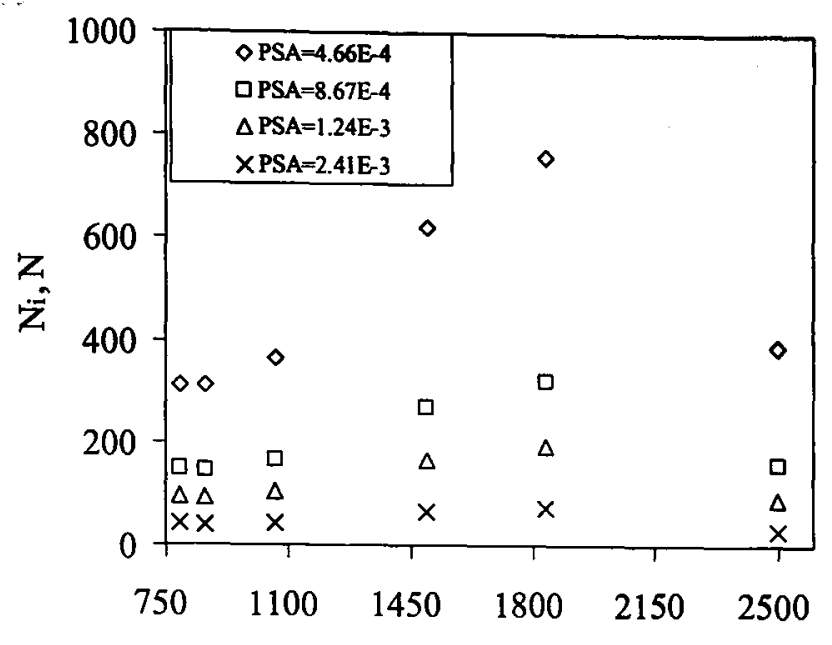

Cyclic strength coefficient (K'), MPa

Figure 3.8 Effect of the cyclic strength coefficient $\left(K^{\prime}\right)$ on the fatigue crack initiation life $\left(N_{i}\right)$ in the $\mathrm{Al}_{2} \mathrm{O}_{3}$ particulate-reinforced, AA6061 aluminum alloy based MMCs tested at $25^{\circ} \mathrm{C}$, with consideration of the variation of $n$.

\subsection{Verification of the New Model}

The fatigue failure process includes both the crack initiation and crack propagation, and the experimental data for the fatigue behavior of the DR-MMCs involve basically the total fatigue life. To verify the above LCF crack initiation model, the crack propagation phase has to be included. Ding et al.'s model [2], Eq. (3.7), is thus applied. It follows that the total LCF life of the particulate-reinforced MMCs, $N_{t}$, can be expressed as:

$$
\begin{aligned}
N_{t}=N_{i}+ & N_{p} \\
= & \frac{\pi E_{c}\left(\gamma_{s p}+\gamma_{s m}-0.48 \sqrt{\gamma_{s p} \gamma_{s m}}\right)-4\left\{K^{\prime}\left[\frac{\Delta \varepsilon_{p}}{2\left(1-V_{f}\right)}\right]^{n^{\prime}}\right\}^{2} a^{*}\left(1-v_{c}{ }^{2}\right)}{2 \pi E_{c} f t K^{!}\left[\frac{\Delta \varepsilon_{p}}{2\left(1-V_{f}\right)}\right]^{n^{\prime}} \frac{\Delta \varepsilon_{p}}{\left(1-V_{f}\right)}}
\end{aligned}
$$




$$
+\left[\frac{96 C_{\varepsilon}^{2}}{\lambda \pi^{2}}\left[V_{f}(s+2) / 2+V_{m}\right]^{2}\left(\frac{n^{\prime}}{n^{\prime}+1}\right)\left(\frac{\sigma_{y, c}}{K^{\prime}}\right)^{3} \ln \left(\frac{a_{f}}{a_{i}}\right)\right]\left(\frac{\Delta \varepsilon_{p}}{2}\right)^{-\left(3 n^{\prime}+1\right)} .
$$

In the following calculations, $C_{\varepsilon}=0.2, s=1.7, a_{f}=2 \mathrm{~mm}[1], a_{i}=2 \mathrm{a}^{*}=2 \times 250 \mathrm{~nm}=500 \mathrm{~nm}$ [38], and the values of $V_{f}, V_{m}, n^{\prime}$ and $K^{\prime}$ for different composite materials are listed in Table 3.2.

Figs. 3.9-3.17 show the life prediction in the double-log scales based on Eq. (3.17) in comparison with the experimental data reported in the literature for a number of composite materials listed in Table 3.2. Also, the results predicted by Ding et al.'s LCF crack growth model [2] are included in these figures. A good agreement is observed from these figures. Besides, compared to the fatigue crack propagation model [2], the accuracy of the life prediction via the present model is improved, especially for the intermediate plastic strain amplitude level, say, $6 \times 10^{-4}<\Delta \varepsilon_{p} / 2<2 \times 10^{-3}$. This is due to the consideration of both fatigue crack initiation and propagation stages. However, at very high level of the plastic strain amplitude, i.e., $\Delta \varepsilon_{p} / 2>3 \times 10^{-3}$, a larger difference is noticed between the experimental data and the prediction from the total life model. While further improvement in the crack initiation model applied to the high plastic strain amplitude level is needed, more attention should be paid to the crack propagation model for the DR-MMCs, since the fatigue crack initiation usually occurs within tens of cycles at a very large plastic strain level. On the other hand, at low plastic strain levels, i.e., $\Delta \varepsilon_{p} / 2<7 \times 10^{-4}$, the number of cycles goes beyond $10^{4}$ and falls into the HCF regime, and the LCF crack propagation model may not work well.

It should be noted that the effect of particle size on the fatigue life was not directly reflected in the above model. As described in Chapter two, the particle size is an important parameter related to the fatigue property of DR-MMCs. It is thus necessary to further model the effect of the particle size on the fatigue life. 
Table 3.2 Parameters used in the calculations in Figs.3.9 - 3.18.

\begin{tabular}{|c|c|c|c|c|c|c|c|c|c|}
\hline $\begin{array}{c}\text { Fig. } \\
\text { No. }\end{array}$ & Material & $\begin{array}{c}E_{c}, \\
\mathrm{GPa}\end{array}$ & $\begin{array}{c}K^{\prime}, \\
\mathrm{MPa}\end{array}$ & $n^{\prime}$ & $\begin{array}{c}f t, 10^{-9} \\
m\end{array}$ & $\lambda$ & $V_{f}$ & $V_{m}$ & $\begin{array}{c}\text { Ref. } \\
\text { No. }\end{array}$ \\
\hline 3.9 & $6061-\mathrm{Al}_{2} \mathrm{O}_{3}$ & 93.3 & 1066 & 0.163 & 3.74 & 0.426 & 0.15 & 0.85 & 2 \\
\hline 3.10 & $6061-\mathrm{Al}_{2} \mathrm{O}_{3}$ & 93.3 & 1839 & 0.312 & 2.09 & 0.314 & 0.15 & 0.85 & 2 \\
\hline 3.11 & $6061-\mathrm{Al}_{2} \mathrm{O}_{3}$ & 93.3 & 866 & 0.122 & 6.66 & 0.687 & 0.15 & 0.85 & 2 \\
\hline 3.12 & $\begin{array}{c}6061-\mathrm{Al}_{2} \mathrm{O}_{3} \\
\left(\mathrm{D}_{2} 0\right)\end{array}$ & 92.6 & 869 & 0.146 & 8.84 & 0.649 & 0.20 & 0.80 & 50 \\
\hline 3.13 & $\begin{array}{c}6061-\mathrm{Al}_{2} \mathrm{O}_{3} \\
(\mathrm{C} 85)\end{array}$ & 89.0 & 824 & 0.140 & 10.30 & 1.359 & 0.20 & 0.80 & 50 \\
\hline 3.14 & $2014-\mathrm{Al}_{2} \mathrm{O}_{3}$ & 84.0 & 520 & 0.100 & 37.70 & 1.620 & 0.10 & 0.90 & 40 \\
\hline 3.15 & $2014-\mathrm{Al}_{2} \mathrm{O}_{3}$ & 89.0 & 580 & 0.140 & 47.80 & 2.645 & 0.15 & 0.85 & 40 \\
\hline 3.16 & $\mathrm{X}_{2080-\mathrm{SiC}_{\mathrm{p}}}$ & 105.0 & 496 & 0.150 & 22.70 & 0.682 & 0.20 & 0.80 & 41 \\
\hline 3.17 & ${\mathrm{X} 2080-\mathrm{SiC}_{\mathrm{p}}}_{2} 99.0$ & 456 & 0.140 & 25.30 & 0.595 & 0.15 & 0.85 & 41 \\
\hline 3.18 & $6061-\mathrm{Al}_{2} \mathrm{O}_{3}$ & 93.3 & 1066 & 0.163 & N/A & N/A & 0.15 & 0.85 & 2 \\
\hline
\end{tabular}

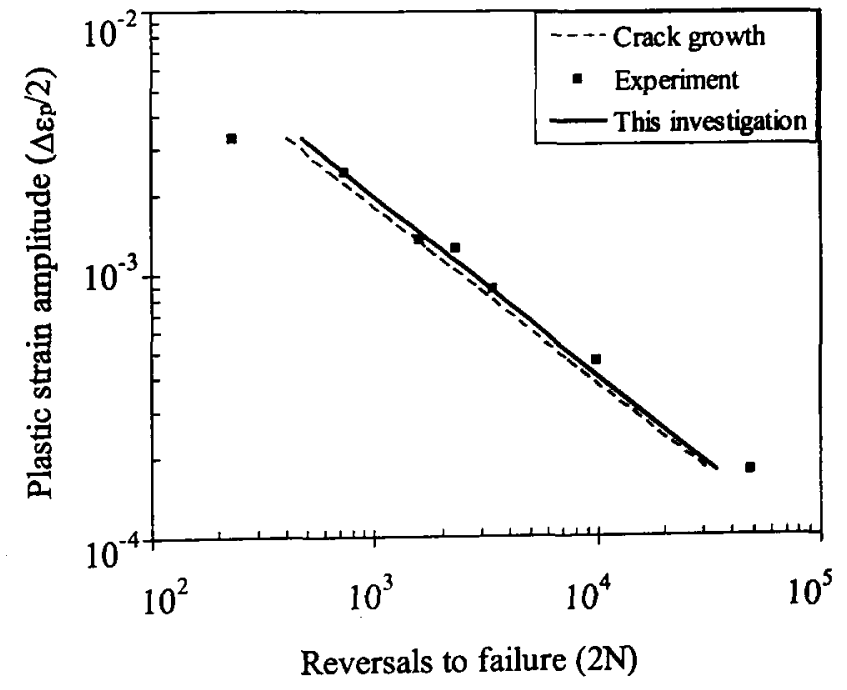

Figure 3.9 A comparison of the total fatigue life model with the crack propagation model [2] and with the experimental data [2] for the $\mathrm{Al}_{2} \mathrm{O}_{3}$ particulate-reinforced AA6061 composite material $\left(V_{f}=15 \%\right)$ tested at $25^{\circ} \mathrm{C}$. 


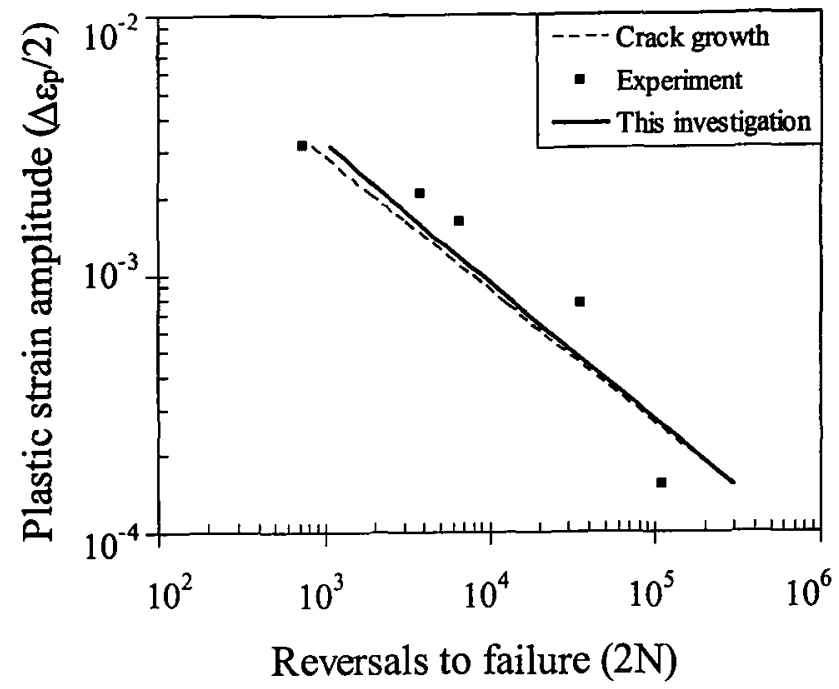

Figure 3.10 A comparison of the total fatigue life model with the crack propagation model [2] and with the experimental data [2] for the $\mathrm{Al}_{2} \mathrm{O}_{3}$ particulate-reinforced AA6061 composite material $\left(V_{f}=15 \%\right)$ tested at $150^{\circ} \mathrm{C}$.

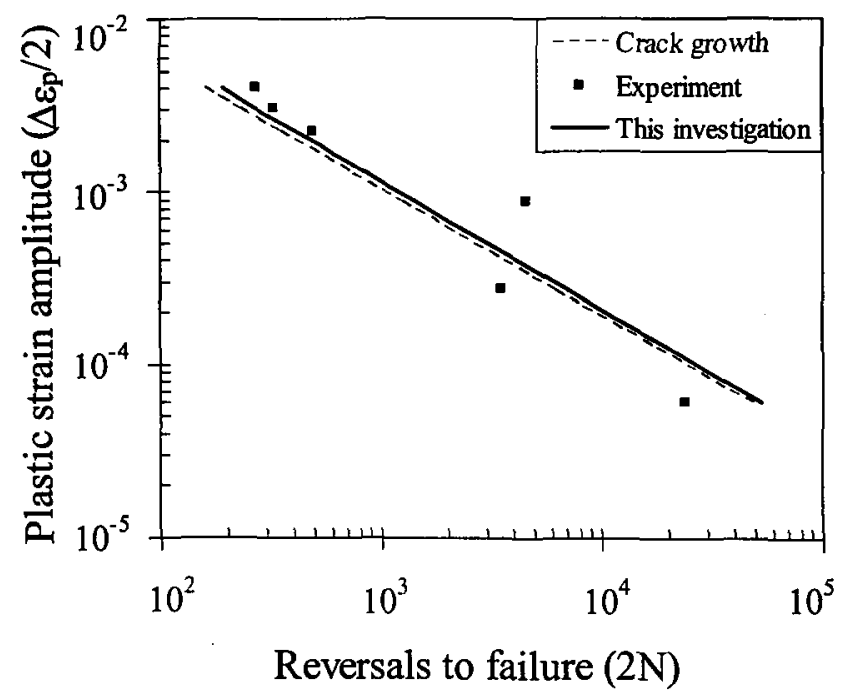

Figure 3.11 A comparison of the total fatigue life model with the crack propagation model [2] and with the experimental data [2] for the $\mathrm{Al}_{2} \mathrm{O}_{3}$ particulate-reinforced AA6061 composite material $\left(V_{f}=15 \%\right)$ tested at $-30^{\circ} \mathrm{C}$. 


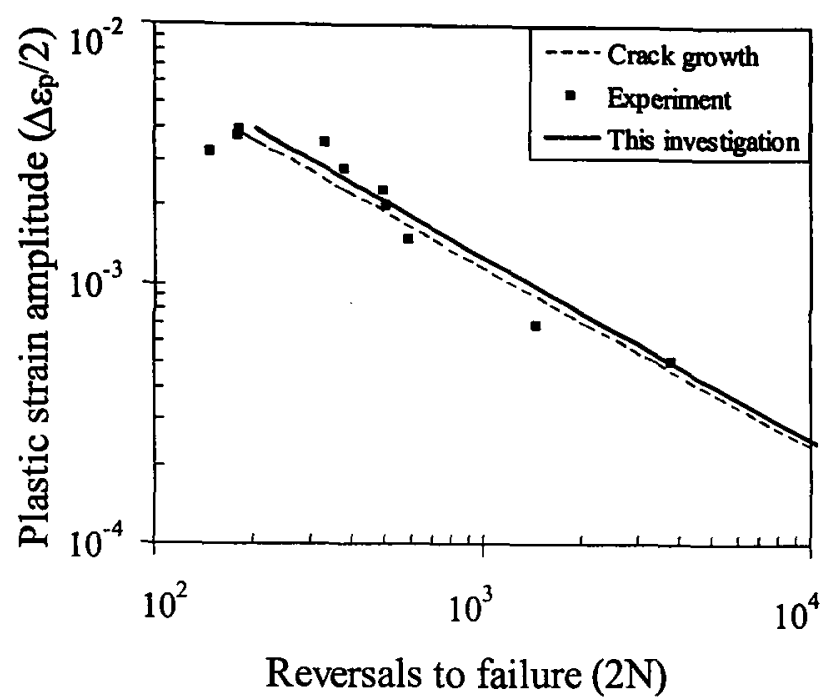

Figure 3.12 A comparison of the total fatigue life model with the crack propagation model [2] and with the experimental data [50] for the $\mathrm{Al}_{2} \mathrm{O}_{3}$ particulate-reinforced 6061 composite material (D20) $\left(V_{f}=20 \%\right)$ tested at RT.

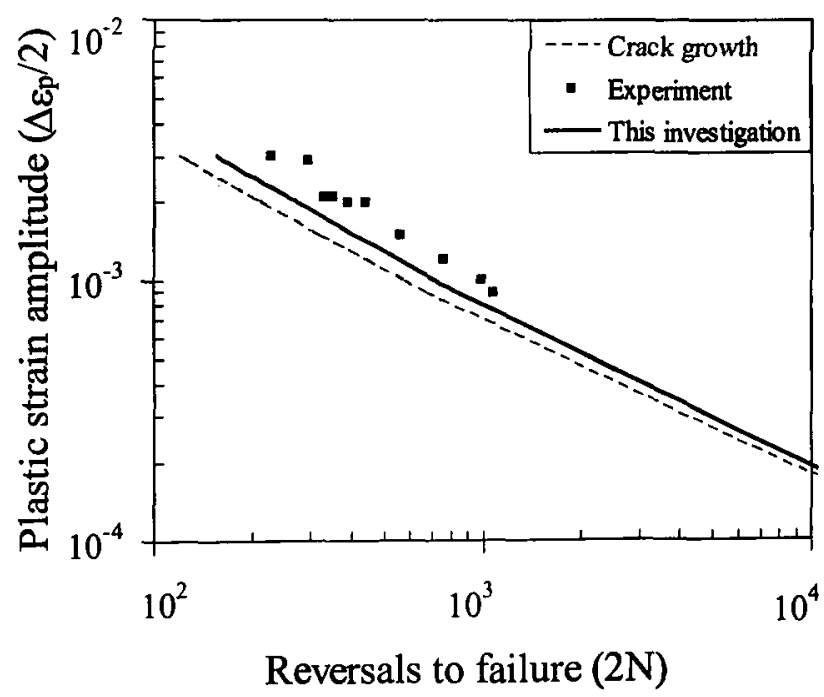

Figure 3.13 A comparison of the total fatigue life model with the crack propagation model [2] and with the experimental data [50] for the $\mathrm{Al}_{2} \mathrm{O}_{3}$ particulate-reinforced 6061 composite material $(\mathrm{C} 85)\left(V_{f}=20 \%\right)$ tested at RT. 


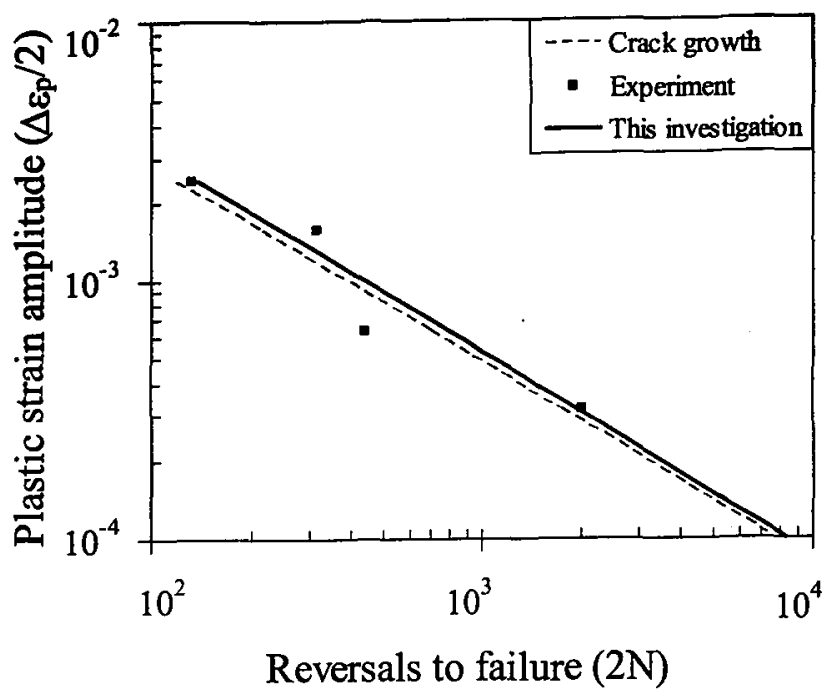

Figure 3.14 A comparison of the total fatigue life model with the crack propagation model [2] and with the experimental data [40] for the $\mathrm{Al}_{2} \mathrm{O}_{3}$ particulate-reinforced 2014 composite material $\left(V_{f}=10 \%\right)$ tested at $100^{\circ} \mathrm{C}$.

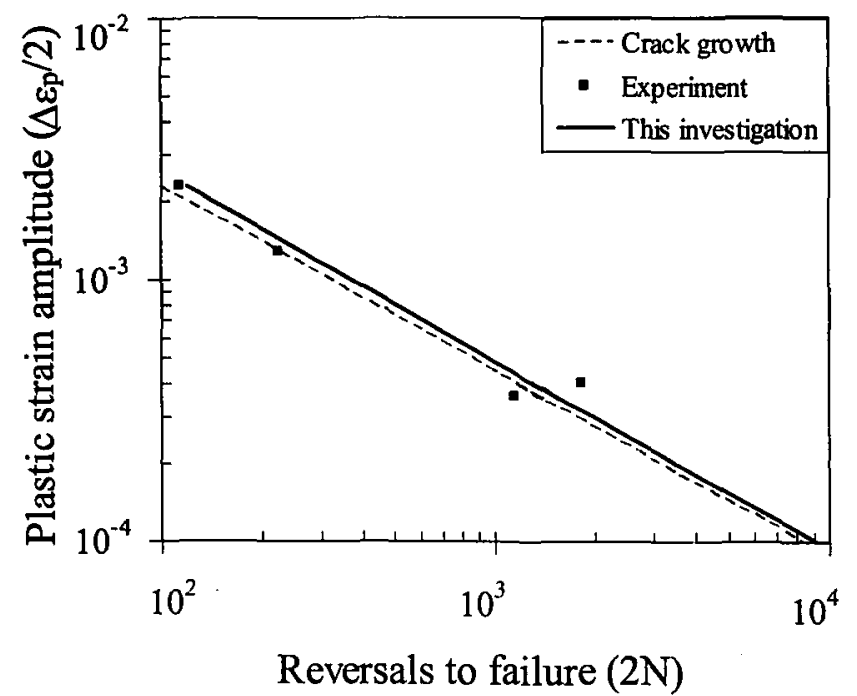

Figure 3.15 A comparison of the total fatigue life model with the crack propagation model [2] and with the experimental data [40] for the $\mathrm{Al}_{2} \mathrm{O}_{3}$ particulate-reinforced 2014 composite material $\left(V_{f}=15 \%\right)$ tested at $100^{\circ} \mathrm{C}$. 


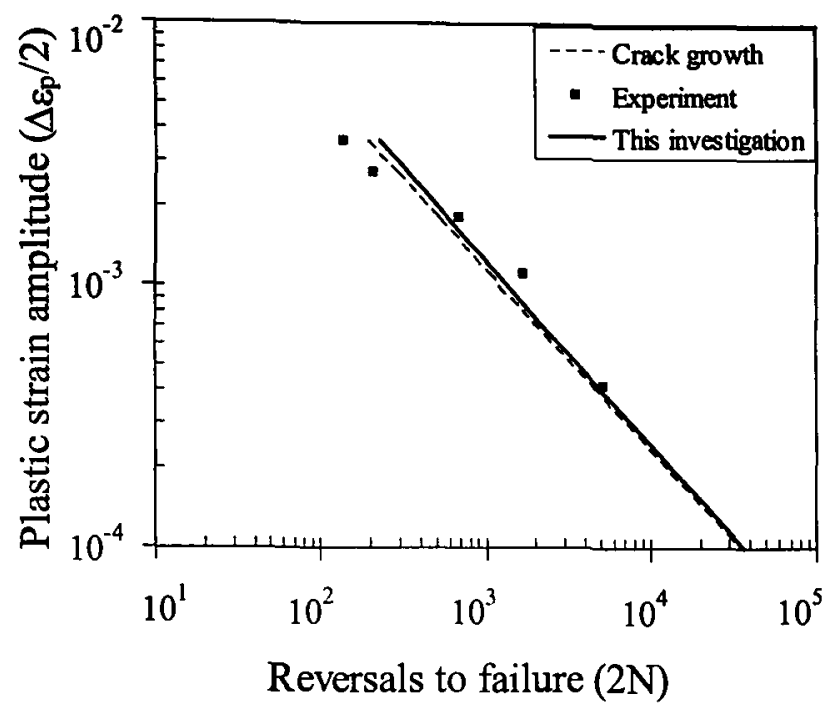

Figure 3.16 A comparison of the total fatigue life model with the crack propagation model [2] and with the experimental data [41] for the SiC particulate-reinforced $\mathrm{X} 2080$ composite material $\left(V_{f}=20 \%\right)$ tested at RT.

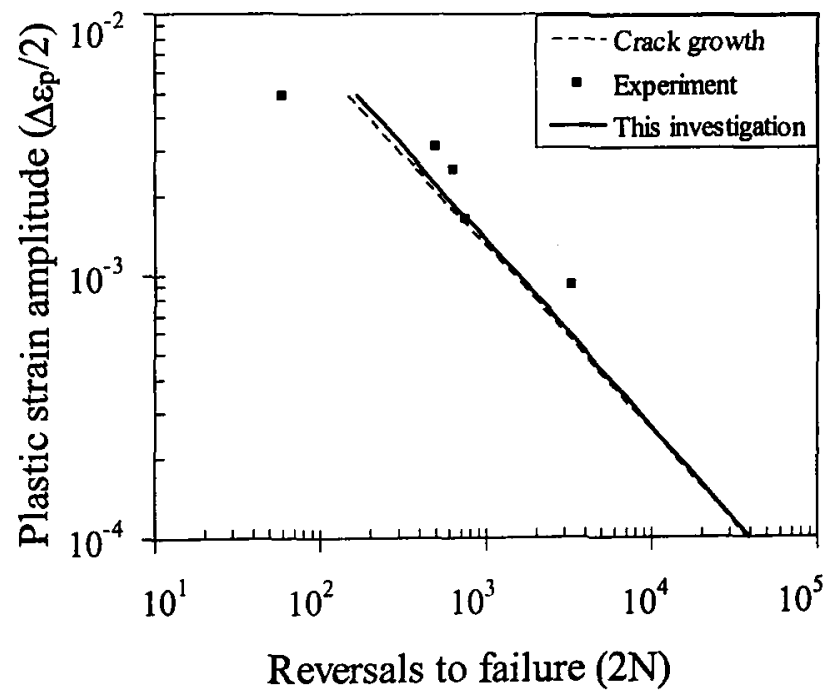

Figure 3.17 A comparison of the total fatigue life model with the crack propagation model [2] and with the experimental data [41] for the $\mathrm{SiC}$ particulate-reinforced X2080 composite material $\left(V_{f}=15 \%\right)$ tested at RT. 


\section{CHAPTER FOUR}

\section{Effect of the Particle Size on the Fatigue Behavior of DR-MMCs}

\subsection{Background}

As presented in Chapter two, many attractive advantages of the discontinuously reinforced aluminum-based metal-matrix composites (DR-MMCs) have made them the competitive candidates for aerospace and automobile industries. These properties include high specific modulus, high strength, high stiffness and wear resistance, low density, reasonable cost, easy fabrication, etc. Regarding fatigue properties, it has been reported that while the addition of reinforcement particles benefits high cycle fatigue (HCF) performance of DR-MMCs, its effect on low cycle fatigue (LCF) is less satisfactory [1-2,7-11,45-46]. The inferior LCF resistance of DR-MMCs compared to their un-reinforced counterparts is considered to be due to the early breakage of reinforcement particles and the higher strain concentration near the particles. The LCF life of DR-MMCs is affected by a number of microstructural parameters, such as the volume fraction, size, shape and distribution of the reinforcing particles, bonding force between the matrix and particles and age condition, etc. For the effect of particle size, Chawla et al. [7] studied an AA2080 reinforced with 10, 20,30\% SiC particles and showed that fine particles benefited fatigue resistance within $10^{4}$ cycles, and Bosi et al. [8] reported a similar result on $\mathrm{AA} 6061 / \mathrm{Al}_{2} \mathrm{O}_{3 \mathrm{p}}$ composites. This was explained by the fact that coarse particles had a lower strength and also brought more microcracks to the composites due to more self-defects compared to finer ones. On the other hand, Han et al. $[9,10]$ reported that coarse particle reinforced composites exhibited slightly superior LCF resistance based on their studies on $\mathrm{SiC}_{\mathrm{p}} / \mathrm{Al}$ composites with a constant reinforcement volume fraction but different particle sizes at ambient and elevated temperatures. This was considered to be due to a larger number of microcracks arising from more particles in the fine particle reinforced composites. Furthermore, a recent study on $\mathrm{AA} 2124 / \mathrm{SiC}_{\mathrm{p}}$ 
composites with different particle sizes by Uygur et al. [11] showed that the reinforcement size has no significant effect on the LCF life of DR-MMCs.

The different results reported in the literature indicated that the effect of reinforcement particle size on the LCF life has not been fully understood. The purpose of this part of the thesis is, therefore, to develop an analytical model that links the LCF life to the particle size, where the fatigue life was considered to be influenced by the yield strength of the composite based on a recent model proposed by Ding et al. [2], and the strengthening effect of the composite was attributed to the enhanced dislocation density in the matrix and the load bearing effect of the reinforcement particles. The obtained results indicated that an increasing particle size results in a lower fatigue life, although this effect was not so strong. The theoretical predictions of the LCF life of DR-MMCs were found to be in good agreement with the experimental data reported in the literature.

\subsection{Size Effect in the Life Prediction Model}

In Ding et al.'s model, if Eq. (3.1) is substituted into Eq.(3.7), another expression can be obtained:

$$
N=\left[\frac{96 C_{\varepsilon}^{2}}{\lambda \pi^{2}} \sigma_{y, m}{ }^{2} \sigma_{y, c}\left(\frac{n^{\prime}}{n^{\prime}+1}\right)\left(\frac{1}{K^{\prime}}\right)^{3} \ln \left(\frac{a_{f}}{a_{i}}\right)\right]\left(\frac{\Delta \varepsilon_{p}}{2}\right)^{-\left(3 n^{\prime}+1\right)} .
$$

There are different ways for calculating the yield strength of the composite, $\sigma_{y, c}$, depending on the strengthening mechanisms. The strengthening effect of DR-MMCs is primarily attributed to two factors which could be understood via two models. One was a modified shear lag (MSL) model in which the entire strengthening effect was ascribed to the load bearing feature of the hard reinforcement based on the shear lag theory, the other was the 
enhanced dislocation density (EDD) model in which the strengthening was mainly attributed to the enhanced strength of the matrix due to the increase in the dislocation density in the matrix. While the strengthening effect in the former case was reported to be constant [45], the enhanced dislocation density effect was revealed to be associated with the relaxation of the thermal residual stress created during manufacturing and the diameter of the particles [1]. On the basis of these two models, the yield strength of the composite may be expressed as $[45]$

$$
\sigma_{y, c}=\sigma_{y, m}\left(1+f_{d}\right)\left(1+f_{l}\right)
$$

where $f_{d}$ and $f_{l}$ are the improvement factors associated with the dislocation strengthening of the matrix and the load bearing effect of the reinforcement respectively. According to Ramakrishnan [45], for the particulate-reinforced composites, $f_{l}=0.50 . f_{d}$ was considered to be a direct consequence of the increase in the dislocation density due to the residual plastic strain caused by the difference in the coefficient of thermal expansion $(\Delta C T E)$ between the reinforcement particles and the matrix during the post-fabrication cooling. It was also reported by Ramakrishnan [45],

$$
f_{d}=\frac{k G_{m} b \sqrt{\rho}}{\sigma_{y, m}}
$$

where $k$ is a constant and approximately equals 1.25 [45], $G_{m}$ is the shear modulus of the matrix, $b$ is the Burgers vector of the matrix, $\rho$ is the enhanced dislocation density. Clyne and Withers [1] reported the following expression for $\rho$ for cube-shaped particles,

$$
\rho=12 \frac{\Delta \alpha \Delta T V_{f}}{b d},
$$


where $d$ is the particle size, $\Delta \alpha$ is the $\Delta \mathrm{CTE}$ as specified above, $\Delta T$ is the difference between the previous annealing and test temperatures. Substituting Eqs. (4.2)-(4.4) into Eq.(4.1) yields,

$$
N=\left[\frac{144 C_{\varepsilon}^{2}}{\lambda \pi^{2}} \sigma_{y, m}^{2}\left(\frac{n^{\prime}}{n^{\prime}+1}\right)\left(\frac{1}{K^{\prime}}\right)^{3} \ln \left(\frac{a_{f}}{a_{i}}\right)\right]\left(\frac{\Delta \varepsilon_{p}}{2}\right)^{-\left(3 n^{\prime}+1\right)}\left[\sigma_{y, m}+\frac{4.33 G_{m} \sqrt{\Delta \alpha \Delta T V_{f} b}}{\sqrt{d}}\right] .
$$

Fig.4.1 presents the analytical results about the effect of the particle size $(d)$ on the cyclic fatigue life, where $d$ is the only variable and other parameters are kept constant. The cyclic number to failure, $N$, is calculated as a function of $d$ based on Eq.(4.5) under different levels of the plastic strain amplitude, $\Delta \varepsilon_{p} / 2$. The data for the $\mathrm{Al}_{2} \mathrm{O}_{3}$ particulate reinforced AA6061-T6 composite $\left(V_{f}=15 \%\right)$ tested at $25^{\circ} \mathrm{C}$ [2] are used: $E_{c}=93.3 \mathrm{GPa}, K^{\prime}=1066 \mathrm{MPa}$, $n^{\prime}=0.163, a_{i}=15 \mu \mathrm{m}, a_{f}=2 \mathrm{~mm}, C_{\varepsilon}=0.2, \lambda=0.2513, \sigma_{y, m}=340 \mathrm{MPa}, V_{f}=0.15, b=2.86 \times 10^{-10} \mathrm{~m}$, $\Delta \varepsilon_{p} / 2=2.41 \times 10^{-3}, 1.24 \times 10^{-3}, 8.67 \times 10^{-4}, 4.66 \times 10^{-4}$, respectively, $\Delta \alpha$ and $G_{m}$ can be found from MatWeb [47] : $G_{m}=26 \mathrm{GPa}, \Delta \alpha=1.72 \times 10^{-5} /{ }^{\circ} \mathrm{C}$. Suppose that the increment of the dislocation density begins with a solid solution treatment which is carried out at about $800 \mathrm{~K}[2,8]$, then $\Delta T \approx 505 \mathrm{~K} . d$ is changed from $1 \mu \mathrm{m}$ to $30 \mu \mathrm{m}$. Two trends can be seen from Fig.4.1: (a) a higher level of the plastic strain amplitude, $\Delta \varepsilon_{p} / 2$, leads to a lower fatigue life $(N)$; (b) a smaller particle size results in a higher fatigue life at the lower plastic strain amplitude level, say, $\Delta \varepsilon_{p} / 2=4.66 \times 10^{-4}$, but this effect becomes weaker at the higher plastic strain amplitude level, especially for $\mathrm{d}>5 \mu \mathrm{m}$. This is mainly due to the breakage of particles during the cyclic deformation, which will be discussed later.

Fig.4.2 shows the analytical results concerning the effect of the volume fraction on the LCF life. In this figure, all parameters remain the same as given above except that $d$ is kept constant $(15 \mu \mathrm{m})$ and $V_{f}$ is changed from $1 \%$ to $30 \%$. An unusual but weak trend is observed: 
as the volume fraction increases, the LCF life becomes slightly longer. The explanation for this will be given in Chapter five.

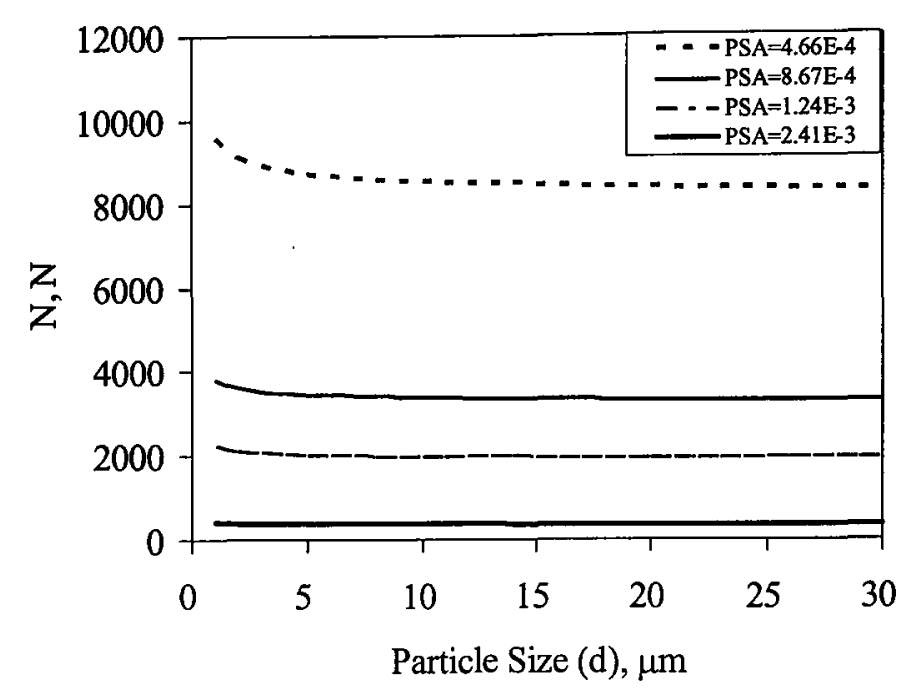

Figure 4.1 Effect of reinforcement particle size on the low cycle fatigue life in an $\mathrm{Al}_{2} \mathrm{O}_{3}$ particulate-reinforced aluminum alloy based MMCs tested at $25^{\circ} \mathrm{C}$.

\subsection{Verification of the Size Effect Model}

Figures 4.3-4.6 show the life prediction based on Eq.(4.5) in comparison with the experimental data reported in the literature. Although, compared to the Ding et al.'s model [2], the LCF life predicted via the present model is somewhat longer, an excellent agreement between the present size effect model and the experimental data reported in the literature is observed. 


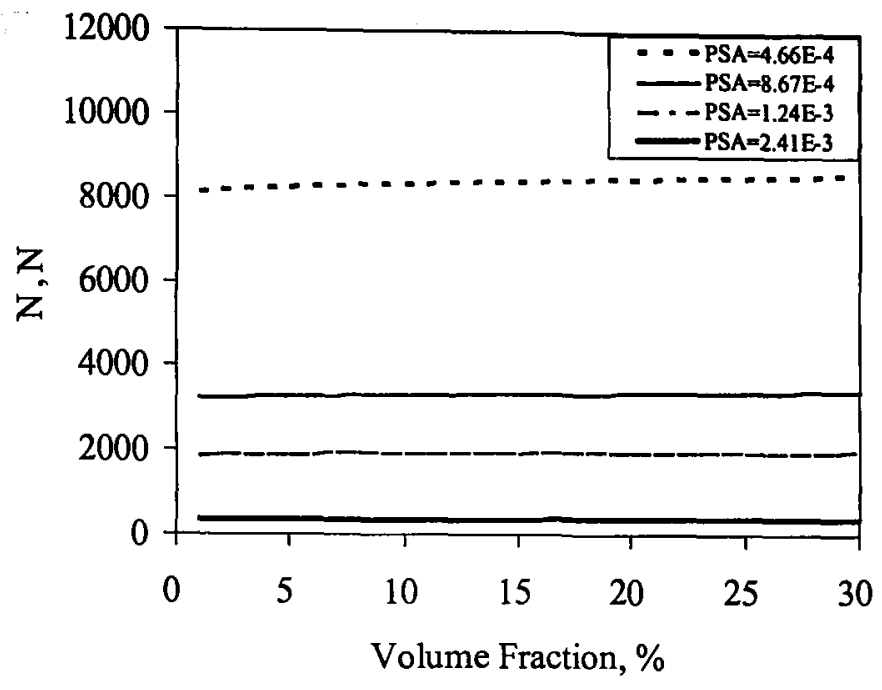

Figure 4.2 Effect of volume fraction on the fatigue life in an $\mathrm{Al}_{2} \mathrm{O}_{3}$ particulate-reinforced AA6061 aluminum alloy MMCs tested at $25^{\circ} \mathrm{C}$.

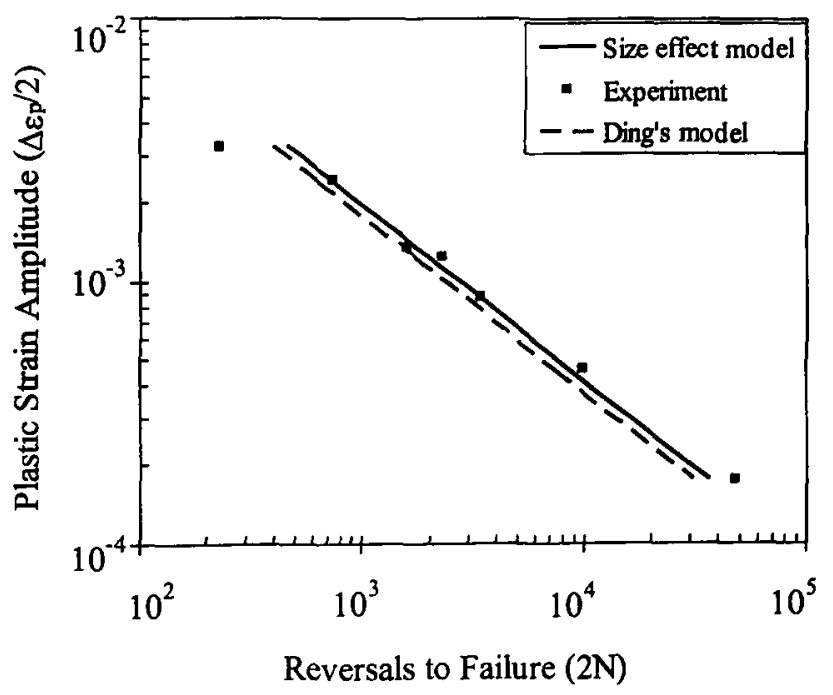

Figure 4.3 A comparison of the present model with Ding et al.'s model [2] and with the experimental data [6] in an $\mathrm{Al}_{2} \mathrm{O}_{3}$ particulate-reinforced $\mathrm{AA} 6061$ composite material $\left(V_{f}=15 \%, d=15 \mu \mathrm{m}\right)$ Tested at $25^{\circ} \mathrm{C}$. 


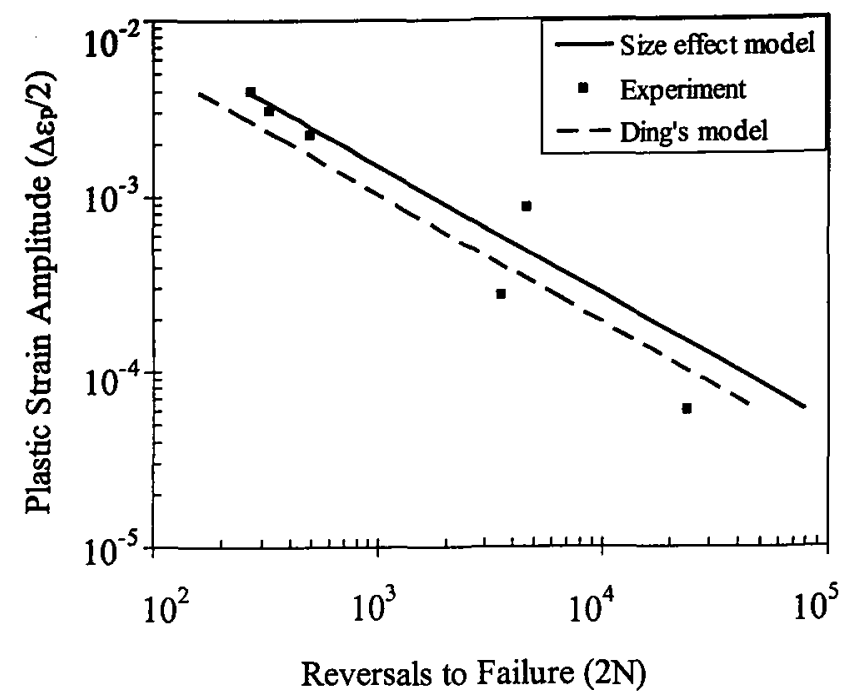

Figure 4.4 A comparison of the present model with Ding et al.'s model [6] and with the experimental data [2] in an $\mathrm{Al}_{2} \mathrm{O}_{3}$ particulate-reinforced $\mathrm{AA} 6061$ composite material $\left(V_{f}=15 \%, d=15 \mu \mathrm{m}\right)$ tested at $-30^{\circ} \mathrm{C}$.

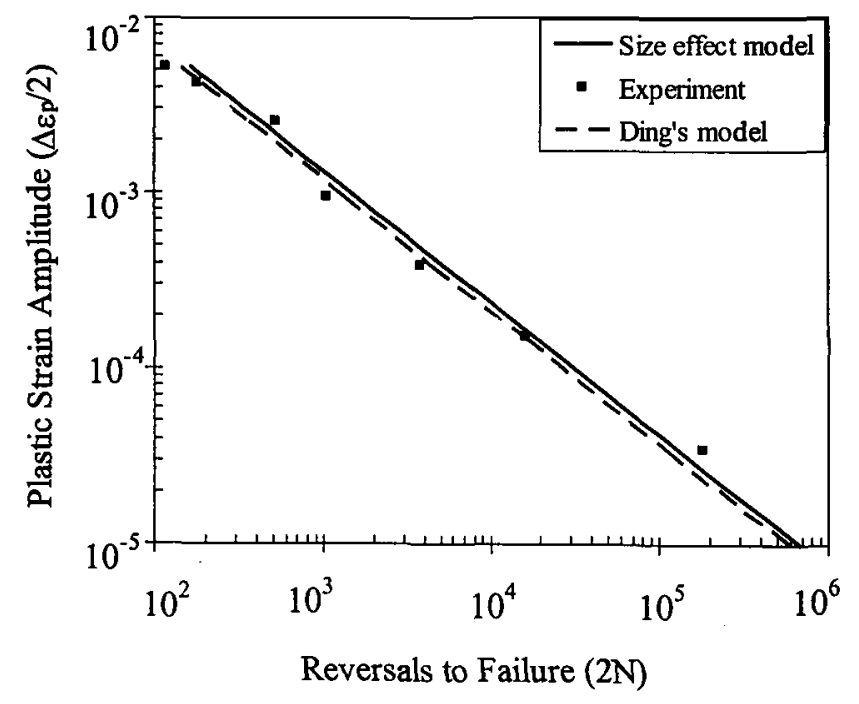

Figure 4.5 A comparison of the present model with Ding et al.'s model [2] and with the experimental data [2] in an $\mathrm{Al}_{2} \mathrm{O}_{3}$ particulate-reinforced AA6061 composite material $\left(V_{f}=20 \%, d=12.8 \mu \mathrm{m}\right)$ tested at $25^{\circ} \mathrm{C}$. 


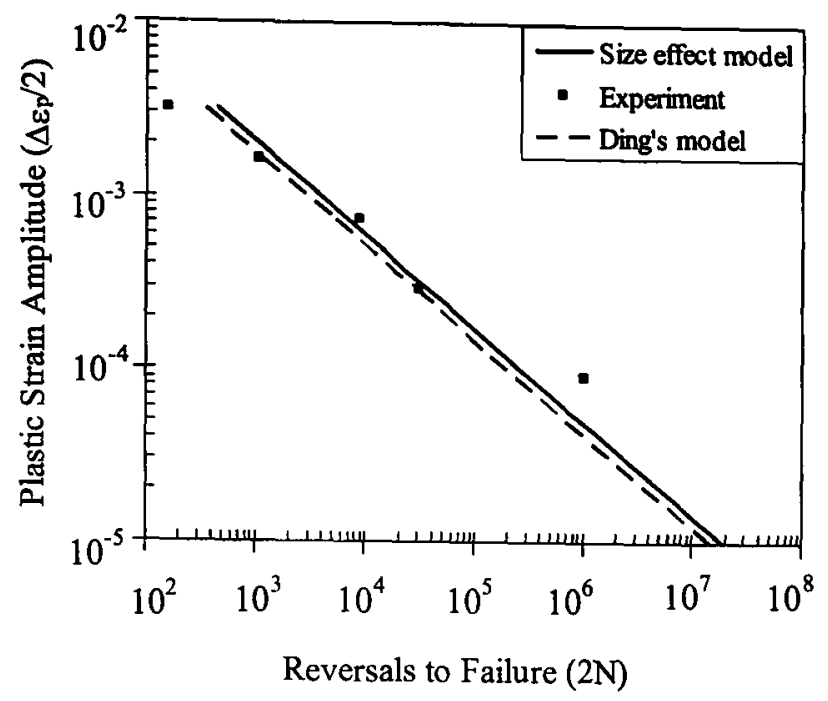

Figure 4.6 A comparison of the present model with Ding et al.'s model [2] and with the experimental data [2] in an $\mathrm{Al}_{2} \mathrm{O}_{3}$ particulate-reinforced AA6061 composite material $\left(V_{f}=20 \%, d=12.8 \mu \mathrm{m}\right)$ tested at $-100^{\circ} \mathrm{C}$.

\subsection{An Alternative Method of Modeling the Particle Size Effect}

According to the above analytical model, fine reinforcement particles had a beneficial effect on the LCF life of DR-MMCs. However, the effect was not so apparent, especially at high plastic strain amplitude levels. In the derivation of that model the modified shear lag effect factor was assumed to be a constant of 0.5 [45], which may not be correct according to the experimental data [2]. The experimental data given in [2] showed that the yield strength of the matrix and $\mathrm{Al}_{2} \mathrm{O}_{3}$ particulate-reinforced AA6061 based MMCs $\left(V_{f}=15 \%, d=15 \mu \mathrm{m}\right.$ tested at $\left.25^{\circ} \mathrm{C}\right)$ were $340 \mathrm{MPa}$ and $383 \mathrm{MPa}$, respectively. This gives a value of only 1.126 for $(1+$ $\left.f_{d}\right)\left(1+f_{l}\right)$ in Eq.(4.2). As a first approximation, one may assume that the maximum improvement factor $f_{l}$ is approximately equal to the volume fraction $V_{f}$. According to Nardone and Prewo [48], a more reasonable estimate could be obtained. In their MSL model, they derived the relationship between $\sigma_{y, c}$ and $\sigma_{y, m}$ for SiC whisker reinforced MMCs as 
follows,

$$
\sigma_{y, c}=\sigma_{y, m}\left[\frac{V_{f}(s+2)}{2}+V_{m}\right]
$$

In the MSL model, Eq.(4.2) can also be written as [45],

$$
\sigma_{y, c}=\sigma_{y, m}\left(1+f_{l}\right) \text {. }
$$

With $s=1$ for cube shaped particles and $V_{f}+V_{m}=1$, substituting Eq.(4.7) into Eq.(4.6) yields,

$$
f_{l}=\frac{V_{f}}{2} \text {. }
$$

Substituting Eqs (4.2)-(4.4), (4.8) into Eq (3.7) yields,

$$
N=\left[\frac{96 C_{s}^{2}}{\lambda \pi^{2}}\left(1+\frac{V_{f}}{2}\right)^{-2}\left(\frac{n^{\prime}}{n^{\prime}+1}\right)\left(\frac{1}{K^{\prime}}\right)^{3} \ln \left(\frac{a_{f}}{a_{i}}\right)\right]\left(\frac{\Delta \varepsilon_{p}}{2}\right)^{-\left(3 n^{\prime}+1\right)}\left[\sigma_{y, m}\left(1+\frac{V_{f}}{2}\right)\left(1+\frac{4.33 G_{m} \sqrt{\Delta \alpha \Delta T V_{f} b}}{\sigma_{y, m} \sqrt{d}}\right)\right]^{3} .
$$

Fig.4.7 presents the analytical results of the effect of the particle size $(d)$ on the fatigue life, where $d$ is the only variable and other parameters are kept constant. The cyclic number to failure $(N)$ is calculated as a function of $d$ based on Eq.(4.9) at different levels of the plastic strain amplitude (PSA). The data used are identical to those given in section 4.2. The same trends can be seen from Fig.4.7. Compared with Fig. 4.1, although the predicted fatigue life is shorter, the size effect becomes stronger, especially when $d<5 \mu \mathrm{m}$. This value could be considered as a critical value beyond which the particle size has little influence on the LCF life of DR-MMCs. 


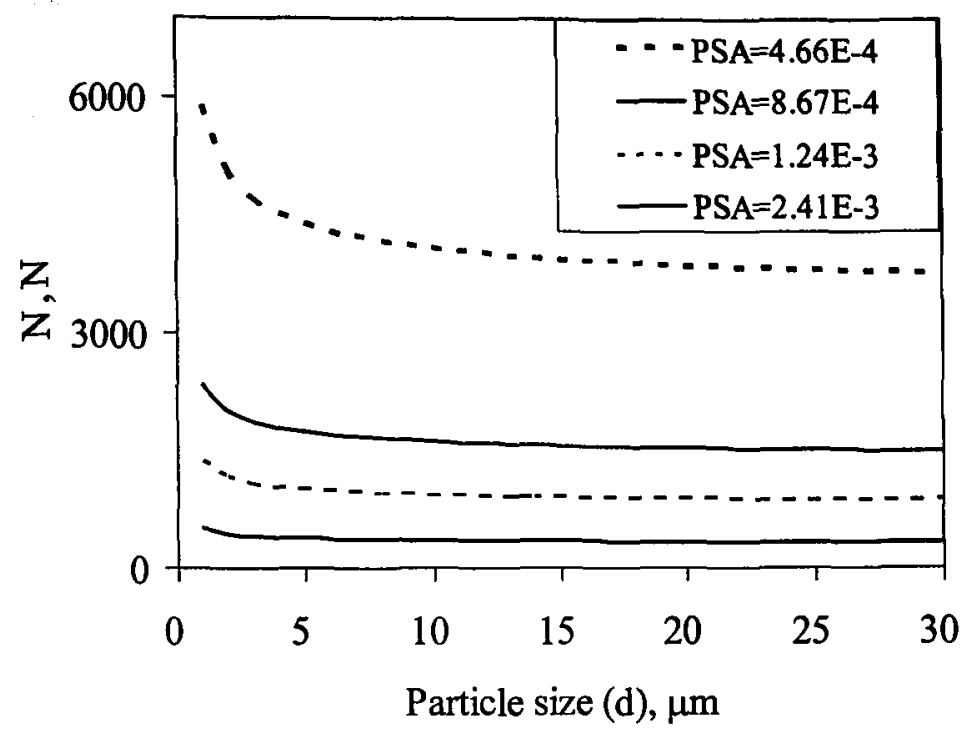

Figure 4.7 Fatigue life as a function of particle size in an $\mathrm{Al}_{2} \mathrm{O}_{3}$ particulate reinforced AA6061 aluminum alloy based MMCs tested at $25^{\circ} \mathrm{C}$. 


\section{CHAPTER FIVE}

\section{Discussion}

\subsection{Unified Effects of $E_{c}, V_{f}, n^{\prime}$ and $K^{\prime}$ on the Fatigue Crack Initiation}

As reported in [2] and also listed in Table 3.1, $E_{c}, V_{f}, n^{\prime}$ and $K^{\prime}$ are usually interrelated, leading to a combined effect of these parameters on the fatigue crack initiation. Fig.3.4 illustrates the combined effects of the volume fraction on the LCF crack initiation life, coupled with the variation of $E_{c}, n^{\prime}, K^{\prime}$ and $f$. Due to the limited data (Table 3.1 ), $V_{f}=15 \%$ and $V_{f}=20 \%$ were considered only. When $V_{f}$ changes from $15 \%$ to $20 \%, E_{c}$ changes from 93.3 GPa to $97.2 \mathrm{GPa}$ according to the experimental data [44] and Eq. (3.15), $K^{\prime}$ values from $1066 \mathrm{MPa}$ to $792 \mathrm{MPa}$, and $n^{\prime}$ values from 0.163 to 0.11 . Based on the experimental data reported in [2], the values of $f t$ can be calculated to change from $3.74 \times 10^{-9} \mathrm{~m}$ to $5.91 \times 10^{-9} \mathrm{~m}$. It is seen from Fig.3.4 that after the unified effect is taken into consideration, the dependence of the LCF crack initiation life on the volume fraction becomes stronger. The larger the volume fraction and the higher the plastic strain amplitude, the lower the number of cycles for the fatigue crack initiation. This is in good agreement with the results reported in the literature. For example, Srivatsan [49] reported the degradation in the LCF resistance with an increase in the volume fraction of $\mathrm{SiC}_{\mathrm{p}}$ reinforcement in the 2124 matrix. Ding et al. [2] pointed out that in the strain-controlled LCF tests the MMCs with the higher volume fraction of reinforcement particles exhibit shorter fatigue lives than composites with a smaller volume fraction. Hadlanfard and Mai [50] showed that the higher the strain amplitude, the higher the rate of decay and the lower the fatigue life.

The monotonic effect of the cyclic strain hardening exponent, $n^{\prime}$, on the LCF crack initiation life (Fig.3.5) may be understood as follows. In the cyclic deformation testing at a given plastic strain amplitude, the cyclic strength coefficient $K^{\prime}$ and cyclic strain hardening 
exponent $n^{\prime}$ are the decisive factors for the cyclic stress amplitude according to Eq. (3.11). Since $\Delta \varepsilon_{p} / 2<1$ and $0.05<n^{\prime}<0.3$ [33], a larger $n^{\prime}$ corresponds to a lower saturated cyclic stress amplitude level, $\Delta \sigma / 2$, if $K^{\prime}$ and $\Delta \varepsilon_{p} / 2$ are constant. In the LCF the cyclic deformation test is normally carried out under strain control. Therefore, an increasing $n^{\prime}$ would lead to a decreasing value of $\Delta \sigma / 2$, which would result in an increasing LCF crack initiation life. This is also in agreement with the statement that in the LCF "materials with larger values of $n^{\prime}$ have longer fatigue lives" [37].

The dependence of the fatigue crack initiation life on the cyclic strain hardening exponent $n^{\prime}$, coupled with the accompanying variation of $E_{c}, V_{f}, K^{\prime}$ and $f t$ has been presented in Fig.3.6. Comparing Fig.3.6 with Fig.3.5, it is seen that such a unified consideration gives rise to quite a complicated effect and a slightly lower number of cycles for the fatigue crack initiation, especially at $n^{\prime} \approx 0.261$. This phenomenon can be attributed to the influence of the cyclic strength coefficient, $K^{\prime}$, on the fatigue crack initiation life, combined with the varying $n^{\prime}$ (Table 3.1). As shown in Fig.3.8, for a given plastic strain amplitude level, the LCF crack initiation life increases with increasing $K^{\prime}$. After reaching a peak value at $K^{\prime} \approx 1839 \mathrm{MPa}, N_{i}$ decreases with increasing $K^{\prime}$. This is associated with the fact that the $n^{\prime}$ effect offsets the $K^{\prime}$ effect on $N_{i}$. Hu and Cao [51] suggested a relationship between $n^{\prime}$ and $K^{\prime}$ as follows,

$$
n^{\prime}=0.34\left(1-\frac{\sigma_{y}}{K^{\prime}}\right)-0.05,
$$

where $\sigma_{y}$ is the yield stress of the material. Clearly, an increasing $K^{\prime}$ leads to an increasing $n^{\prime}$, which can also be seen from Table 3.1 at a given test temperature. Mathematically, the exponent $n^{\prime}$ has a stronger effect on $\Delta \sigma / 2$ than the coefficient $K^{\prime}$ does according to Eq. (3.12). These two points could be used to explain Figs.3.6 and 3.8.

In Fig.3.6, while an increasing $n^{\prime}$ tries to decrease the saturated stress amplitude level, $\Delta \sigma / 2$, the increasing $K^{\prime}$, resulting from the increased $n^{\prime}$ based on Eq. (5.1), would offset a part of 
the $\Delta \sigma / 2$ decreasing effect. As $n^{\prime}$ has a stronger influence on $\Delta \sigma / 2$, the offsetting effect of the increased $K^{\prime}$ can not change much of the total decreasing trend of $\Delta \sigma / 2$ which would lead to an increasing $N_{i}$. However, when the effects of $E_{c}, V_{f}$ and $f t$ are taken into consideration, a weak or little dependence $\left(n^{\prime}<0.261\right)$ and a strong dependence $\left(\mathrm{n}^{\prime}>0.261\right)$ of the LCF crack initiation life on the cyclic strain hardening exponent is observed, as shown in Fig.3.6. On the other hand, in Fig.3.8, as an increasing $K^{\prime}$ leads to an increasing saturated stress amplitude level in terms of Eq. (3.12), the increasing $n^{\prime}$ arising from the increased $K^{\prime}$ according to Eq. (5.1) would offset the majority of the increasing effect, because of its stronger influence on $\Delta \sigma / 2$. As a result, the LCF crack initiation life should increase with increasing $K^{\prime}$. This trend can be found in Fig.3.8 for $K^{\prime}<1839$ MPa. However, for the last point, $K^{\prime}=2500 \mathrm{MPa}$, the LCF crack initiation life becomes lower. This may be due to the scatter of the experimental data of $K^{\prime}$ and $n^{\prime}$ in this range. As shown in Table 3.1, when $K^{\prime}$ increased from $1839 \mathrm{MPa}$ to $2500 \mathrm{MPa}, n^{\prime}$ decreased from 0.312 to 0.283 , which does not coincide with the trend described by Eq. (5.1). The reason why this material deviates from Eq. (5.1) in this range is unclear. Further study is needed.

In brief, $n^{\prime}$ and $K^{\prime}$ have an opposite effect on $N_{i}$. While an increasing $n^{\prime}$, as an only variable in Eq. (3.14), would lead to an increasing $N_{i}$ (Fig.3.5), an increasing $K^{\prime}$, as an only variable in Eq. (3.14), would result in a decreasing $N_{i}$ (Fig.3.7). Although their effects on $N_{i}$ are inter-related, $n^{\prime}$ has been indicated to have a stronger influence. The combined effect of both $n^{\prime}$ and $K^{\prime}$ results in a rather complicated dependence of the LCF crack initiation life on either $n^{\prime}$ or $K^{\prime}$, as shown in Fig.3.6 and Fig.3.8.

\section{2 $f t$ - An Indicator of the Energy Stored from Cycle to Cycle}

A parameter that deserves further analysis is $f t$, where $f$ is the defect-energy-absorbing efficiency factor, $t$ is the total thickness of the regions on each side of the crack drained of 
defects when the crack forms. In the calculation of the crack initiation, $f t$ is considered as a material constant which determines the percentage of the hysteresis loop area stored as the defect energy to be released when a crack initiates. This combined parameter may be influenced by the microstructural parameters and environmental conditions, such as volume fraction, reinforcement particle size, temperature, etc. As mentioned earlier, if a set of experimental data of $N_{p}$ versus $\Delta \varepsilon_{p} / 2$ is given, the value of $f t$ can be calculated from Eq. (3.14) for a given material. Figs.5.1 and 5.2 illustrate the effect of the volume fraction and temperature on the value of $f t$ based on the data listed in Table 3.1. It is seen that the value of $f t$ decreases with increasing volume fraction when $E_{c}, n^{\prime}$ and $K^{\prime}$ remain constant (Fig.5.1). However, when the effect of the volume fraction on $E_{c}, n^{\prime}$ and $K^{\prime}$ is simultaneously considered, an opposite trend is observed (Fig.5.2). It means that the combination of $E_{c}, n^{\prime}$ and $K^{\prime}$ has a stronger effect on the value of $f t$ than the volume fraction alone. Regarding the effect of test temperatures, the higher the temperature, the stronger the dependence of the value of $f t$ on the volume fraction, as shown in Fig. 5.2. The reason for this is unclear, and further study is needed.

\subsection{On the Crack Initiation Process}

It was reported that damage was initially generated randomly throughout the specimens, and the predominant damage micromechanisms detected at this stage were the fracture of reinforcement particles, decohesion at the matrix/reinforcement interface, and the formation of matrix cracks. This situation of homogeneous damage continued until a predominant microcrack nucleated at the specimen surface, and damage was then rapidly localized around the propagating crack [14]. In this study, the formation of a predominant microcrack was considered as the crack initiation, in which the energy change produced by the decohesion at the matrix/reinforcement interface was taken into account when calculating the free energy change. As the surface energy arises from the unbalance of the force between 


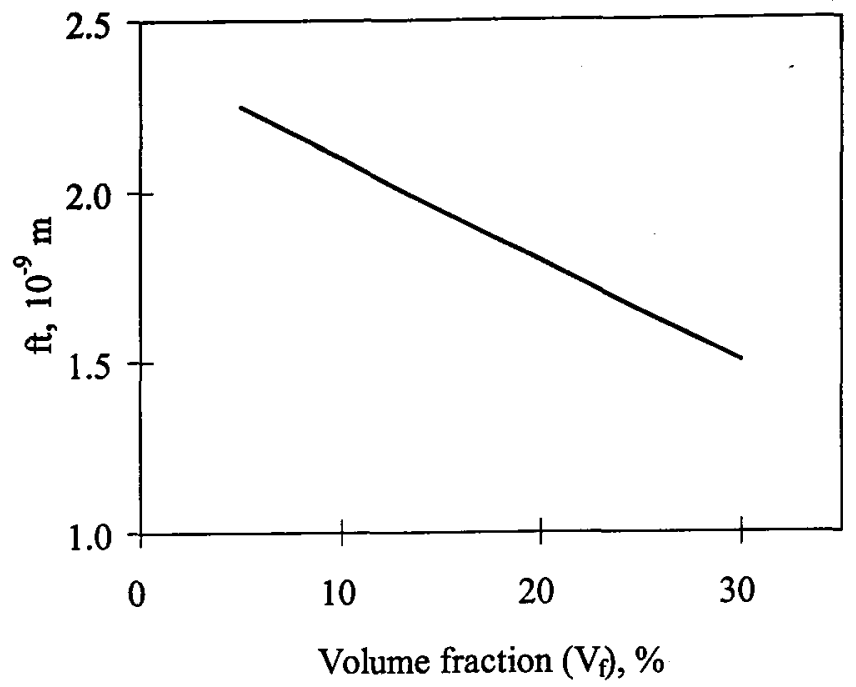

Figure 5.1 Effect of the volume fraction on the indicator of the energy (the value of $f t$ ) in the $\mathrm{Al}_{2} \mathrm{O}_{3}$ particulate-reinforced, AA6061 based MMCs (where $E_{c}, n^{\prime}$ and $K^{\prime}$ are kept constant).

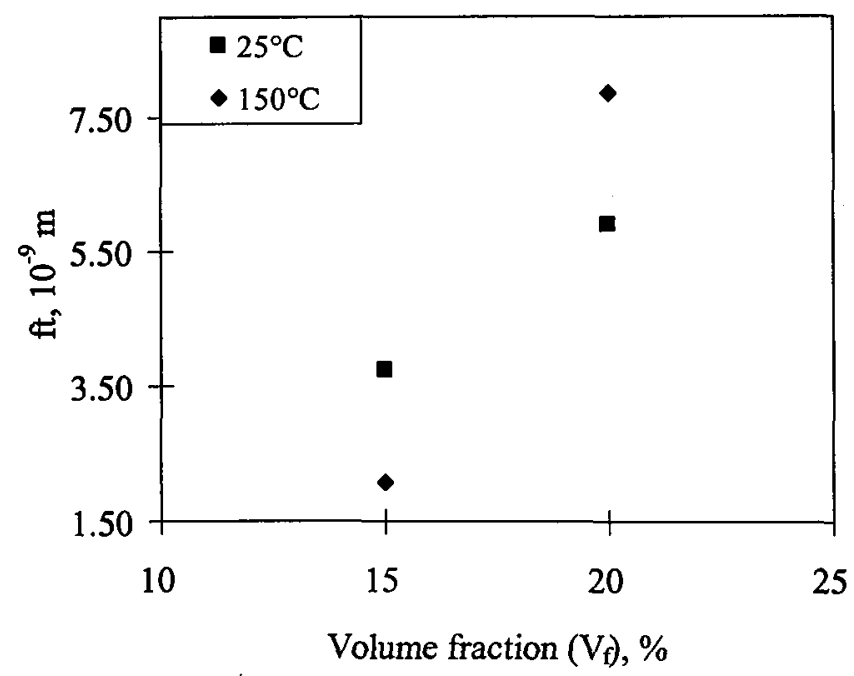

Figure 5.2. Effect of the volume fraction on the indicator of the energy (the value of $f t$ ) in the $\mathrm{Al}_{2} \mathrm{O}_{3}$ particulate-reinforced, $\mathrm{AA} 6061$ based $\mathrm{MMCs}$ at different temperatures, with consideration of the variation of $E_{c}, n^{\prime}$ and $K^{\prime}$ values with the volume fraction. 
inner atoms or molecules and the interface, it is thus sensitive to the surface morphology, chemical composition and the environment. Consequently, the surface energy would vary with matrix and reinforcement particles. However, as a first approximation, the surface energy could be considered to be a constant of about $1 \mathrm{Nm}^{-1}$, as reported in recent studies $[38,40,41]$. A quantitative analysis of the change in the surface energy density caused by the surface morphology, composition and environment is possible, but it would make the derived equation more complicated.

There was no clear definition of crack size for the crack initiation, which was normally determined via experiments, e.g., [2,38]. As suggested in [38], a crack initiation size of 500 $\mathrm{nm}(2 \times 250 \mathrm{~nm})$ was used in this investigation, which was limited by the ability to detect small cracks. As techniques of detecting cracks progress, the size of the crack initiation may be changed accordingly. As a first approximation, $\sim 15 \%$ of the total fatigue life might be considered as the crack initiation life. While the crack initiation life model was basically validated via the indirect total fatigue life data, the verification of the model using the experimental data involving the direct fatigue crack initiation would be ideal. Such crack initiation life data are thus important. Although the particle shape was specified as a short fiber with varying aspect ratios in Eq.(3.15), and other important parameters, e.g., the volume fraction, cyclic strain hardening exponent, cyclic strength coefficient, were reflected in the model as well, Eq. (3.14) or (3.17) did not include the effect of the particle size. To model the particle size dependence, a slightly modified consideration has been presented elsewhere [52].

\subsection{Effect of the Particle Size on the Fatigue Life}

The present size effect model is actually based upon the load-bearing effect and the reinforcement-particle-strengthening effect on the matrix. High stiffness and high strength are among the main reasons why MMCs are so attractive. However, just as every coin has 
two faces, those advantages may sometimes go the other way. As LCF tests are usually conducted under total or plastic strain control, to reach a certain amount of strain, a higher stress level is required in MMCs than in their un-reinforced counterparts due to their high stiffness and high strength. This could be the reason why MMCs have a LCF life inferior to the constituent matrix material. One of the strengthening mechanisms in MMCs is the load bearing feature of the hard reinforcement. In the LCF of DR-MMCs, more loads are shared by the reinforcement particles because of the required high stress. By assuming that the fracture of a reinforcement particle is stress controlled (maximum-stress principle) due to its elastic deformation, Srivatsan [49] reported that the "intrinsic strength" of each particle, $\sigma_{p}$, is inversely proportional to the square root of its characteristic dimension $(d)$ :

$$
\sigma_{p}=\left[\frac{\pi E G_{p m}}{2\left(1-v^{2}\right) d}\right]^{1 / 2},
$$

where $E$ is Young's modulus, $v$ is Poisson's ratio, and $G_{p m}$ is the critical strain energy release rate for the propagation of the microcrack initiated at a brittle reinforcement particle. Consequently, smaller particles do not crack easily, but larger particles tend to break under lower stresses due to their relatively low "intrinsic strength". The broken particles act as the sources of microcracks in the matrix which will coalesce into macrocracks and lead to fatigue failure of the MMCs eventually. In addition, the larger particles are likely to contain larger inherent defects than the smaller ones. These defects would typically be sharp corners or re-entrant angles that act as potential stress concentrators in the ductile matrix [49].

Furthermore, short crack growth occupies a large proportion of fatigue lives of DR-MMCs. Therefore, short crack trapping by the microstructure plays an important part in the resistance of the material to fatigue failure. Li \& Ellyin [53] reported that the short crack trapping/untrapping is both particle size and volume fraction dependent, and their 
experimental observations indicated that a large particle dramatically reduces a nearby short crack growth rate, but the fractured particle releases the trapped short crack and leads to a considerable increase in its growth rate. Their FEM model also showed that for a given volume fraction, a fine particle composite provided a better resistance to the short crack growth. Since crack growth results from the damage caused by the reversible movement of dislocations in the cyclic plastic zone ahead of the crack tip, the barriers to the movement of dislocations play an important role in crack growth. In the DR-MMCs, the particles are strong barriers to the movement of dislocations, and the high multiaxial internal stress in the area surrounded by the particles impedes the stage I growth [53]. Therefore, the average spacing among particles appears to be a dominant material parameter for short crack growth in the DR-MMCs. For a constant reinforcement volume fraction, smaller particles imply more particles embedded in the matrix, i.e., more barriers to the dislocation movement, and consequently, to the short crack growth. Dieter [37] presented a relationship among the inter-particle spacing $(l)$, volume fraction $\left(V_{f}\right)$ and particle diameter $(d)$ :

$$
l=\frac{2\left(1-V_{f}\right) d}{3 V_{f}} .
$$

Eq.(5.3) indicates that a decreasing particle size $d$ results in a smaller inter-particle spacing and consequently leads to more multiaxial-internal-stressed areas, giving rise to a lower short crack growth.

All of the above points can be used to understand why larger particles result in a lower LCF life predicted on the basis of Eq.(4.5) or Eq.(4.9), especially at low plastic strain levels (Fig.4.1 or Fig.4.7). Chawla et al. [7] showed the same trend for the fatigue life under $10^{4}$ cycles based upon their study of AA2080 composites reinforced with $10,20,30 \% \mathrm{SiC}$ particles, and Bosi et al. [8] reported a similar result on the basis of their work on 
AA6061/ $\mathrm{Al}_{2} \mathrm{O}_{3 \mathrm{p}}$ composites.

However, in LCF with increasing plastic strain amplitudes, not only large particles break during cyclic deformation, some smaller particles get broken or decohered, which can act as sources of cracks and voids. In view of the fact that there are more particles in the small particle reinforced $\mathrm{MMCs}$, at a very large plastic strain amplitude, there would be more cracked or de-cohered particles in MMCs with smaller particles. This may offset some of the advantages of small particles mentioned above in resisting fatigue failure, giving rise to only a weak size effect at high plastic strain amplitude levels shown in Fig.4.1 or Fig.4.7. However, how these factors affect the fatigue life quantitatively is not clear and further studies are needed.

\subsection{Effect of Volume Fraction on the Fatigue Life}

As shown in Fig.4.2, fatigue life increases slightly with increasing volume fraction of reinforcement particles when the volume fraction is treated as an only variable. However, most investigators $[1,2,7,49]$ pointed out that an increasing volume fraction led to a decreasing LCF life. This difference can be related to the fact that the volume fraction has also an effect on other microstructural parameters, i.e., $K^{\prime}, n^{\prime}, C_{\varepsilon}$, etc. When these effects are taken into consideration, it can be found that the lower the volume fraction, the longer the LCF life. Based on the available data given in [2], Table 5.1 lists the calculated LCF life where the effect of volume fraction on $E, K^{\prime}, n^{\prime}$ is considered. Apparently, when the volume fraction changes from $15 \%$ to $20 \%$, fatigue life becomes shorter at all four levels of plastic strain amplitudes, in agreement with the findings reported in the literature $[1,2,7,49]$. 
Table 5.1 - Effect of volume fraction on the LCF Life based on the present model with consideration of relevant changes of $E, K^{\prime}, n^{\prime}$.

\begin{tabular}{ccc}
\hline & \multicolumn{2}{c}{ LCF Life, $\mathrm{N}$} \\
\cline { 2 - 3 } & $\mathrm{V}_{\mathrm{f}}=15 \%$ & $\mathrm{~V}_{\mathrm{f}}=20 \%^{*}$ \\
\cline { 2 - 3 } & Present model/Experimental & Present model \\
\hline $2.41 \mathrm{E}-03$ & $368 / 372$ & 244 \\
\hline $1.24 \mathrm{E}-03$ & $987 / 1161$ & 588 \\
\hline $8.67 \mathrm{E}-04$ & $1691 / 1685$ & 950 \\
\hline $4.66 \mathrm{E}-04$ & $4261 / 4941$ & 2169 \\
\hline
\end{tabular}

* No experimental data are available at these plastic strain amplitude levels for $V_{F}=20 \%$. 


\section{CHAPTER SIX}

\section{Conclusions and Future Work}

\subsection{Conclusions}

Based on the above research, the following conclusions can be drawn.

1. An equation for predicting the crack initiation life of discontinuously reinforced metal matrix composites in the low cycle fatigue has been developed. This equation can be used to predict the effects of a number of material or microstructural parameters, including:

(1) A higher level of the plastic strain amplitude leads to a shorter fatigue crack initiation life.

(2) The higher the volume fraction of the reinforcement particles, the shorter the fatigue crack initiation life.

(3) The cyclic strain hardening exponent has only a weak or little effect on the low cycle fatigue crack initiation life when $n^{\prime}<0.261$. However, the low cycle fatigue crack initiation life increases strongly with increasing cyclic strain hardening exponent when $n>0.261$.

(4) With increasing cyclic strength coefficient, the low cycle fatigue crack initiation life first increases, and then decreases. The maximum crack initiation life appears at $K^{\prime} \approx 1839 \mathrm{MPa}$, which seems to be independent of the applied plastic strain amplitude.

2. A model for predicting the total low cycle fatigue life has been put forward by uniting the proposed crack initiation model with Ding et al.'s crack propagation model. The results predicted by means of this unified model are in good agreement with the experimental data reported in the literature for a number of particulate-reinforced MMCs. Since both the crack initiation and propagation processes have been taken into 
consideration, the accuracy of predicting the low cycle fatigue life is improved.

3. In light of the strengthening effects based on both the modified shear lag model and the enhanced dislocation density model, another low cycle fatigue (LCF) life prediction model involving the effect of the particle size has been proposed.

4. It is shown that an increasing particle size results in a decreasing LCF life of discontinuously reinforced metal matrix composites (DR-MMCs), especially at a relatively low plastic strain amplitude. The predicted LCF life is in good agreement with the experimental results reported in the literature.

5. When the volume fraction is considered to be an only variable, a larger volume fraction tends to increase slightly the LCF life of DR-MMCs. However, when the effects of the volume fraction on other microstructural parameters are simultaneously taken into consideration, the higher the volume fraction, the lower the LCF life. This is also consistent with the results reported in the literature.

\subsection{Recommendations for Future Work}

1. Although the predictions based on the currently proposed models are in good agreement with the experimental data reported in the literature, more experiments are still needed to directly verify these models.

2. For the effect of the particle size on the LCF life of DR-MMCs, a particle size of $\mathbf{5}$ $\mu \mathrm{m}$ appears to be a critical value, but further studies are needed to find out the reasons.

3. The combined effect of cyclic strain hardening exponent $n^{\prime}$ and cyclic strength coefficient $K^{\prime}$ on the LCF fatigue crack initiation of DR-MMCs is still not clear by now, both theoretical and experimental investigations are needed in this aspect.

4. The influence of $E_{c}, n^{\prime}$ and $K^{\prime}$ on the value of $f t$ deserves further study. 


\section{References}

[1] T.W. Clyne, P.J. Withers, An Introduction to Metal Matrix Composites, Cambridge University Press, 1995, pp 1-11, 454-471.

[2] H.Z. Ding, H. Biermann, H. Mughrabi, Modeling low-cycle fatigue life of particulate-reinforced metal-matrix composites. Materials Science and Engineering, 2002, A333, 295-305.

[3] W.J. Fleming, J.M. Temis, Numerical simulation of cyclic plasticity and damage of an aluminum metal matrix composite with particulate $\mathrm{SiC}$ inclusions. Int. J. Fatigue, 2002, 24, 1079-1088.

[4] S.K. Koh, S.J. Oh, C. Li, F. Ellyin, Low-cycle fatigue life of SiC-prticulate-reinforced Al-Si cast alloy composites with tensile mean strain effects, Int. J. Fatigue, 1999, 21, 1019-1032.

[5] M. Levin, B. Karlsson, Crack initiation and growth during low-cycle fatigue of discontinuously reinforced metal-matrix composites. Int. J. Fatigue, 1993, 15(5), 377-387.

[6] T.O. Pedersen, V. Tvergaard, On low cycle fatigue in metal matrix composites. International Journal of Damage Mechanics, 2000, 9, 154-173.

[7] N. Chawla, C. Andres, J.W. Jones and J.E. Allison, The effect of reinforcement volume fraction and particle size on the fatigue behavior of an aluminum alloy/SiC composite, Industrial Heating, February 1999, 61-66.

[8] C. Bosi, G.L. Garagnani, R. Tovo and M. Vedani, Effect of matrix and reinforcement properties on low-and-high-cycle fatigue behavior of particulate-reinforced MMCs, International Journal of Materials \& Product Technology, 2002, 17, (3/4), 228-242.

[9] N.L. Han, Z.G. Wang and L.Z. Sun, Effect of reinforcement size on low cycle fatigue behavior of $\mathrm{SiC}$ particle reinforced aluminum matrix composites, Scripta Metallurgica et Materialia, 1995, 33, (5), 781-787. 
[10] N.L. Han, Z.G. Wang and G.D. Zhang, Effect of reinforcement size on the elevated-temperature tensile properties and low-cycle fatigue behavior of particulate SiC/Al composites, Composites Science and Technology, 1997, 57, 1491-1499.

[11] I. Uygur and M.K. Kulekci, Low cycle fatigue properties of 2124/SiCp Al-alloy composites, Turkish Journal of Engineering and Environmental Science, 2000, 26, 265-274.

[12] T. Das, P.R. Munroe and S. Bandyopadhyay, Some observations on the mechanical properties of particulate-reinforced 6061 aluminum metal matrix composites. Int. J. Materials and Product Technology, 2003, 19, 3/4, 218-227.

[13] B. Terry and G. Jones, Metal Matrix Composites - Current Developments and Future Trends in Industrial Research and Applications. Elsevier Advanced Technology, Mayfield House, Oxford OX2 7DH, UK, 1990, 7-30.

[14] J. Llorca. Fatigue of particle and whisker reinforced metal-matrix composites, Progress in Mater, Sci. 2002, 47, 283-353.

[15] S.S. Yau, PhD thesis, North Carolina State Univ, 1983.

[16] C. R. Crowe and D. F. Hasson, Corrosion fatigue of SiC/Al MMC, Salt Laden Moist Air, Proc. Of ICSMA VI, Melbourne, R. C. Gifkins (ed.), Pergamon, 1982, 859-865.

[17] W. A. Logsdon and P. K. Liaw, Tensile, fracture toughness and fatigue crack growth rate properties of $\mathrm{SiCw}$ and $\mathrm{SiCp}$ reinforced $\mathrm{Al}$ MMCs, Eng. Fract. Mech., 1986, 24, 737-51.

[18] D. Lloyd, Aspects of particle fracture in particulate reinforced MMCs, Acta Met. et. Mat., 1991, 39, 59-72

[19] M. Manoharan and J. J. Lewandowski, Crack initiation and growth toughness of an Al MMC, Acta Met. et Mat., 1990, 38, 489-96.

[20] A.J. Padkin, M. F. Boreton and W. J. Plumbridge, Fatigue crack growth in two-phase alloys, Mat. Sci. \& Tech., 1987, 3, 217-23.

[21] J. J. Lewandowsk, C. Liu and W. H. Hunt, Effects of matrix microstructure and particle 
distribution on fracture of an Al MMC, Mat. Sci. \& Eng., 1989, A107, 241-55.

[22] J.K. Shang and R. O. Ritchite, Mechanisms Associated with Near Threshold Fatigue Crack Propagation in SiCp Reinforced Al Composites, in Proc. ICCM VII, Guangzou, W. Yunshu, G. Zhenlong and W. Renjie (eds.), Pergamon, New York, 1989, 590-4.

[23] J. K. Shang, W. Yu and R. O. Ritchie, Role of $\mathrm{SiC}_{\mathrm{p}}$ Particles in fgtigue crack growth SiC-particulate reinforced Al alloy composites, Mat. Sci. \& Eng., 1988, A102, 181-92.

[24] N. Chawla., C. Andres, L.C. Davis, J.W. Jones, and J.E. Allison, The interactive role of inclusions and $\mathrm{SiC}$ reinforcement on the high cycle fatigue resistance of particle reinforced metal matrix composites, Metallurgical and Materials Transactions A, 2000, Volume 31A, 951-960.

[25] J.N. Hall, Particle size, volume fraction and matrix strength effects on fatigue behavior and particle fracture in 2124 aluminum-SiCp composites, Materials Science and Engineering. 1994, A183, 69-80.

[26] I. Sinclair and P.J. Gregson, Structural performance of discontinuous metal matrix composites, Materials Science and Technology, September 1997, 13, 709-718.

[27] K. Tokaji, H. Shiota and K. Kobayashi, Effect of particle size on fatigue behavior in SiC particulate-reinforced aluminum alloy composites, Fatigue Fract Engng Mater Struct., 1999, 22, 281-288.

[28] Knowles, D. M. and King, J.E., Role of reinforcement/matrix interfacial strength in fatigue crack propagation in particulate $\mathrm{SiC}$ reinforced aluminum alloy 8090, Mater. Sci. Technol., 1992, 8, 500-509.

[29] Davidson , D.L., Plasticity induced fatigue crack closure Metall. Trans., 1987, 18A, 2115-2132.

[30] Flom, Y. and Arsenault, J.D., Interfacial bond strength in an aluminum alloy 6061-SiC composite, Mater. Sci. Engng., 1986, 77, 191-197.

[31] C. R. Crowe, R. A. Gray and D. F. Hasson, Microstructure controlled fracture toughness of SiC/Al metal matrix composites, in Proc. 5th Int. Conf. Comp. Mats. $(I C C M V)$, San Diego, W. C. Harrigan, J. Strife and A. K. Dhingra (eds.), TMS-AIME, $1985,843-66$. 
[32] W.H. Hunt, O. Richmond and R. D. Young, Fracture initiation in particle hardened materials with high volume fraction, in Proc. ICCM VI/ECCM 2, London, F. L. Matthews, N. C. R. Buskell, J. M. Hodgkinson and J. Morton (eds.), Elservier, 1987, 209-23

[33] M. Klensil, P. Lukas, Fatigue of Metallic Materials. Second revised edition, Elsevier, Amsterdam, 1992, 10-26.

[34] Grifffith A. A., Philos, Trans. R. So, London, 1920, A221, 163-165.

[35] V.V. Bolotin, Mechanics of fatigue, CRC Mechanical Engineering series. CRC Press, Boca Raton, London, New York Washington, D.C., 1999, 15-25.

[36] Irwin G. R., Fracturing of Metals, American Society for Metals, Cleveland, Ohio, 1949, $20,147$.

[37] G.E. Dieter, Mechanical Metallurgy, Third edition, McGraw-Hill, Boston, 1986, 389-392.

[38] S.P. Bhat, M.E. Fine, Fatigue crack nucleation in iron and a high strength low alloy steel, Mater. Sci. Eng. A, 2001, A314, 90-96.

[39] B.K Dhindaw, Interfacial energy issues in ceramic particulate reinforced metal matrix composites, Bull. Mater. Sci., 1999, 22(3), 665-669.

[40] T.S. Srivatsan, Cyclic strain resistance and fracture behavior of $\mathrm{Al}_{2} \mathrm{O}_{3}$ particulate-reinforced 2014 Aluminum alloy metal-matrix composites, Int. J. Fatigue, 1995, 17(3), 183-199.

[41] T.S. Srivatsan, V.K. Vasudevan, Cyclic plastic strain response and fracture behavior of 2080 aluminum alloy metal matrix composite, Int. J. Fatigue, 1998, 20(3), 187-202.

[42] N.L. Han, J.M. Yang, Z.G. Wang, Role of real matrix strain in low cycle fatigue life of a SiC particulate reinforced aluminum composite, Scripta Mater., 2000, 43, 801-805.

[43] S. Gorsse, Y. Le Petitcorps, S. Matar, F. Rebillat, Investigation of the Young's modulus of TiB needles, Mater. Sci. Eng. A, 2003, A340, 80-87.

[44] N.E. Dowling, Mechanical behavior of materials: engineering methods for 
deformation, fracture, and fatigue, Second edition, Englewood Cliffs, N.J.; Toronto: Prentice Hall, 1993, 178-179.

[45] N. Ramakrishnan, An analytical study on strengthening of particulate reinforced metal matrix composites, Acta Materialia, 1996, 44(1), 69-77.

[46] L. Wang, Z.M. Sun, T. Kobayashi, H. Toda and Z.G. Wang, Cycle deformation and low cycle fatigue behavior in a $6061 \mathrm{Al} / 22 \mathrm{vol} \% \mathrm{SiC}$ whisker composites, Materials Transactions, JIM, 1996, 37( 4), 762-768.

[47] http://www.matweb.com/index.asp.

[48] V.C. Nardone and K.M. Prewo, On the strength of discontinuous silicon carbide reinforced aluminium composites, Scripta Metall., 1986, 20, 43-48.

[49] T.S. Srivatsan, The low cycle fatigue behavior of an aluminum alloy ceramic particle composite, Int. J. Fatigue, 1992, 14(3), 173-182.

[50] M. J. Hadianfard, Y.W. Mai, Low cycle fatigue behavior of particulate reinforced metal matrix composites, J. Mater. Sci., 2000, 35, 1715-1723.

[51] Z.Z. Hu, S.Z. Cao, Relation between strain-hardening exponent and strength, Journal of Xi'an Jiaotong University, 1993, 27(6), 71-76.

[52] Q. Zhang, D.L. Chen, A model for predicting the particle size dependence of the low cycle fatigue life in discontinuously reinforced MMCs, Scripta Mater., 2004, in print.

[53] C.S. Li and F. Ellyin, Short crack trapping/untrapping in particle-reinforced metal-matrix composites, Composites Science and Technology, 1994, 52, 117-124. 


\section{QIAN ZHANG}

1615 - 52 Mabelle Avenue

(416) 234-0783

Etobicoke ON M9A 4X9

\section{PROFESSIONAL EXPERIENCE}

Smiths Aerospace Orillia, Ontario, Estimator/Process Planer

June 2004 - present

Ryerson University, Toronto, Canada, Teaching Assistant

Sept. 2002 - present

Roto-Form, Tesma, Toronto, Canada, CNC Programmer

July 2001 - Sept. 2002

Honeywell, Nanjing China, Mechanical Engineer

Oct. 1997 - Dec. 2000

Nanjing Automobile Factory, Tool Plant, Nanjing, China

Mechanical Designer/Draftsperson

July 1993 - Sept. 1997

\section{EDUCATION}

MASc. Student in Mechanical Engineering

Ryerson University, Toronto, Canada

Sept. $2002-$ present

B. Sc. Degree in Mechanical Engineering

1988

Wuhan University of Technology, Wuhan, China

\section{LIST OF PUBLICATIONS (in the past two years during my MASc study)}

1. Q. Zhang \& D.L. Chen. "A model for predicting the particle size dependence of the low cycle fatigue life in discontinuously reinforced MMCs." Scripta Materialia, Accepted, 2004, 51 (9), pp. 863-867.

2. Q. Zhang \& D.L. Chen. "A model for the low cycle fatigue life prediction of discontinuously reinforced MMCs." International Journal of Fatigue, accepted on August 2, 2004.

3. Q. Zhang \& D.L. Chen. "Effect of particle size on the low cycle fatigue life of discontinuously reinforced MMCs." COM 2004: The 2nd International Symposium on Aerospace Materials and Manufacturing: Development Testing \& Life Cycle Issues, COM 2004, Hamilton Ontario, August 22-25, 2004, accepted.

4. Q. Zhang \& D.L. Chen. "Modeling low cycle fatigue life of discontinuously reinforced metal matrix composite materials." Abstract Book of the 16th Canadian Materials Science Conference, Ottawa, June 5-8, 2004, edited by J. Beddoes, p.39. 


$$
\text { BEL }-4-12
$$

